\author{
Universidade de São Paulo \\ Instituto de Física
}

\title{
Modelagem estocástica de neurônios e sua interação em tempo real com neurônios biológicos.
}

\author{
Pedro Valadão Carelli \\ Orientador: Prof. Dr. Reynaldo Daniel Pinto
}

Tese de doutorado apresentada ao Instituto de Física para a obtenção do título de Doutor em Ciências

Banca examinadora:

Prof. Dr. Reynaldo Daniel Pinto - IF-USP

Prof. Dr. Joaquim Procópio de Araujo Filho - ICB-USP

Prof. Dr. Mário José de Oliveira - IF-USP

Prof. Dr. Antônio Carlos Roque da Silva Filho - FFCLRP-USP

Prof. Dr. Rita Maria Zorzenon dos Santos - UFPE

São Paulo 
FICHA CATALOGRÁFICA

Preparada pelo Serviço de Biblioteca e Informação do Instituto de Física da Universidade de São Paulo

Carelli, Pedro Valadão

Modelagem estocástica de neurônios e sua interação em tempo real com neurônios biológicos - 2008

Tese (Doutorado) - Universidade de São Paulo. Instituto de Física - Depto. de Física Geral

Orientador: Prof. Dr. Reynaldo Daniel Pinto

Área de Concentração: Física Geral

Unitermos: 1. Física; 2. Física Experimental; 3. Mecânica Estatística. 


\section{Agradecimentos}

Em primeiro lugar agradeço ao Reynaldo, pela orientação e ótima convivência que tivemos.

Ao Sartorelli por sua experiência e pelas conversas em momentos importantes.

Agradeço ao Marcelo pela ajuda no desenvolvimento do trabalho, e muitas discussões proveitosas.

Ao Bóris pela ajuda no trabalho e na revisão do texto.

À Ludmila pelo apoio no laboratório.

À Vivi pela força na revisão final da tese.

Ao Thiagão, Caroline e todos do LFNL pela agradável companhia no ambiente de trabalho.

À Carol pela companhia e confiança todos esses anos.

Gostaria de agradecer a todos que me acompanharam durante todo o desenvolvimento deste trabalho.

Agradeço à FAPESP pelo suporte financeiro. 
Aos meus pais,

Vincent e Virgínia. 


\section{Resumo}

Desenvolvemos um modelo estocástico da atividade elétrica de um neurônio motor do gânglio estomatogástrico de crustáceos, a partir de um modelo determinístico eletrofisiologicamente plausível. Com isso recuperamos características da dinâmica neural sempre observadas em neurônios isolados, tais como irregularidades nos padrões de disparos que não são reproduzidas pelo modelo determinístico original.

Implementamos otimizações e simplificações no método numérico de simulação estocástica que permitiram rodar a simulação em tempo real para interagir modelos computacionais com neurônios biológicos, implementando sinapses artificiais entre eles.

Por fim utilizamos o modelo e os métodos de simulação desenvolvidos para substituir neurônios do gânglio estomatogástrico e construir sistemas híbridos, que foram usados para verificar como ocorre a transmissão de informação entre neurônios biológicos e artificiais, quando a dinâmicas destes é estocástica ou determinística. 


\section{Abstract}

We developed a mathematical model of the electrical activity of a motor neuron from the stomatogastric ganglion of crustaceans. It was inspired on a previous existing deterministic model which is considered as electrophysiologically plausible in the recent literature. However, this deterministic model were not able to reproduce the irregular bursting behavior found in those biological neurons when isolated from the neural circuit. Our model, based on the microscopic stochastic behavior of the membrane ion channels, successfully reproduced the intrinsic irregular properties that were missing in the original deterministic model.

To allow the real time performing of the stochastic model simulations we have to deal with some simplifications and to implement several optimizations that are also describe in detail. The real time version of our stochastic model was implemented in a dynamic clamp protocol to interface the computational model to real neurons.

Finally, we applied the implemented versions of real time simulation and interfacing protocols to replace some biological bursting neurons of the stomatogastric ganglion. These hibrid neural networks were used to study how the information (different patterns of interspike intervals) is transmitted between biological and two types of artificial neurons: deterministic and stochastic. 


\section{Conteúdo}

1 Introdução $\quad 8$

2 Aspectos gerais $\quad 16$

2.1 Neurônios . . . . . . . . . . . . . . . . . . . 16

2.1.1 Propriedades passivas . . . . . . . . . . . 16

2.1.2 Propriedades estocásticas dos canais iônicos . . . . . 20

2.1.3 Canais iônicos dependentes de voltagem e o potencial de ação ....................... 22

2.1.4 Canais iônicos responsáveis por rajadas de potenciais

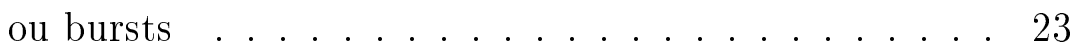

2.2 O modelo de Hodgkin-Huxley . . . . . . . . . . . 26

2.3 Breve histórico da modelagem estocástica de neurônios . . . 30

2.4 O gânglio estomatogástrico (STG) de crustáceos . . . . . . . 34

2.5 Centros geradores de padrões (CPGs) do STG . . . . . . . . 35

2.6 Teoria da informação . . . . . . . . . . . . . . 38

3 Métodos $\quad 40$

3.1 Dissecação do gânglio estomatogástrico . . . . . . . . . . . 40

3.2 Dynamic clamp: introduzindo condutâncias artificiais em neurônios biológicos . . . . . . . . . . . . . . . 44 
3.3 Teoria da informação e o CPG pilórico . . . . . . . . . . . 46

4 Implementação de modelos $\quad 50$

4.1 Modelagem determinística . . . . . . . . . . . 50

4.2 Modelagem estocástica . . . . . . . . . . . . . 54

4.3 Simulação estocástica em tempo real . . . . . . . . . . 57

4.4 Implementação do modelo estocástico no dynamic clamp . . . 59

$\begin{array}{lll}5 & \text { Resultados e discussão } & 61\end{array}$

5.1 Simulação da atividade de neurônios isolados . . . . . . . . . 61

5.2 Perturbando as variáveis dinâmicas . . . . . . . . . 73

5.3 Transmissão de informação entre modelos "in silico" e o CPG pilórico........................ 76

5.4 CPGs artificiais .................... 81

5.4.1 CPGs de modelos estocásticos e neurônios eletrônicos 81

5.4 .2 CPGs de modelos estocásticos . . . . . . . . . 84

5.5 Modelos de dois compartimentos . . . . . . . . . 87

5.6 Modelo determinístico multicompartimentos . . . . . . . . 90

6 Conclusões $\quad 93$

$\begin{array}{ll}\text { Referências } & 96\end{array}$

$\begin{array}{ll}\text { Apêndices } & 103\end{array}$

A Variável aleatória com distribuição gaussiana. 104

$\begin{array}{ll}\text { B Artigo publicado } & 105\end{array}$ 


\section{Capítulo 1}

\section{Introdução}

O estudo de modelos realistas da atividade elétrica de neurônios, onde pode-se livremente manipular a dinâmica de condutâncias individuais e testar diversas hipóteses sobre o comportamento de células, é uma importante ferramenta para responder questões abertas em neurofisiologia: como condutâncias iônicas individuais modulam o comportamento elétrico da célula, ou qual o papel destas propriedades celulares em determinar o comportamento de uma rede complexa(Marder, 1998). Mesmo nas menores redes neurais, essas questões estão longe de serem respondidas, pois os neurônios são sistemas altamente não lineares e complexos (Holden, 1997; Rinzel e Ermentrout, 1998; Izhikevich, 2000).

Modelos de neurônios, construídos a partir de dados eletrofisiológicos, não são apenas úteis para testar hipóteses sobre os processos que geram um comportamento particular observado experimentalmente, mas também podem ser usados para fazer previsões e orientar o pesquisador a fazer experimentos que revelem novas propriedades dos neurônios ou das redes neurais (Marder, 1998; Dayan e Abbott, 2001).

Este ciclo de troca de informações entre experimentos e modelos pode 
atingir níveis muito interessantes quando consideramos a possibilidade de interagir, em tempo real, modelos computacionais e tecido vivo para construir sistemas híbridos (Szücs et al., 2000; Pinto et al., 2000; Prinz, 2004) e tentar entender melhor como redes vivas operam (Selverston et al., 2000), para recuperar propriedades de sistemas neurais danificados (Szücs et al., 2000), construir circuitos com propriedades novas (Ayers, 2004) e até mesmo alimentar uma rede neural viva com dados sensoriais vindos de dispositivos artificiais ou controlar dispositivos como interfaces cérebro máquina (Carmena et al., 2003).

Desde o trabalho pioneiro introduzindo o método voltage-clamp e a modelagem matemática da atividade do axônio gigante da lula (Hodgkin e Huxley, 1952), modelos determinísticos que descrevem o comportamento das condutâncias iônicas têm sido adotados por neurofisiologistas como o principal paradigma para o comportamento elétrico macroscópico de membranas nervosas.

A razão principal do sucesso destes modelos é que eles são capazes de explicar muitos aspectos do comportamento elétrico de células nervosas, incluindo o potencial de ação, usando uma estrutura matemática rigorosa. Como a maioria dos parâmetros do modelo podem ser inferidos quase diretamente de experimentos de voltage-clamp (Hodgkin e Huxley, 1952; Kandel et al., 1991), onde as contribuições de cada corrente iônica da membrana podem ser separadas e estudadas em detalhes, os modelos determinísticos se tornaram muito populares entre os pesquisadores (Kandel et al., 1991; Dayan e Abbott, 2001).

Esses modelos são chamados determinísticos porque, uma vez especificadas as condições iniciais, a integração no tempo de um conjunto de equações diferenciais determina uma única solução que representa a evolução temporal 
do potencial de membrana.

No entanto, é bem conhecido que a atividade elétrica intrínseca de muitos neurônios vivos está muito longe de ser determinística. Experimentos onde neurônios do córtex são isolados sujeitos repetidamente um mesmo estímulo de corrente artificialmente gerado (Mainen e Sejnowski, 1995) mostraram que a confiabilidade do instante de disparo dos potenciais de ação depende de propriedades estatísticas do sinal aplicado, em desacordo com previsões determinísticas.

Até mesmo em circuitos especializados em prover ritmos periódicos e confiáveis para controlar a atividade de músculos, como o Centro Gerador de Padrões (CPG) pilórico do Gânglio Estomatogástrico (STG) de crustáceos (Mulloney e Selverston, 1974; Selverston e Moulins, 1986), a maioria dos neurônios motores do circuito apresentam um comportamento irregular de rajadas de potenciais de ação (bursts) quando isolados sinapticamente (Rabinovich et al., 1997; Elson et al., 1999; Selverston et al., 2000).

Cada vez que um desses neurônios é isolado do CPG pilórico, ele revela um repertório similar de comportamentos irregulares, no entanto é sabido que existem, pelo menos pequenas diferenças nas condutâncias iônicas da membrana, de neurônio para neurônio e de animal para animal. Matematicamente isso significa que se for possível escrever equações que modelem o comportamento observado experimentalmente, essas equações não poderiam ser especificadas exatamente, sendo esperado que elas apresentem um comportamento similar quando seus parâmetros são ligeiramente variados. Essa é a idéia da estabilidade estrutural, na teoria dos sistemas dinâmicos (Abraham e Shaw, 1992).

Sendo assim, o comportamento irregular, relacionado com as propriedades não-lineares das células (Rabinovich et al., 1997; Falcke et al., 2000), é 
estruturalmente estável em um espaço de parâmetros experimental de alta dimensionalidade, onde os neurônios estão sujeitos a pequenas variações, não apenas nas suas propriedades intrínsecas mas em diversos outros parâmetros externos, como temperatura, concentrações iônicas, etc.

A estabilidade estrutural do comportamento irregular é um sério obstáculo para o desenvolvimento de modelos do tipo Hodgkin-Huxley (HH) determinísticos. Em modelos HH simples da dinâmica do axônio, um comportamento irregular compatível com o encontrado nos neurônios biológicos é estruturalmente instável, pois é confinado a um volume muito pequeno do espaço de parâmetros (Guckenheimer e Oliva, 2002). Em modelos mais realistas, onde se tem dezenas de equações não lineares acopladas, é intuitivo esperar que a alta complexidade aumentaria as regiões do espaço de parâmetros que correspondem a comportamento irregular, dando estabilidade estrutural a eles. Surpreendentemente este não é o caso.

Recentemente, um modelo tipo HH determinístico para células em cultura do STG (Turrigiano et al., 1995), que é capaz de reproduzir bem tanto regimes de comportamento tônico quanto de bursts, foi exaustivamente estudado (Prinz et al., 2003a) e uma base de dados de cerca de 1,7 milhões de diferentes neurônios (cada um correspondendo a um conjunto particular de valores de condutâncias em um espaço de parametros de 8 dimensões) foi feita para caracterizar os possíveis tipos de comportamento. De toda a base de dados, apenas $0,1 \%$ dos neurônios correspondem a comportamentos verdadeiramente irregulares (não relacionados a transições de adição de período). Além disso, esta pequena porcentagem de comportamentos irregulares não estão condensadas em uma região específica, mas sim espalhadas pelo espaço de parâmetros (Prinz et al., 2004), sugerindo que o comportamento irregular não é estruturalmente estável neste modelo. 
Comportamento caótico estruturalmente estável foi encontrado em alguns modelos tipo HH determinísticos (Komendantov e Kononenko, 1996; Falcke et al., 2000) que incluem uma dinâmica não linear de troca de cálcio entre o retículo endoplasmático e o citosol. O principal apelo desses modelos é que a modulação da concentração intracelular de cálcio é importante para regular muitos processos celulares (Ikeda, 2004). Esses modelos prevêem que a célula precisa apresentar oscilações macroscópicas lentas dos níveis citosólicos de cálcio. No entanto, oscilações dessa amplitude foram observadas experimentalmente apenas em alguns neurônios de vertebrados (Parri e Crunelli, 2001; Zhang et al., 2003), mas nunca em neurônios do STG (Levi et al., 2003).

Os motivos pelos quais modelos $\mathrm{HH}$ determinísticos falham em reproduzir a variabilidade encontrada no comportamente de neurônios vivos são as simplificações introduzidas pelo método voltage clamp. Quando um neurônio é submetido ao voltage-clamp, não se tem acesso à real distribuição espacial do potencial de membrana, mas apenas a um ponto onde é feita a medição, que é considerada uma boa aproximação para o potencial de membrana de todo o neurônio. Além disso, as propriedades discretas e probabilísticas da abertura e fechamento dos canais iônicos da membrana (Hille, 1992; Levitan e Kaczmarek, 1997) são substituídos pela condutância média da ativação e inativação. Essas duas simplificações tornam possível escrever equações diferenciais relativamente simples, mais tratáveis para a análise ou simulação do que modelos complicados de muitos compartimentos com canais iônicos probabilísticos. Além disso, como a maioria dos dados experimentais usados para caracterizar as correntes iônicas presentes nos neurônios do STG vêm de neurônios em cultura submetidos a voltage-clamp, não existem dados suficientes para decidir, sem qualquer especulação, quantos compartimentos são 
necessários nem como distribuir as condutâncias iônicas entre os compartimentos.

Mesmo assim, algumas das propriedades perdidas podem ser recuperadas mesmo em um modelo simplificado, de compartimento único, usando-se um modelo estocástico baseado nos estados markovianos dos canais iônicos (Desthexhe et al., 1994) onde o caráter probabilístico dos canais é uma propriedade intrínseca (Hille, 1992; Skaugen e Walloe, 1979; White et al., 1998; White et al., 2000) e nenhum ruído aditivo precisa ser incluído. Se considerarmos um modelo markoviano simples onde uma população de canais com apenas dois estados possíveis independentes (fechado e aberto), o número médio de canais $(\mathrm{N})$ que se espera que sofra a transição do estado fechado para o aberto, em um intervalo de tempo $\Delta t$ pode ser facilmente obtido das taxas de abertura do modelo HH. A flutuação (desvio padrão) do número de canais iônicos que eventualmente sofrem a transição é da ordem de $\sqrt{N}$. Considerando N como $10^{6}$ (para os canais de sódio) as flutuações serão da ordem de $0,1 \%$ de $\mathrm{N}$, e o comportamento da corrente estocástica de sódio deve ser praticamente igual a sua versão determinística. No entanto, se considerarmos que os potenciais de ação são gerados no cone de implantação axonal (spike initiation zone), região (patch) bem menor do que todo o axônio, com uma quantidade em torno de $10^{3}$ ou $10^{4}$ canais de sódio, e então os spikes são propagados para outras regiões da membrana, as flutuações do número de canais sofrendo a transição de fechado para aberto serão da ordem de $2 \%$ de $\mathrm{N}$, suficientes para produzir efeitos macroscópicos no potencial de membrana.

Baseados nesse mecanismo de potencialização dos efeitos de flutuações de um número pequeno de canais iônicos, um modelo estocástico de um pedaço da membrana axonal (Schneidman et al., 1998) foi comparado com sua versão 
determinística e verificou-se que o modelo estocástico é capaz de reproduzir as propriedades de precisão e confiabilidade encontradas em neurônios vivos (Mainen e Sejnowski, 1995) em situações em que o modelo determinístico falha.

Inspirados pelo sucesso do "patch" estocástico do axônio e pelo fato dos neurônios do gânglio estomatogástrico terem suas condutâncias iônicas lentas, que são as responsáveis por começar e parar um burst de potenciais de ação, ordens de grandeza menores do que as condutâncias axonais de sódio e potássio (Prinz et al., 2003b), apresentamos um modelo estocástico de compartimento único para um neurônio estomatogástrico.

O modelo estocástico aqui apresentado foi obtido da tradução de um modelo determinístico atual para um neurônio estomatogástrico (Turrigiano et al., 1995; Prinz et al., 2003b). Nosso algoritmo foi adaptado de um método desenvolvido para simulação de reações químicas (Gillespie, 1977) e depois implementado para as condutâncias iônicas da membrana (Skaugen e Walloe, 1979). Embora esse método seja computacionalmente caro, ele é considerado um algoritmo exato (Mino et al., 2002).

A tradução do modelo determinístico foi cuidadosamente feita, para não mudar ou incluir nenhuma nova dinâmica ou fonte de ruído que não estivesse presente no modelo original. Dessa forma podemos comparar diretamente nossos resultados com os do modelo determinístico quando submetidos aos mesmos parâmetros (principalmente as condutâncias iônicas máximas de diferentes tipos iônicos), o que faz com que qualquer dinâmica não periódica que apareça possa ser totalmente atribuída à natureza estocástica da dinâmica dos canais iônicos e sua capacidade de gerar flutuações macroscópicas no potencial de membrana.

A beleza do modelo apresentado aqui é que ele permite recuperar as 
irregularidades encontradas em neurônios reais, apresentando um comportamento global caótico a partir de uma dinâmica estocástica local, a qual foi diretamente traduzida de um modelo determinístico realista de compartimento único que não apresenta qualquer comportamento irregular estruturalmente estável. Este tema é de interesse geral e correntemente estudado por grupos que trabalham com sistemas dinâmicos (Liu et al., 2002).

Também descrevemos em detalhes a elaboração desse modelo estocástico e do algoritmo adaptado para simulações, assim como os resultados obtidos em experimentos em que interagimos em tempo real os modelos com tecido neural vivo, para estudar a geração de padrões e o processamento de informação em redes neurais biológicas.

Alguns dos resultados aqui apresentados estão publicados na referência (Carelli et al., 2005). Mais recentemente, influenciados pelo sucesso de nossa proposta, alguns autores passaram a utilizar modelos estocásticos de células inteiras, tanto de multicompartimentos (Faisal e Laughlin, 2007) para simular a propagação do potencial de ação em axônios finos, quanto de compartimento único (Saarinen et al., 2008), para simular a excitabilidade de células granulares. Além disso (Saarinen et al., 2008) apresentaram uma maneira automática de ajustar os parâmetros da atividade dos modelos usando um método de máxima verossimilhança. O desenvolvimento de algoritmos de simulação mais eficientes assim como formas automatizadas para ajustar os parâmetros podem tornar a modelagem estocástica mais popular entre pesquisadores e portanto aproximar os modelos de modo mais fiel aos neurônios biológicos. 


\section{Capítulo 2}

\section{Aspectos gerais}

\section{$2.1 \quad$ Neurônios}

Os neurônios são células excitáveis, capazes de produzir e propagar sinais elétricos. Como estas características permitem processar e transmitir informações, estas células tornaram-se os blocos fundamentais presentes nos sistemas nervosos dos mais diferentes animais. São os neurônios que ativam desde a codificação de estímulos sensoriais até a contração de músculos, passando por todas as etapas intermediárias de processamento das informações sensoriais, memória, tomada de decisões, etc.

Neste capítulo vamos abordar apenas as propriedades básicas dos neurônios, necessárias para entender a atividade elétrica destas células e sua modelagem matemática.

\subsubsection{Propriedades passivas}

A membrana celular é uma bicamada lipídica que isola os meios intra e extracelulares. Quando há um desequilíbrio de cargas dentro e fora da célula, seu excedente rapidamente se acumula no entorno da membrana, dando 
origem a uma diferença de potencial chamada potencial de membrana (Fig. 2.1).

$$
V_{\mathrm{m}}=V_{\text {intra }}-V_{\text {extra }}
$$

sendo $V_{\mathrm{m}}$ o potencial de membrana, $V_{\text {intra }}$ o potencial no meio intracelular, e $V_{\text {extra }}$ o potencial no meio extracelular.

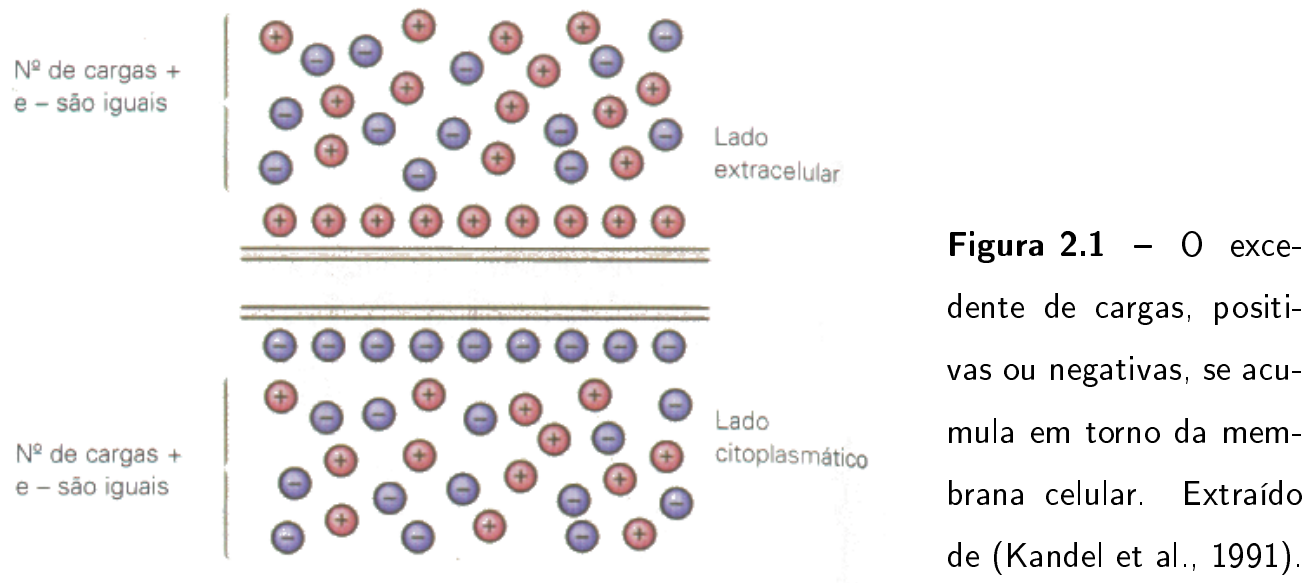

Apesar da membrana celular isolar os dois meios, existem proteínas (canais iônicos) que a atravessam formando verdadeiros poros que permitem a passagem de correntes iônicas que alteram o potencial de membrana. Os canais iônicos no entanto, não deixam passar qualquer tipo de íon, são seletivos a um ou mais tipos iônicos.

Além disso as concentrações iônicas não são simétricas dos dois lados da membrana, por exemplo, temos uma predominância de sódio $\left(\mathrm{Na}^{+}\right)$e cloreto $\left(\mathrm{Cl}^{-}\right)$no meio extracelular, e de potássio $\left(\mathrm{K}^{+}\right)$e ânions orgânicos $\left(\mathrm{A}^{-}\right)$no meio intracelular. Essa diferença de concentrações dos dois lados da membrana dá origem a um potencial difusivo diferente para cada tipo de íon presente nos meios intra e extracelulares. Uma membrana celular com um canal iônico de potássio pode ser modelada por um circuito, como 
A)

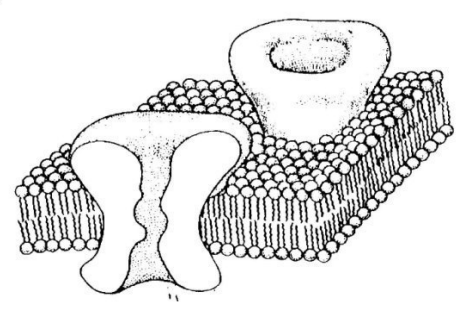

B)

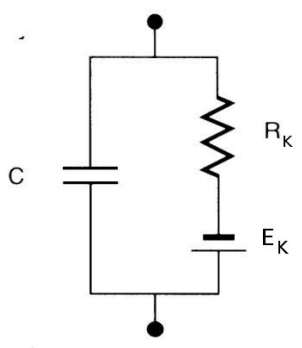

Figura 2.2 - (A) Esquema da membrana celular com um canal iônico de potássio que a atravessa. (B) Circuito equivalente, onde a membrana é representada por um capacitor, ligado em paralelo com um resistor e uma bateria, que representam respectivamente o canal iônico de potássio, e o potencial de Nernst (Eq. 2.1) para o mesmo íon. Extraído de (Koch, 1999).

mostra a figura 2.2, composto por um capacitor (que representa a membrana celular), ligado em paralelo com um resistor (canal iônico) em série com uma bateria (potencial difusivo devido a diferença de concentração dos dois lados da membrana).

Diversas células têm um potencial de membrana fixo a menos que sejam perturbadas, que é conhecido como potencial de repouso: sua origem é dada principalmente pela assimetria das concentrações iônicas nos meios intra e extracelulares e pela diferença na permeabilidade da membrana a cada tipo iônico, como explicado a seguir.

Imaginemos uma situação onde temos uma membrana impermeável, com alta concentração de $\mathrm{Na}^{+}$e $\mathrm{Cl}^{-}$no lado extracelular,e alta concentração de $\mathrm{K}^{+}$e $\mathrm{A}^{-}$(ânions orgânicos) no lado intracelular, sendo que os dois lados têm a mesma quantidade de cargas positivas e negativas. Nessa situação não há qualquer diferença de potencial entre os dois lados. Quando colocamos um canal iônico de potássio nessa membrana, os íons de potássio começam a atravessá-la do lado com maior concentração (intra) para o outro (extra), 

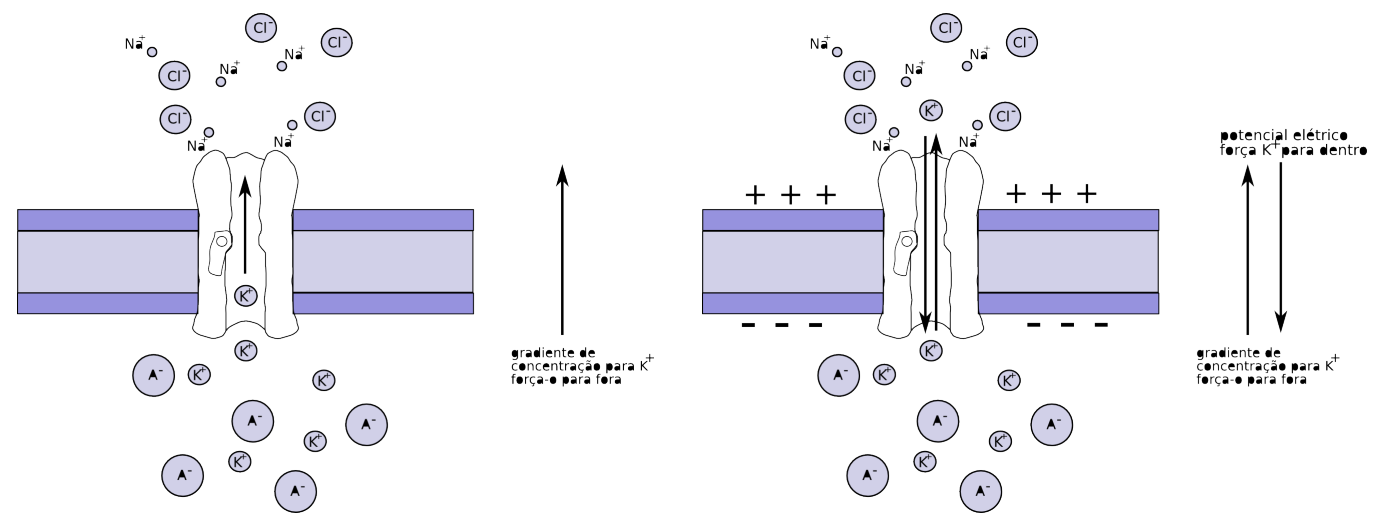

Figura 2.3 - Esquema explicativo da formação do potencial de repouso. (A) Na ausência de um potencial de membrana, e esta sendo permeável apenas ao potássio $\left(K^{+}\right)$, o potencial difusivo faz com que o potássio vá do meio intracelular para o meio extracelular. (B) Devido à saída de potássio da célula, forma-se um potencial de membrana que força o potássio para dentro da célula. Quando atingido o potencial de Nernst (Eq. 2.1), a quantidade de potássio que entra na célula é igual a que sai, e o potencial de membrana não varia mais.

devido ao seu potencial químico. Isso acarreta no acúmulo de cargas positivas no meio extracelular e, consequentemente, a formação de uma diferença de potencial através da membrana (Fig. 2.3). Essa diferença de potencial exerce uma força elétrica sobre os íons no sentido de levá-los do lado com menor concentração para o lado com maior concentração, o que tende a contrabalancear o potencial químico (Fig. 2.3). A equação de Nernst (Eq. 2.1) nos dá o potencial elétrico em que as duas tendências (difusiva e elétrica) se equilibram.

$$
E_{K}=\frac{R T}{Z F} \ln \frac{[K]_{\circ}}{[K]_{i}}
$$

Para o caso em que temos permeabilidade a mais de um íon é necessário ponderar os potenciais de equilíbrio $E_{i}$ de cada íon pela sua condutância $g_{i}$. 


$$
V_{m}=\frac{\sum_{k} E_{k} \times g_{k}}{\sum_{k} g_{k}}
$$

Esta equação é conhecida como equação de Goldman. O potencial de repouso (geralmente em torno de $-65 \mathrm{mV}$ ) é formado principalmente devido aos canais iônicos de potássio que têm um potencial de Nernst $\left(E_{K}\right)$ de -75 $m V$, com um efeito secundário dos canais de sódio, com um potencial de Nernst $\left(E_{N a}\right)$ de $+55 \mathrm{mV}$.

\subsubsection{Propriedades estocásticas dos canais iônicos}

Com a descoberta do método patch-clamp ${ }^{1}$, foi possível estudar o comportamento de um único canal iônico (estrutura básica responsável pela condutância iônica através da membrana celular), medindo a corrente que passa por ele.

Independentemente das particularidades das dinâmicas de abertura/fechamento de cada tipo de canal iônico, é comum a todos um comportamento do tipo tudo ou nada (Fig. 2.4a). Quando estão fechados, não conduzem nenhuma corrente iônica, e quando estão abertos, têm uma condutância bem determinada, sendo a corrente iônica que passa por eles linearmente proporcional ao potencial de membrana (Fig. 2.4b)(conduzem de acordo com a lei de Ohm (Hille, 1992; Kandel et al., 1991)).

Além disso, a transição entre os estados aberto/fechado é aleatória (Fig. 2.4a), podendo ser descrita apenas em termos de probabilidades, que em geral podem depender do potencial de membrana, ligações com moléculas, e do tempo.

\footnotetext{
${ }^{1}$ Método experimental que utiliza como eletrodo uma micropipeta de vidro preenchida com solução salina, e permite medir a corrente elétrica que passa por um único canal iônico (Kandel et al., 1991).
} 

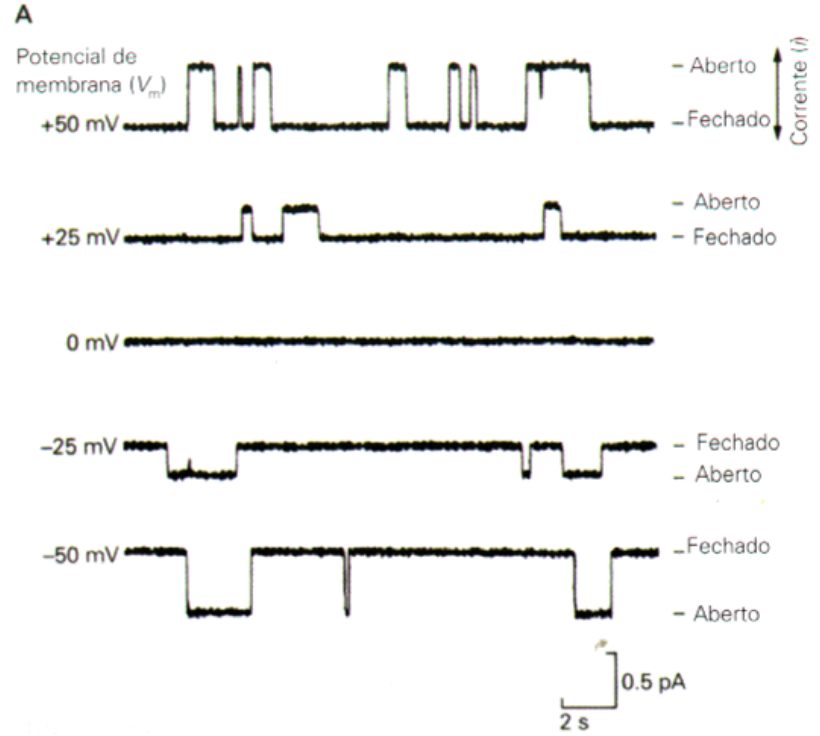

B

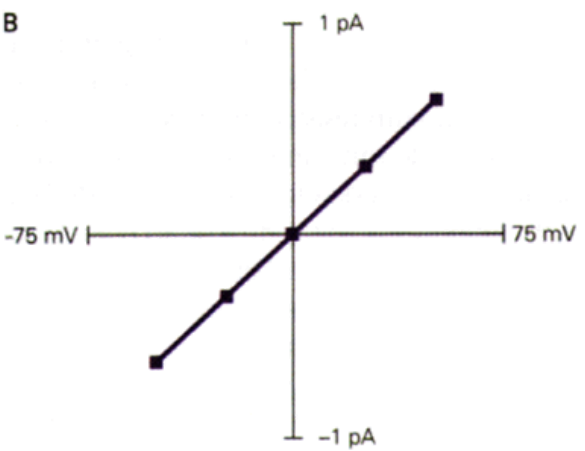

Figura 2.4-Comportamento de um canal iônico medido pelo método patch clamp. Dado um potencial de membrana, a corrente que passa pelo canal iônico oscila aleatóriamente entre dois patamares: zero, que corresponde ao canal iônico estar fechado, e um valor fixo não nulo (a). Com informação sobre o canal iônico quando exposto a diferentes potenciais de membrana, verifica-se a relação linear da intensidade da corrente conduzida com o potencial de membrana (b). Extraído de (Kandel et al., 1991) 


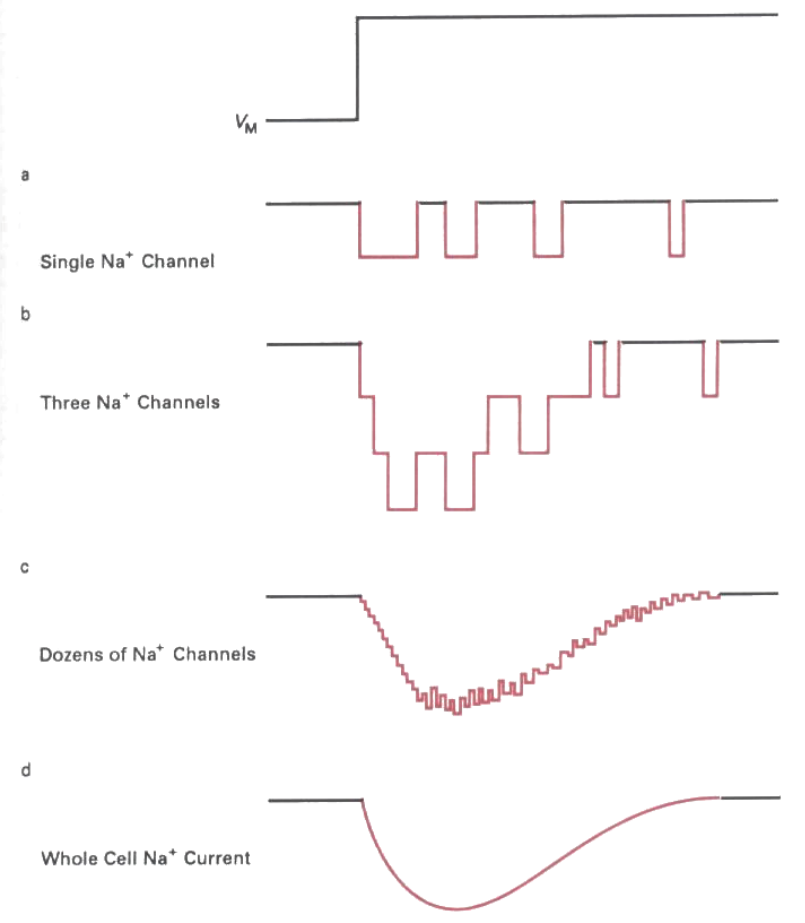

Figura 2.5 - Correntes iônicas devido a atividade conjunta de canais iônicos individuais durante uma despolarização sustentada do potencial de membrana, para diferentes quantidades de canais iônicos. a) um canal, b) três canais, c) dezenas de canais, d) número arbitrariamente grande de canais. (Extraído de (Levitan e Kaczmarek, 1997))

\subsubsection{Canais iônicos dependentes de voltagem e o po- tencial de ação}

Alguns tipos de canais iônicos são capazes de abrir e fechar para a passagem de íons pela ligação de moléculas, outros pela aplicação de um campo elétrico. Estes últimos são de particular interesse pois explicam a formação e propagação do potencial de ação (PA).

Já vimos anteriormente que o potencial de repouso dos neurônios é aproximadamente $-65 \mathrm{mV}$. Quando ele é ligeiramente aumentado, rapidamente abrem-se canais iônicos de sódio dependentes da voltagem, que geram uma entrada de sódio na célula e, consequentemente, despolarizam ainda mais a membrana. Um pouco depois da abertura dos canais de sódio, a despolarização abre os canais de potássio dependentes de voltagem com dinâmica lenta, permitindo a saída de potássio da célula. Além disso os, próprios canais de 
sódio se inativam, interrompendo a entrada de sódio na célula. Esses dois fenômenos fazem com que a membrana volte a se polarizar (Fig. 2.6).

O mecanismo de geração do potencial de ação (descrito acima) permite que ele se propague sem atenuação por grandes distâncias nos axônios e, além disso, faz com que a sinalização dos neurônios tenha um caráter do tipo tudo ou nada. A descrição matemática deste fenômeno é explicada na seção 2.2.

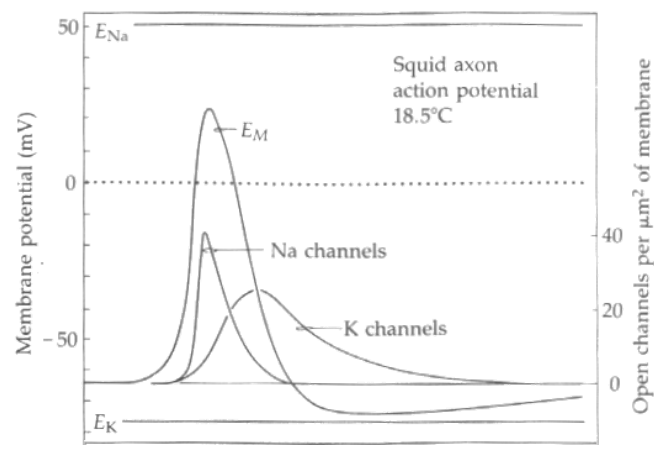

Figura 2.6 - Potencial de membrana $\left(E_{m}\right)$, e condutâncias de sódio e potássio, durante o potencial de ação, em função do tempo e do espaço. (Extraído de (Kandel et al., 1991))

\subsubsection{Canais iônicos responsáveis por rajadas de poten- ciais ou bursts}

Existem alguns tipos de canais iônicos dependentes da voltagem que são importantes na geração de atividade espontânea nos neurônios, e em especial na geração de bursts. Aqui destacamos: os canais de cálcio, que podem ser de dinâmica rápida e transiente, ou de dinâmica mais lenta e persistente (CaT e CaS); e os canais de potássio dependente de cálcio, que tem uma dinâmica lenta, ativada com a combinação de despolarização da membrana e aumento na concentração intracelular de cálcio.

Na figura 2.7 apresentamos a série temporal de um neurônio do gânglio estomatogástrico (stg - seção 2.5) que dispara potenciais de ação em rajadas. 


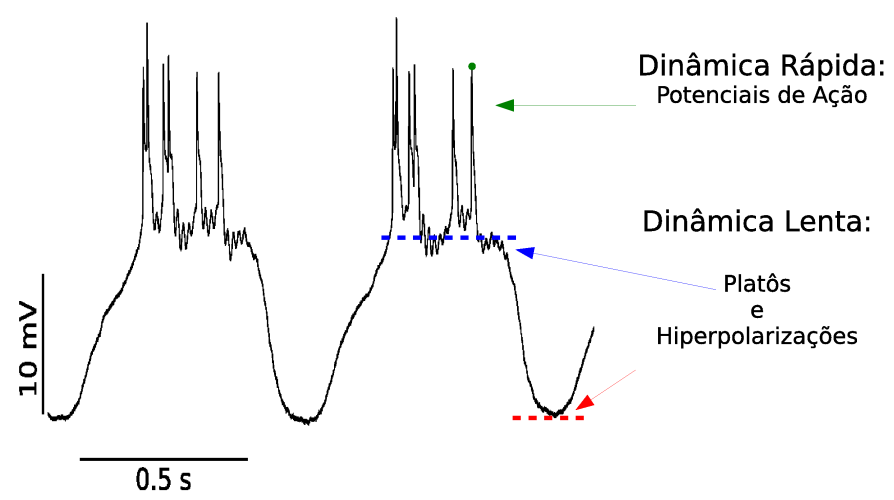

Figura 2.7 - Atividade típica de um neurônio lateral pilórico (LP) do gânglio estomatogástrico. Temos duas escalas de tempo típicas neste comportamento, uma rápida que corresponde aos potenciais de ação, e uma lenta que corresponde aos platôs de despolarização e hiperpolarizações.

A dinâmica rápida dos potenciais de ação é dada pelos canais de sódio e potássio como vimos na seção anterior. Mas aqui temos também uma dinâmica lenta, de despolarização e manutenção de um patamar de despolarização (platô). Durante esse patamar de despolarização, ocorrem diversos potenciais de ação e então ocorre uma hiperpolarização, fazendo com que o neurônio permaneça "silencioso" por algum tempo.

A despolarização e manutenção do platô são causadas pela abertura de canais iônicos de cálcio $\left(\mathrm{Ca}^{2+}\right)$. Este, ao entrar na célula ativa um tipo de canal iônico de potássio dependente de cálcio $\left(K_{(C a)}\right)$, o qual é caracterizado por uma dinâmica lenta cuja ativação depende tanto de concentração de íons de cálcio $\left(\left[\mathrm{Ca}^{2+}\right]\right)$ intracelular como da despolarização da membrana. Quando esses canais se ativam, tendem a repolarizar a membrana, terminando o platô e causando a hiperpolarização. No capítulo 4 apresentamos uma descrição matemática detalhada da dinâmica dessas correntes.

Esse mecanismo de geração de rajadas também é usado para outras fun- 
ções, como por exemplo na adaptação da frequência de disparos de neurônios sensórios sujeitos a um estímulo duradouro (Kandel et al., 1991). 


\subsection{O modelo determinístico de Hodgkin-Huxley}

O trabalho de Hodgkin-Huxley (Hodgkin e Huxley, 1952) quantificou a dependência das condutâncias de $\mathrm{Na}^{+}$e $K^{+}$com o potencial de membrana e com o tempo.

O modelo, considerar a membrana como um capacitor que altera seu potencial elétrico de acordo com as correntes elétricas aplicadas, consiste em quatro equações diferenciais: uma para o potencial de membrana, duas para a corrente de sódio, e uma para a corrente de potássio.

$$
\begin{aligned}
& C_{m} \frac{d V}{d t}=\overline{g_{K}} n^{4}\left(V-E_{K}\right)+\overline{g_{N a}} m^{3} h\left(V-E_{N a}\right)+\overline{g_{l e a k}}\left(V-E_{\text {leak }}\right)+I \\
& \frac{d m}{d t}=\alpha_{m}(1-m)-\beta_{m} m \\
& \frac{d h}{d t}=\alpha_{h}(1-h)-\beta_{h} h \\
& \frac{d n}{d t}=\alpha_{n}(1-n)-\beta_{n} n \\
& \overline{\alpha_{n}(V) \frac{0.01(10-V)}{\exp [(10-V) / 10]-1}} \\
& \alpha_{m}(V) \frac{0.1(25-V)}{\exp [(25-V) / 10]-1} \\
& \alpha_{h}(V) \quad 0.07 \exp [-V / 20] \\
& \beta_{n}(V) \quad 0.125 \exp [-V / 80] \\
& \beta_{m}(V) \quad 4.0 \exp [-V / 18] \\
& \beta_{h}(V) \quad \frac{1}{\exp [(30-V) / 10]+1}
\end{aligned}
$$

Tabela 2.1 - Taxas de transição do modelo de Hodgkin-Huxley. 
A equação 2.3 é a equação de um circuito $R C$, sendo $C_{m}$ a capacitância da membrana, $V$ o potencial de membrana, $I$ uma corrente externa aplicada, $E_{i}(i=N a, K$ ou leak - corrente de fuga) o potencial de Nernst do íon $i$ e $\overline{g_{i}}$ a condutância máxima da membrana com relação ao íon $i$. Os termos incomuns são o $n^{4}$ multiplicando a condutância de $K^{+}$e os termos $m^{3}$ e $h$ multiplicando a condutância de $N a^{+}$, que contêm a dinâmica de abertura e fechamento dos canais iônicos em função de $V$ e do tempo. Os expoentes desses termos (4, 3 e 1), foram tirados originalmente de um ajuste numérico e justificados pelos autores como sendo devido ao diferente número de "partículas de ativação e inativação" que cada condutância possuía. Com o avanço de técnicas de cristalografia de raio X e genética, 40 anos após o modelo ter sido introduzido por $\mathrm{HH}$, foi mostrado que esses expoentes realmente refletiam a estrutura microscópica dos canais iônicoscomo postulado pelos autores que sequer sabiam de sua existência.

O canal iônico de potássio é uma proteína que tem 4 (daí o expoente) subunidades idênticas, que se abrem e fecham de forma independente, sendo $n$ a probabilidade de uma subunidade se encontrar aberta. Para que este canal iônico conduza, é preciso que todas suas subunidades estejam abertas, o que acontece com probabilidade $n^{4}$.

Para o canal iônico de sódio a situação é análoga. Este canal têm 3 subunidades $m$ de ativação, e uma subunidade $h$ de inativação.

As funções $\alpha_{n, m \text {, ou } h}$ e $\beta_{n, m \text {, ou } h}$ (Tabela 2.1) são as taxas de abertura e fechamento das respectivas subunidades.

Fazendo a transformação:

$$
n_{\infty}=\frac{\alpha_{n}}{\alpha_{n}+\beta_{n}} \quad \text { e } \quad \tau_{n}=\frac{1}{\alpha_{n}+\beta_{n}}
$$


Temos uma maneira alternativa de ver as equações 2.4 a 2.6:

$$
\frac{d n}{d t}=\frac{n_{\infty}-n}{\tau_{n}}
$$

onde $n_{\infty}(V)$ representa a probabilidade de uma subunidade do canal de potássio encontrar-se no estado aberto para um dado potencial de membrana $V$ em um tempo infinito, e $\tau_{n}$ representa um tempo de relaxação. $\mathrm{Na}$ literatura pode-se encontrar as duas formulações, que são completamente equivalentes. No entanto, para a modelagem estocástica (Capítulo 4) é mais conveniente utilizar a formulação original, em termos de taxas de transição.

Embora as equações sejam não lineares e dependam do potencial de membrana através de funções exponenciais e sigmoidais, o comportamento desse modelo é bastante simples. Basicamente ele tem dois estados estacionários qualitativamente diferentes, dependendo da corrente DC aplicada. Quando esta é menor do que um certo limiar, o potencial de membrana do modelo se estabiliza em um valor constante. Esse é o estado silencioso. Se a corrente aplicada ultrapassar esse limiar, o potencial de membrana passa a oscilar periodicamente, gerando pulsos de despolarização chamados potenciais de ação (P.A.)(Fig. 2.8). No estado silencioso, pequenos pulsos de corrente (positivos ou negativos) são capazes de produzir um P.A. após o qual o neurônio modelado retorna ao estado silencioso, ou seja ele é excitável.

Embora esse modelo seja ótimo para explicar a geração e a propagação do potencial de ação nos nervos, ele está muito longe de explicar o funcionamento de diversos neurônios, especialmente os neurônios capazes de disparar potenciais de ação em salvas. Para tanto, é necessário considerar outras condutâncias iônicas. 


\section{(A) Diagrama de Bifurcações}
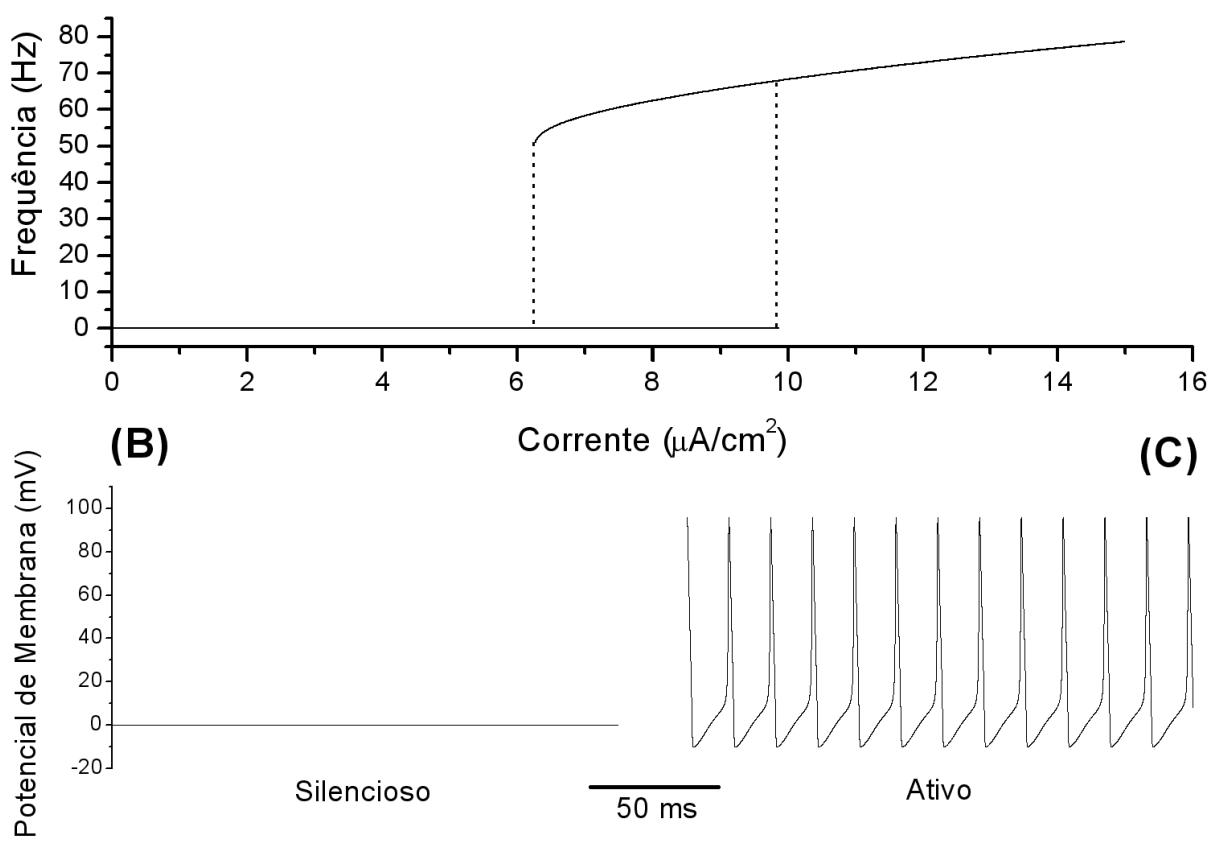

Figura 2.8 - (A) Diagrama de bifurcações da frequência de disparos pela corrente injetada, no modelo de Hodgkin-Huxley. Entre as linhas tracejadas temos uma região de biestabilidade onde os estados silencioso e tônico coexistem. (B) Exemplo de série temporal no estado silencioso. (C) Exemplo de série temporal no estado ativo (ou de disparo tônico). 


\subsection{Breve histórico da modelagem estocástica de neurônios}

O primeiro trabalho envolvendo um modelo tipo Hodgkin-Huxley estocástico foi o de Skaugen 1979 (Skaugen e Walloe, 1979). Este trabalho explorou os efeitos das condutâncias iônicas de sódio e potássio serem estocásticas no comportamento de um pequeno trecho do potencial de membrana de um axônio, em especial nas curvas de frequência por corrente injetada. Na época, não havia ainda nenhuma estimativa de quantos canais iônicos haviam em um neurônio, portanto as implicações práticas deste trabalho eram puramente especulativas.

Mais recentemente, outros trabalhos (Chow e White, 1996; White et al., 2000) mostram outros efeitos decorrentes da estocasticidade dos canais iônicos, tais como potenciais de ação espontâneos (que não seriam disparados por neurônios determinísticos) e potenciais de ação perdidos (falhas em uma atividade de disparo tônico de potenciais de ação). Este fenômenos têm especial relevância em nós de Ranvier (Rubinstein, 1995) e na propagação do potencial de ação em axônios finos (Faisal e Laughlin, 2007). Além disso um artigo de revisão argumenta que as flutuações estocásticas dos canais iônicos (também conhecidada na literatura como "channel noise") são responsável por aumentar a quantidade de comportamentos acessíveis à algumas populações de neurônios (White et al., 2000).

Recentemente, um experimento feito por Mainen 1995 (Mainen e Sejnowski, 1995), utilizou neurônios de ratos (neurônios do córtex que permanecem inativos se não forem estimulados), repetindo diversas vezes a aplicação de um degrau de corrente. O que se observou sobrepondo essas repetições é que o instante em que ocorre o primeiro potencial de ação com relação 
ao início da injeção de corrente é sempre muito próximo, enquanto que os próximos potenciais de ação vão rapidamente perdendo a confiabilidade e se embaralhando (figura 2.9 A). Para comparar com este resultado ele fizeram também a mesma experiência aplicando várias vezes uma corrente ruidosa ao invés de um degrau. O que se observa sobrepondo os resultados para a corrente ruidosa é que o instante de ocorrência dos potenciais de ação é bastante confiável (figura 2.9 B).
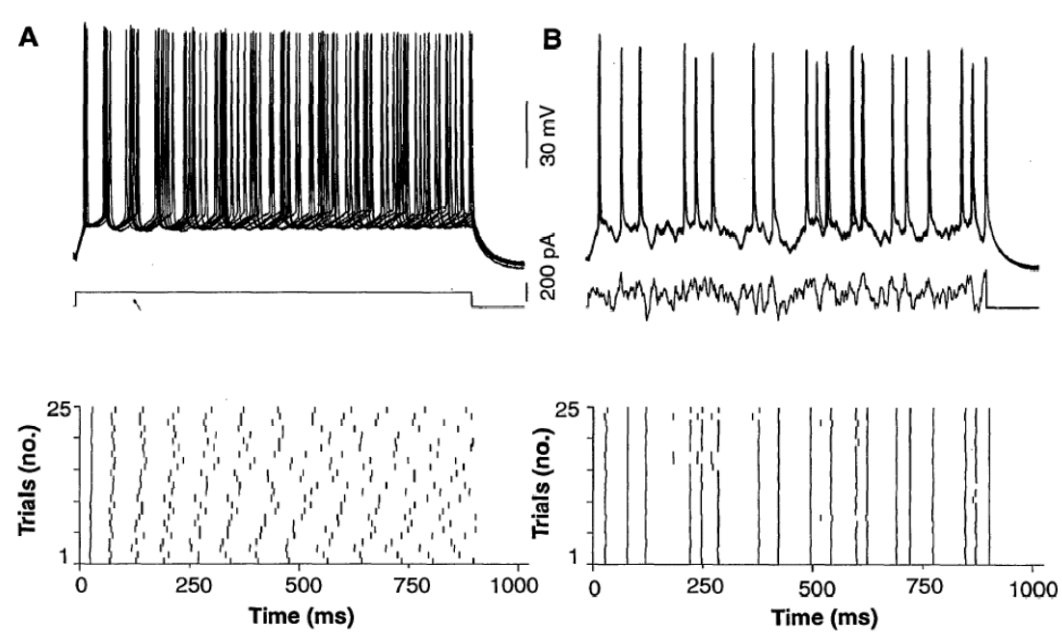

Figura 2.9 - (A) Acima temos a sobreposição das respostas do neurônio do córtex do rato à aplicação de um degrau de corrente de 200 pA, exibido na figura do meio; abaixo temos os instantes de ocorrência de cada uma dos potenciais de ação para cada uma das 25 tentativas. (B) Acima temos a sobreposição das respostas do neurônio à aplicação de uma corrente ruidosa, exibida na figura do meio; abaixo temos os instantes de ocorrência de cada uma dos potenciais de ação para cada uma das 25 tentativas. Extraído de (Mainen e Sejnowski, 1995).

O trabalho experimental de (Mainen e Sejnowski, 1995) caracterizou a resposta de um neurônio do córtex quando submetido a estímulos contínuos ou ruidosos (figura 2.9). Mostrou-se que quando se apresenta um mesmo estímulo repetidamente a esse neurônio, ele não responde sempre da mesma 
forma, sua confiabilidade (reprodutibilidade) depende de propriedades estatísticas do sinal de estímulo. No caso de um estímulo constante, o neurônio dispara com uma certa precisão os primeiros potenciais de ação enquanto os últimos são bem pouco confiáveis. No caso de um estímulo ruidoso, as posições dos spikes do neurônio são bem mais precisas, e sua confiabilidade depende da variância do estímulo.

Mais recentemente um estudo considerou que a área de geração dos potenciais de ação seria muito menor do que a área total da membrana do neurônio e isso amplificaria os efeitos estocásticos dos canais iônicos trazendo implicações para a geração do potencial de ação (Schneidman et al., 1998). Este modelo é bem sucedido em reproduzir as propriedades de precisão e confiabilidade de neurônios do córtex, quando submetidos a estímulos constantes ou flutuantes, enquanto o modelo HH determinístico não diferencia os dois tipos de estímulo (figura 2.10). 

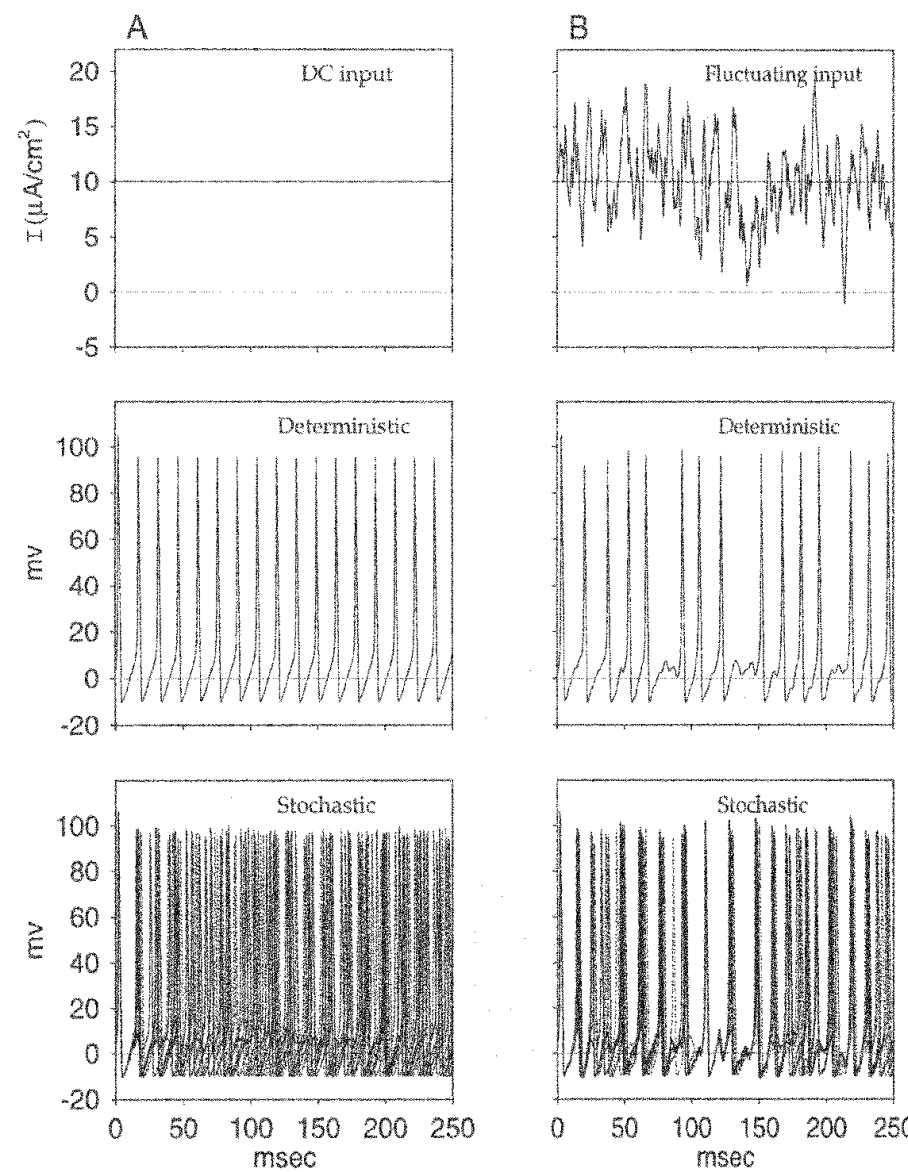

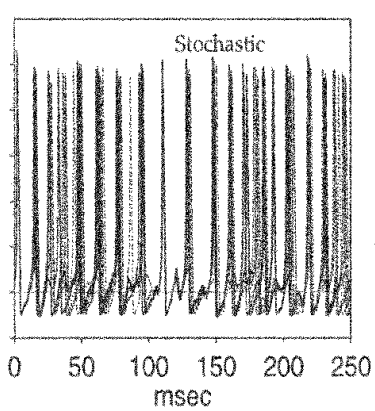

Figura 2.10

Comparação entre os resultados de neurônios modelo submetidos a correntes do tipo degrau e ruidosa. $\mathrm{O}$ Modelo HH determinístico responde sempre da mesma maneira tanto para o degrau de corrente quanto para o sinal ruidoso. O modelo Estocástico comporta-se de modo mais confiável para o sinal ruidoso que para o sinal de degrau de corrente. Extraído de (Schneidman et al., 1998). 


\subsection{O gânglio estomatogástrico (STG) de crus-} táceos

Crustáceos são artrópodes (decápodas) e estão entre os invertebrados mais populares em neurociência experimental. O interesse experimental por esses animais vem do fato de eles não mastigarem sua comida oralmente. Para escapar dos predadores, usam suas garras (quando presentes) e mandíbula para cortar o alimento em pedaços pequenos o suficiente para passarem pelo esôfago e o engolem rapidamente para retornar ao abrigo ou esconderijo, onde seu estômago adaptado (possui dentes e musculatura especializada) executa a mastigação. O gânglio estomatogástrico (STG), é o responsável pela geração e controle dos ritmos de contração do estômago e dos dentes gástricos.

O STG contém aproximadamente 30 neurônios e, quando isolado experimentalmente do corpo do animal, continua a gerar os padrões de atividade rítmica complexa que controlam os músculos do estômago produzindo praticamente os mesmos padrões observados nos animais intactos, desde que se mantenha a conexão com os gânglios superiores que fornecem sinais moduladores (Selverston e Moulins, 1986).

A parte do sistema nervoso que controla o esôfago e o estômago consiste em dois gânglios comissurais (CG), que formam protuberâncias nos conectivos circumesofágicos quando estes passam pelo esôfago; um pequeno gânglio esofágico (OG), localizado na superfície anterior do esôfago; e um gânglio estomatogástrico, localizado na superfície dorsal do estômago, dentro da artéria oftálmica. Na Figura 2.11 é mostrado um esquema com a localização dos vários gânglios do sistema nervoso estomatogástrico. O OG conecta-se diretamente ao gânglio supraesofágico (cérebro) através do nervo ventricular inferior (ivn), e ao STG através do nervo estomatogástrico (sgn). 


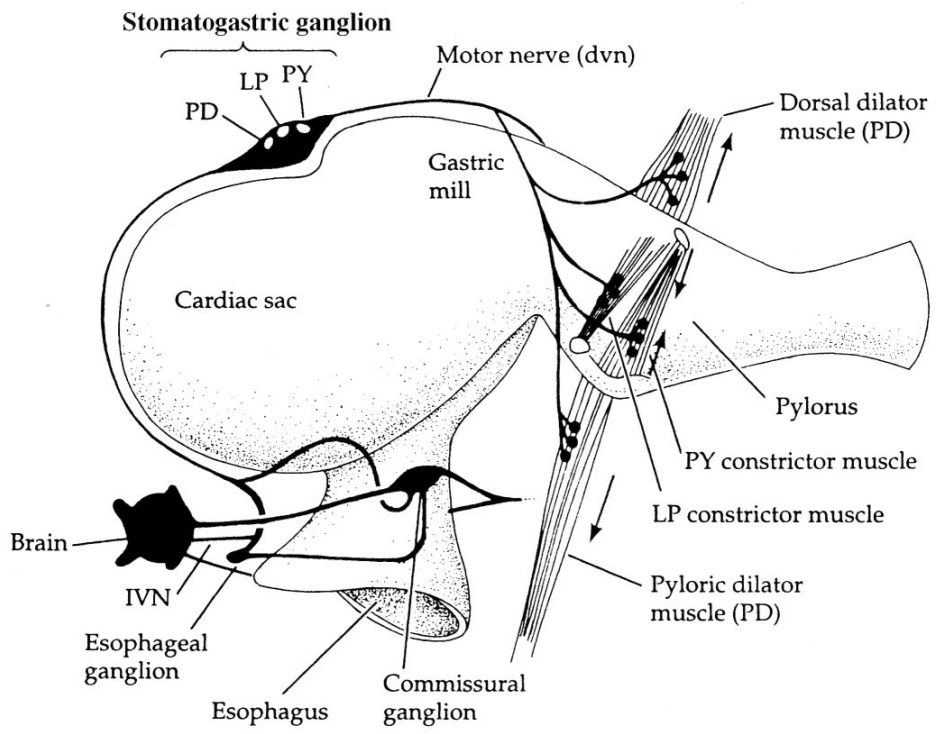

Figura 2.11 - Vista esquemática do estômago e do sistema nervoso estomatogástrico associado, consistindo em dois gânglios comissurais que formam protuberâncias nos conectivos circumesofágicos, um pequeno gânglio esofágico localizado na superfície anterior do esôfago e um gânglio estomatogástrico localizado na superfície dorsal do estômago.

Os músculos do estômago são comandados por axônios originados em neurônios motores localizados no STG. Os músculos são pareados bilateralmente, mas os neurônios motores não. Cada neurônio motor controla os dois membros de um par de músculos apropriados; o axônio bifurca-se e conecta-se aos dois músculos componentes do par.

\subsection{Centros geradores de padrões (CPGs) do STG}

O gânglio estomatogástrico, é um dos circuitos neurais mais estudados de toda a literatura científica de neurociência. Isso se deve a diversas razões. Em primeiro lugar, esse gânglio funciona de forma autônoma em relação ao 


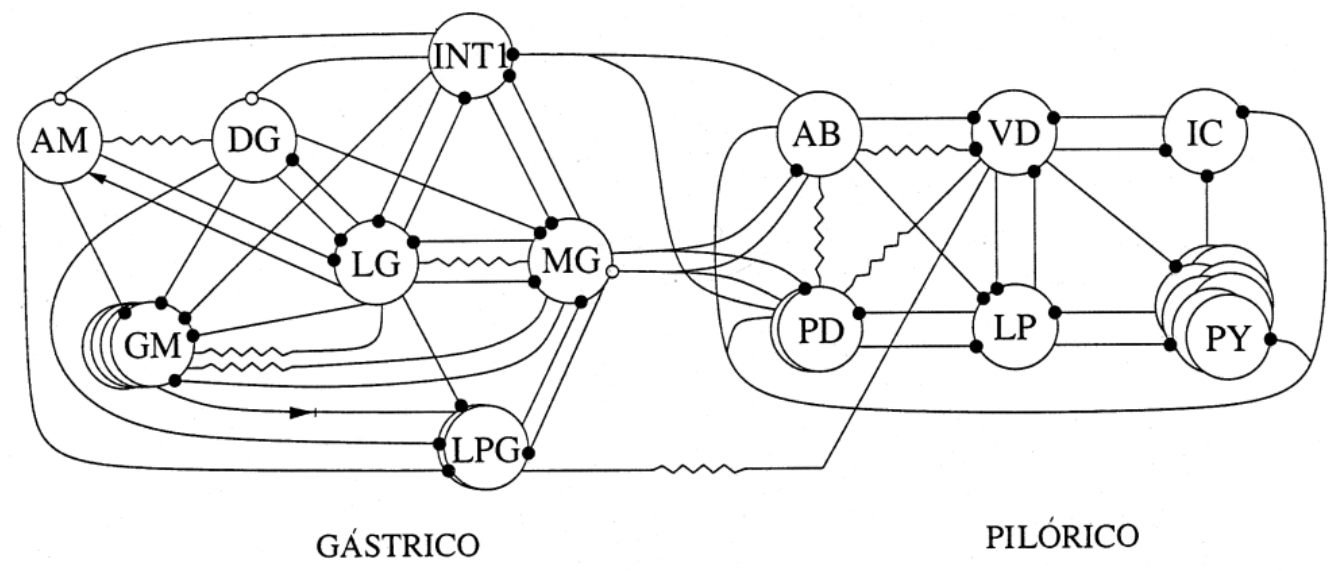

Figura 2.12 - Esquema dos circuitos que formam o STG. O circuito gástrico é responsável pela mastigação dos alimentos no estômago. O circuito pilórico é responsável pelo bombeamento de comida para o intestino. O nome dos neurônios é determinado pelo músculo que ele enerva (ver figura 2.11)

cérebro, sendo apenas modulado por gânglios de "hierarquia mais alta", e quando removido do animal continua a gerar o mesmo padrão que gerava no animal vivo, ou seja, é formado por circuitos conhecidos como centros geradores de padrões (CPGs). Isso permite que este sistema seja estudado in vitro sem perder suas características mais importantes. Outra vantagem desse sistema é que ele possui um número relativamente pequeno de células (cerca de 30 neurônios), que podem ser individualmente identificadas, e assim o mesmo experimento pode ser reproduzido em diferentes animais. Uma grande quantidade de artigos já explorou esta vantagem para mostrar os mais diferentes aspectos de redes de neurônios e neurônios isolados.

Dentro do gânglio estomatogástrico existem dois circuitos neurais, o CPG gástrico, que controla a mastigação no estômago, e o CPG pilórico, que controla o bombeamento de comida do estômago para o intestino (Fig. 2.12).

Na década de 70, quando se descobriu este gânglio, a idéia era em pri- 
meiro lugar conhecer as conexões sinápticas entre todos os neurônios, em seguida isolar os neurônios para conhecer suas propriedades intrínsecas, e então construir modelos para os neurônios e sinapses e juntar tudo num modelo completo de CPG. Esta abordagem é reducionista, e apresenta problemas quando tentamos aplicá-la a sistemas complexos, como é o caso do sistema nervoso.

A principal dificuldade encontrada foi (e ainda é) explicar porque os neurônios isolados de um CPG que apresenta padrões periódicos se comporta de maneira irregular. Ou seja, não era possível explicar o ritmo produzido pelo circuito todo como uma combinação de ritmos produzidos pelas partes constituintes.

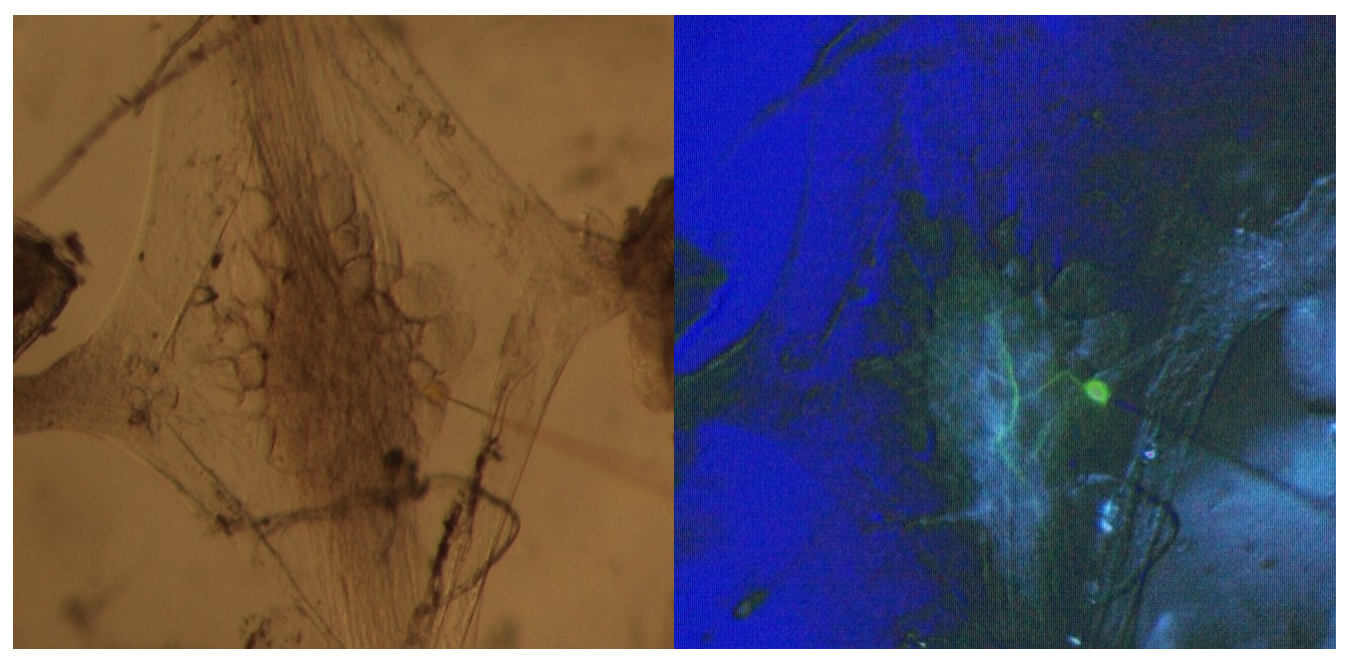

Figura 2.13 - Fotomicrografias do gânglio estomatogástrico - a largura de cada foto corresponde a aproximadamente $1 \mathrm{~mm}$. À esquerda temos o gânglio exposto e o neurônio $A B$ empalado pelo eletrodo usado para injetar um corante. À direita temos a imagem do gânglio sendo iluminado com um feixe de luz azul produzido por um LED e uma lente colimadora, que faz com que o corante carboxifluoresceína destrua as proteínas do neurônio $A B$ e emita uma luz amarela. 


\subsection{Teoria da informação}

Dada uma fonte que emite mensagens $r$ dentro de um conjunto $R$, com uma probabilidade $p(r)$, a teoria da informação diz que o conteúdo informacional $i(r)$ dessa mensagem é:

$$
i(r)=\log _{2}\left(\frac{1}{p(r)}\right)
$$

A entropia $H(R)$ dessa fonte é uma medida da informação que em média é necessária para transmitir cada mensagem desta fonte. Sempre vamos usar tanto entropia quanto informação em bits.

$$
H(R)=-\sum_{r} p(r) \log _{2} p(r)
$$

Imaginemos agora uma situação onde temos duas fontes. Uma fonte $S$, que chamaremos de estímulo, manda mensagens para uma fonte $R$, que chamaremos de resposta. Esta, em princípio, pode mandar suas mensagens baseadas naquelas que recebeu de $S$ ou ignorá-las. A informação mútua média (AMI - sigla em inglês) é uma medida de quanta informação sobre o estímulo está contida na resposta:

$$
A M I(S, R)=H(R)-H(R \mid S)
$$

onde $H(R \mid S)$ é a entropia da resposta $(R)$, dado o estímulo $(S)$ :

$$
H(R \mid S)=-\sum_{j} p\left(s_{j}\right) \sum_{i} p\left(r_{i} \mid s_{j}\right) \log _{2} p\left(r_{i} \mid s_{j}\right)
$$

Note que se a resposta é independente do estímulo ( $r_{i}$ não depende de $s_{j}$ ), $p\left(r_{i} \mid s_{j}\right)=p\left(r_{i}\right)$, o que implica que $H(R \mid S)=H(R)$. Portanto a equação 2.11 vale zero, ou seja, se olharmos a resposta não teremos qualquer informação sobre o estímulo. 
Em alguns casos dividimos a AMI pela entropia da resposta, obtendo a fração desta que está destinada a codificar o estímulo. 


\section{Capítulo 3}

\section{Métodos}

\subsection{Dissecação do gânglio estomatogástrico}

Começamos o procedimento de dissecação anestesiando o animal por imersão em gelo fundente durante aproximadamente 30 minutos. Após a anestesia são removidas as garras e as patas. O estômago é exposto com a remoção da parte dorsal do exoesqueleto e da pele interior. O estômago é removido cortando-se a artéria oftálmica na região posterior ao estômago e removendo-se todas as conexões do gânglio supraesofágico, exceto as conectivas circumesofágicas. Usando uma pinça curva para segurar a base do esôfago e uma pequena tesoura desconecta-se o esôfago do exoesqueleto. Após levantar o estômago, puxando pelo esôfago e cortando simultaneamente as duas conectivas circumesofágicas, este pode ser removido do animal. As conexões do estômago com o intestino e o hepatopâncreas normalmente quebram quando o estômago é levantado e, portanto, não precisam ser cortadas. Esta primeira fase da preparação leva cerca de 20 minutos.

Após a remoção do estômago este é lavado repetidamente com a solução fisiológica específica do crustáceo, para remover os sucos gástricos que pode- 
riam danificar o sistema nervoso, e aberto na linha média ventral partindo-se da abertura para o intestino até a abertura do esôfago. Dois cortes laterais na direção dos ossículos (dentes) permitem que o estômago adquira um perfil plano que facilita sua fixação a uma placa de dissecação. Também cortamse as pontas dos três dentes que constituem a moela gástrica para tornar o estômago plano. Esta fase da preparação leva aproximadamente 5 minutos. Neste ponto, a preparação consiste no estômago, no gânglio supraesofágico, nas conectivas circumesofágicas e no sistema nervoso estomatogástrico e muscular completo fixado a uma placa de dissecação preenchida com a solução fisiológica do crustáceo, conforme mostrado na Figura 3.1.

Na última fase da dissecação, cada um dos nervos é identificado, observandose, para tal, qual é músculo a que o nervo é conectado. O nervo é então removido da superfície do músculo, da gordura e do tecido conectivo ao redor até o ponto onde o mesmo entra na artéria oftálmica. Esta artéria juntamente com todo o sistema nervoso estomatogástrico é transferida para uma placa de Petri revestida com silicone transparente e preenchida com solução fisiológica. Os nervos são fixados à placa de Petri na mesma posição relativa que possuíam no estômago como mostrado na Figura 3.2. Efetua-se então a limpeza do sistema nervoso do tecido conectivo remanescente, gordura ou excesso de tecido das artérias. Corta-se uma janela na parede arterial ao redor do STG para que este possa ser iluminado por baixo da placa de Petri. Finalmente as células do STG são expostas (na seção 2.5 mostramos uma foto do gânglio exposto com as células à mostra - Figura 2.13), removendo-se uma fina camada de tecido conectivo protetor, usando pinças e tesouras especiais para microcirurgia. Esta fase final da dissecação pode demorar de 2 a 5 horas, dependendo principalmente da quantidade de gordura encontrada nos tecidos. 


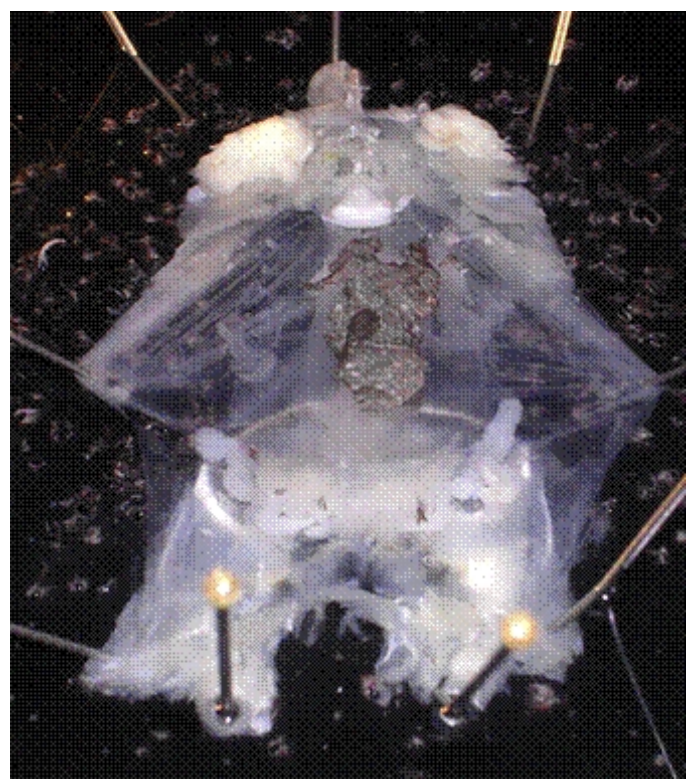

Figura 3.1 - O estômago aberto do siri, contendo o sistema nervoso estomatogástrico e o cérebro do animal, fixado com pinos de aço-inóx à placa de dissecação onde é mantido imerso em solução fisiológica.

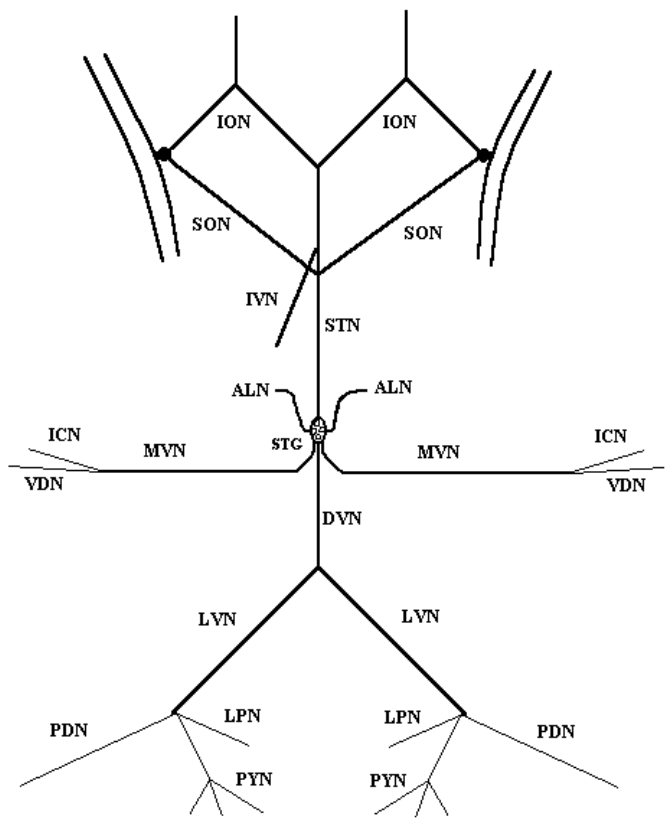

Figura 3.2 - Esquema dos nervos do sistema nervoso estomatogástrico, na posição que estão na imagem ao lado. 
O soma dos neurônios componentes do STG não tem uma posição fixa ou previsível no gânglio, portanto, o primeiro passo após a dissecação é identificar e mapear a posição do corpo celular dos neurônios. A identificação dos neurônios é feita empalando cada uma das células visíveis com microeletrodos, e comparando o sinal delas com um sinal medido nos nervos que saem do gânglio para enervar os músculos do piloro (Figura 3.3). Quando há uma correlação perfeita entre os potenciais de ação medidos pelo microeletrodo com os medidos no nervo, está estabelecida a identidade da célula.

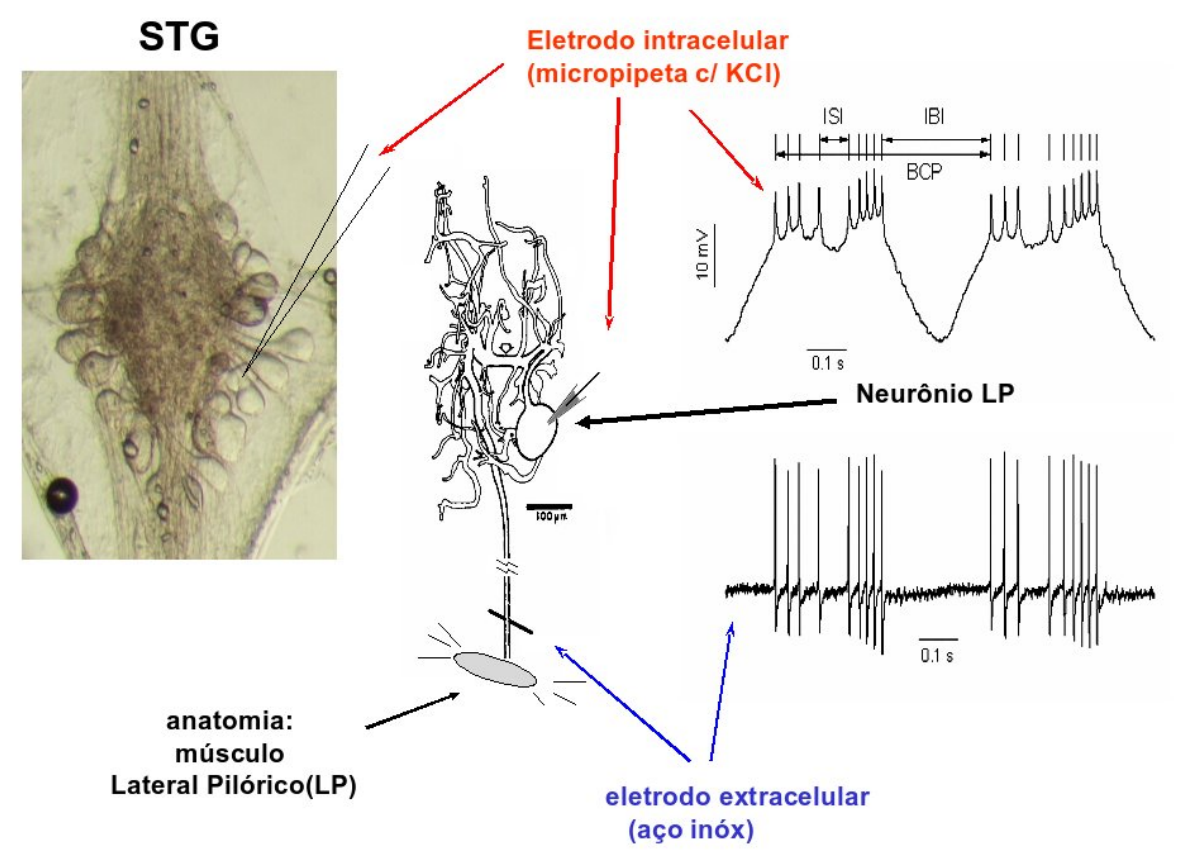

Figura 3.3 - Identificação dos neurônios comparando medidas intracelulares com medidas extracelulares. O sinal observado no nervo LP é proveniente do neurônio LP. Assim, a sincronização entre os potenciais de ação provenientes do corpo celular e os potenciais de ação em um dos axônios conhecidos estabelece a identidade da célula. 


\subsection{Dynamic clamp: introduzindo condutâncias artificiais em neurônios biológicos}

O dynamic clamp é um protocolo usado para inserir condutâncias artificiais em neurônios biológicos. Ele é tradicionalmente utilizado tanto para alterar as condutâncias iônicas dependentes de voltagem em um neurônio, quanto para criar sinapses artificiais entre neurônios. Neste trabalho utilizamos o dynamic clamp para criar sinapses artificiais entre um neurônio modelo (simulado em tempo real pelo computador) e um neurônio biológico.

O computador que calcula o dynamic clamp, através de uma interface conversora analógico-digital e digital-analógica marca Axon modelo Digidata 1200A, lê o sinal analógico do potencial de membrana do neurônio biológico, então calcula o potencial de membrana do neurônio modelo (CN - sigla em inglês para computer neuron) e as correntes devidas às sinapses artificiais de CN para o neurônio biológico e vice versa. Este computador coloca nas saídas analógicas da placa Digidata tanto o potencial de CN quanto o valor de corrente a ser injetado no neurônio biológico. Um outro computador é usado para fazer adquirir os dados, que incluem os três sinais (potenciais de membrana do neurônio biológico e de CN, e corrente injetada no neurônio biológico). Na Figura 3.4 apresentamos um esquema da montagem experimental utilizada. 


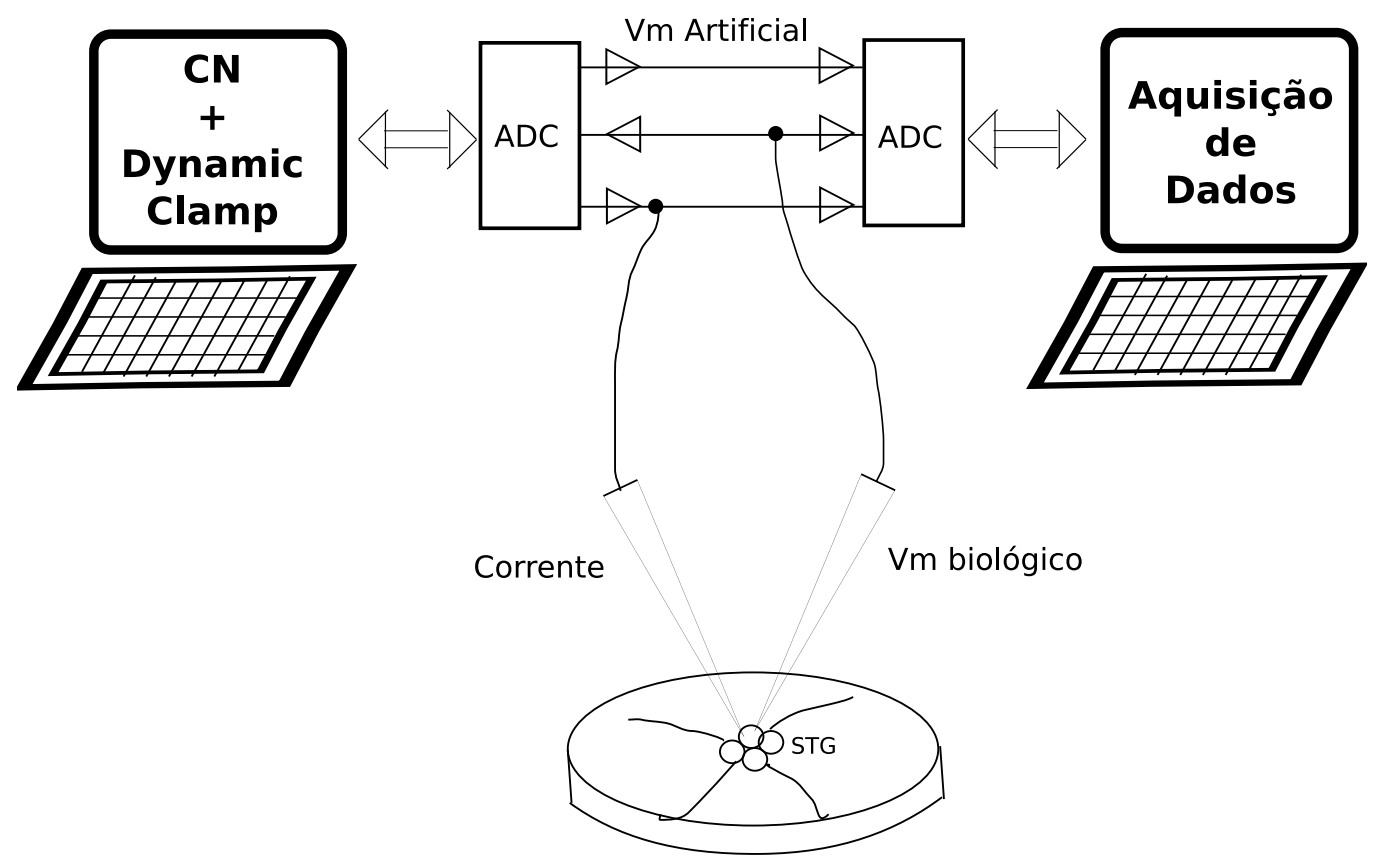

Figura 3.4 - Aparato experimental utilizado para interagir o modelo estocástico com um neurônio do gânglio estomatogástrico. O computador que executa o dynamic clamp é alimentado com o potencial de membrana do neurônio biológico ( $\mathrm{Vm}$ biológico), e coloca em saídas analógicas o sinal calculado do neurônio modelo (CN) e a corrente a ser injetada no neurônio biológico. Outro computador recebe todos esses sinais e faz a aquisição de dados. 


\subsection{Teoria da informação e o CPG pilórico}

No CPG pilórico, temos os neurônios LP e PD que disparam em anti-fase. Foi mostrado (Szucs et al., 2003) que quando um neurônio do CPG pilórico é inibido e silenciado, o neurônio PD continua a gerar o mesmo padrão de bursts o que significa que os músculos que ele controla estariam se contraindo da mesma forma. No entanto quando observamos a estrutura de disparos dentro do burst do PD, ela se altera de uma maneira diferente dependendo de qual dos neurônios do CPG pilórico foi silenciado (Szucs et al., 2003). Isso sugere que a estrutura de disparos dentro do burst do PD é capaz de codificar (usando um código que desconhecemos) o que está acontecendo com os outros neurônios do circuito.

A teoria da informação é útil nesse caso, pois nos permite ter uma medida quantitativa das correlações e incertezas de dois conjuntos de eventos (no caso a estrutura de disparos de dois neurônios distintos) sem fazer qualquer hipótese sobre o código utilizado.

A análise da série temporal é feita em duas etapas: digitalização e posicionamento binário dos potenciais de ação, e depois o cálculo da informação mútua média entre os neurônios.

Em primeiro lugar o programa de análise varre as séries temporais detectando os potenciais de ação. Como estamos interessados em analisar a informação contida em pares de bursts estímulo e resposta, impomos uma condição de causalidade. O burst de estímulo deve começar antes do início do burst de resposta e também deve terminar antes do final do final do burst de resposta. Se o par de bursts satisfizer estas condições, eles são chamados "joint bursts" e entram na estatística, caso contrário são descartados. Feito isso, tomamos como referência temporal o primeiro spike do burst do neurônio resposta, e escolhemos um tempo $T_{1}$ para a duração do burst do estímulo 
e um tempo $T_{2}$ para a duração do burst de resposta (Ver figura 3.5). Em seguida a série temporal é dividida em intervalos de duração $\Delta T_{1}$ (ou $\Delta T_{2}$ ) e para cada intervalo atribuímos o valor 1 se houver ocorrência de um spike ou 0 se não houver ocorrência de spike. Assim transformamos a série temporal em sequências de bits tendo o burst de estímulo $T_{1} / \Delta T_{1}=N_{1}$ bits e o burst de resposta $T_{2} / \Delta T_{2}=N_{2}$ bits. A escolha de $\Delta T$ tem que ser feita com cuidado, pois se este for muito grande teremos todos os bits da série iguais a 1 e, logo, entropia 0 , mas também não pode ser muito pequeno senão quase todos os bits terão o valor 0 e a entropia também tenderá a zero. Uma boa estimativa é $\Delta T_{1} \approx T_{1} / 2 n_{1}$, onde $n_{1}$ é o número médio de spikes por burst do neurônio estímulo o que nos dá uma quantidade equilibrada de zeros e uns.

Para fazer os cálculos da teoria da informação temos que definir um espaço de eventos (palavras). Escolhemos um número $P$ de bits para o tamanho da nossa palavra e separamos as sequências de bits dos bursts de resposta em vários subconjuntos $R_{1}, R_{2}, \ldots, R_{n}$, sendo que o subconjunto $R_{i}$ é formado pelos bits entre $i$ e $i+P$. Separamos os bursts de estímulo em subconjuntos $E_{1}, E_{2}, \ldots, E_{m}$, de forma análoga ao que foi feito para os bursts de resposta. Dessa forma obtemos uma matriz $A M I\left(R_{i}, E_{j}\right)$ e podemos comparar quais trechos do estímulo estão mais relacionados com quais trechos da resposta. 


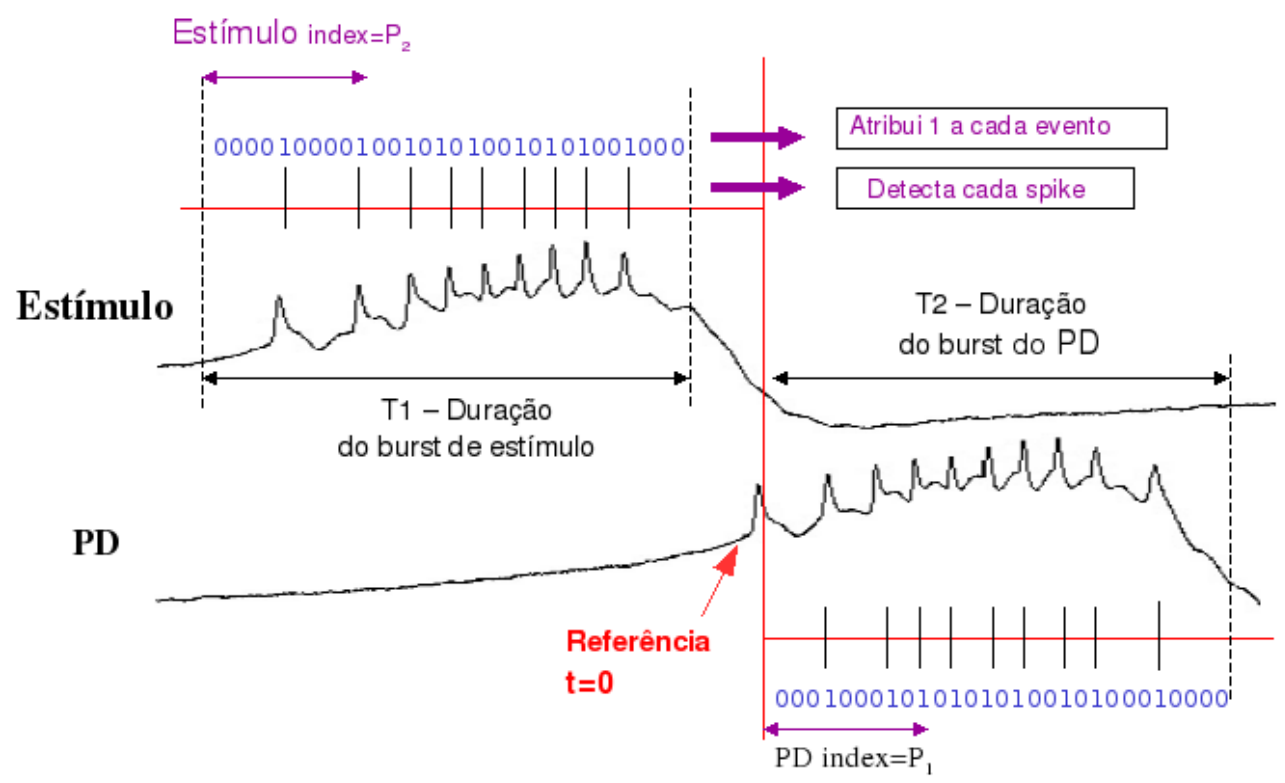

Figura 3.5 - Esquema de como os bursts de estímulo e resposta são discretizados e codificados em bits. Em primeiro lugar, são detectados os instantes em que os spikes ocorrem nos neurônios. Em seguida adota-se o primeiro spike do PD como referência de tempo. Então escolhe-se um número total de intervalos para discretizar a série: se houver um spike ocorrendo num determinado intervalo de tempo, atribui-se a este intervalo o valor 1 , caso contrário atribui-se o valor 0 . Para os cálculos de informação e entropia usamos palavras de 8 bits, tanto no estímulo quanto na resposta. Usamos os índices Estmulo index e PD index para determinar de qual posição dentro do burst são extraídos os 8 bits que usamos para calcular a informação, tanto no estímulo quanto na resposta. Dessa forma, ao invés de termos somente um valor da $A M I$ entre o padrão aleatório e o modelo, teremos uma matriz de valores de $A M I$ relacionando cada trecho do estímulo com cada trecho da resposta. 


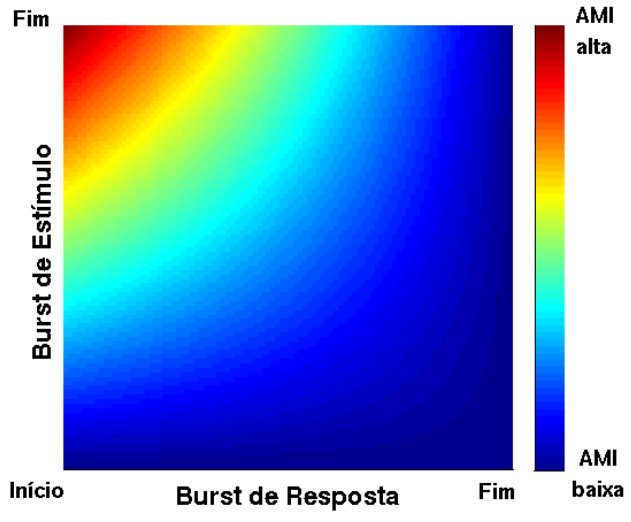

Figura 3.6 - Resultado hipotético da análise da AMI (unidades arbitrárias). Uma vez que o burst de estímulo acaba logo antes do burst de resposta, imaginávamos que o começo do burst de resposta se "lembraria" mais do final do burst de estímulo, ou seja que evento com uma maior proximidade temporal estivessem mais correlacionados e que a correlação deveria cair gradualmente. Nesta situação teríamos um pico de AMI correspondendo ao começo do burst de resposta e fim do burst de estímulo. 


\section{Capítulo 4}

\section{Implementação de modelos}

\subsection{Modelagem determinística}

O modelo tipo HH que utilizamos é um modelo de compartimento único baseado em experimentos de células em cultura do STG (Turrigiano et al., 1995; Prinz et al., 2003b). Ajustando apropriadamente as condutâncias iônicas máximas, este modelo é capaz de apresentar comportamentos tanto de bursts quanto de disparo tônico (Fig. 4.1).
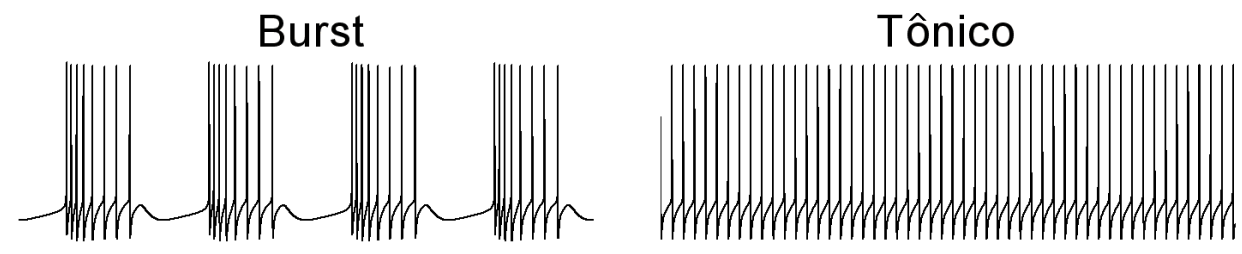

Figura 4.1 - Exemplos de comportamentos elétricos que o modelo modelo HH determinístico de um neurônio do STG é capaz de apresentar, em função dos parâmetros escolhidos.

A dinâmica do potencial de membrana é dada por:

$$
\frac{d V}{d t}=-\frac{1}{C_{m}} \sum_{i} g_{i}\left(V-V_{i}\right)
$$


Onde $V$ é o potencial de membrana, $C_{m}$ é a capacitância da membrana, $V_{i}$ é o potencial de Nernst do íon $i$. A condutância do tipo $i$ ( $i=N a$ (Sódio), $K d$ (Potássio retificador), CaT(Cálcio transiente), CaS(Cálcio), K(Ca) (Potássio dependente de cálcio), $A$ (corrente de Adaptação), e corrente $H)\left(g_{i}\right)$ é expressada como $g_{i}(V, t)=\overline{g_{i}} m_{i}^{\gamma_{i}} h_{i}^{\delta_{i}}$, onde $\overline{g_{i}}$ é a condutância máxima do tipo $i, m_{i}$ e $h_{i}$ são variáveis que assumem valores no intervalo $[0,1]$.

As dinâmicas de $m_{i}$ e $h_{i}$ (para todos os tipos de condutâncias com exceção do $\left.K_{(C a)}\right)$ são determinadas por:

$$
\begin{aligned}
\frac{d m_{i}}{d t} & =\frac{m_{i_{\infty}}(V)-m_{i}(t)}{\tau_{m_{i}}(V)} \\
\frac{d h_{i}}{d t} & =\frac{h_{i_{\infty}}(V)-h_{i}(t)}{\tau_{h_{i}}(V)}
\end{aligned}
$$

Onde $m_{i_{\infty}}, \tau_{m_{i}}, h_{i_{\infty}}, \tau_{h_{i}}$ são funções sigmoidais de $V$ ajustadas de dados experimentais. A variável de ativação da corrente de potássio dependente do cálcio, diferentemente das outras, é função do potencial de membrana e da concentração intracelular de cálcio $\left(m_{K(C a)_{\infty}}\left(V,\left[\mathrm{Ca}^{2+}\right]\right)\right)$.

A concentração intracelular de cálcio é alterada pela entrada de $C a^{2+}$ através das correntes iônicas $C a T$ e $C a S$, e por um mecanismo simplificado de extrusão:

$$
\frac{d[C a]}{d t}=-\frac{1}{\tau_{C a}}\left(f\left(I_{C a T}+I_{C a S}\right)+[C a]-[C a]_{0}\right)
$$

Sendo $\tau_{C a}=200 \mathrm{~ms}, f=14.96 \mu M / n A$ e $[C a]_{0}=0.5 \mu M$.

Os parâmetros utilizados na maioria das nossas simulações foram: 1) $C_{m}=1 \mu \mathrm{F} / \mathrm{cm}^{2}$ e área da membrana $\left.A_{m}=6.28 \times 10^{-4} \mathrm{~cm} ; 2\right)$ Condutâncias máximas $\left(\overline{g_{i}}\right)$ em $m S / m^{2}$ foram 200 para $N a, 100$ para $K_{d}, 2.5$ para $C a T, 4.0$ para $C a S, 5.0$ para $K_{(C a)}, 50$ para $A, 0.01$ para $H$ e 0.01 para a corrente leak; os potenciais de reversão em $m V$ foram +50 para $N a$, -80 para $K_{d}, K_{(C a)}$ e $A,-50$ para leak e -20 para $H$. Como a concentração intracelular de cálcio 
não é constante, $V_{C a}$ é calculado em função de $\left[\mathrm{Ca}^{2+}\right]$ considerando uma concentração extracelular de $3000 \mu M$ de acordo com a equação de Nernst:

$$
V_{C a}=12.5 \ln \left(\frac{3000}{\left[\mathrm{Ca}^{2+}\right]}\right)
$$

Para integrar as equações diferenciais do modelo utilizamos um algoritmo Runge-Kutta de $6^{a}$ ordem, com passo fixo de $10 \mu \mathrm{s}$. 


\begin{tabular}{|c|c|c|c|c|c|c|}
\hline & $\gamma_{i}$ & $\delta_{i}$ & $m_{\infty}$ & $h_{\infty}$ & $\tau_{m}$ & $\tau_{h}$ \\
\hline \multirow[t]{2}{*}{$I_{N a}$} & 3 & 1 & $\frac{1}{1+e^{\left(\frac{V+25.5}{-5.29}\right)}}$ & $\frac{1}{1+e^{\left(\frac{V+48.9}{5.18}\right)}}$ & $2.64-\frac{2.52}{1+e^{\left(\frac{V+120}{-25}\right)}}$ & $\frac{1.34}{1+e^{\left(\frac{V+62.9}{-10}\right)}} *$ \\
\hline & & & & & & $\left(1.5+\frac{1}{1+e^{\left(\frac{V+34.9}{3.6}\right)}}\right)$ \\
\hline$I_{C a T}$ & 3 & 1 & $\frac{1}{1+e^{\left(\frac{V+27.1}{-7.2}\right)}}$ & $\frac{1}{1+e^{\left(\frac{V+32.1}{5.5}\right)}}$ & $43.4-\frac{42.6}{1+e^{\left(\frac{V+68.1}{-20.5}\right)}}$ & $210-\frac{179.6}{1+e^{\left(\frac{V+55}{-16.9}\right)}}$ \\
\hline$I_{C a S}$ & 3 & 1 & $\frac{1}{1+e^{\left(\frac{V+33}{-8.1}\right)}}$ & $\frac{1}{1+e^{\left(\frac{V+60}{6.2}\right)}}$ & $2.8+\frac{14}{e^{\left(\frac{V+27}{10}\right)}+e^{\left(\frac{V+70}{-13}\right)}}$ & $120+\frac{300}{e^{\left(\frac{V+55}{9}\right)}+e^{\left(\frac{V+65}{-16}\right)}}$ \\
\hline$I_{A}$ & 3 & 1 & $\frac{1}{1+e^{\left(\frac{V+27.2}{-8.7}\right)}}$ & $\frac{1}{1+e^{\left(\frac{V+56.9}{4.9}\right)}}$ & $23.2-\frac{20.8}{1+e^{\left(\frac{V+32.9}{-15.2}\right)}}$ & $77.2-\frac{58.4}{1+e^{\left(\frac{V+38.9}{-26.5}\right)}}$ \\
\hline \multirow[t]{2}{*}{$I_{K(C a)}$} & 4 & 0 & $\frac{[C a]}{[C a]+3} *$ & & $180.6-\frac{150.2}{1+e^{\left(\frac{V+46}{-22.7}\right)}}$ & \\
\hline & & & $\frac{1}{1+e^{\left(\frac{V+28.3}{-12.6}\right)}}$ & & & \\
\hline$I_{K d}$ & 4 & 0 & $\frac{1}{1+e^{\left(\frac{V+12.3}{-11.8}\right)}}$ & & $14.4-\frac{12.8}{1+e^{\left(\frac{V+28.3}{-19.2}\right)}}$ & \\
\hline$I_{H}$ & 1 & 0 & $\frac{1}{1+e^{\left(\frac{V+75}{5.5}\right)}}$ & & $\frac{2}{e^{\left(\frac{V+169.7}{-11.6}\right)}+e^{\left(\frac{V-26.7}{14.3}\right)}}$ & \\
\hline
\end{tabular}

Tabela 4.1 - Funções de ativação e inativação, e expoentes que determinam a dinâmica das correntes iônicas do modelo. Observe que nos casos onde $\gamma_{i}=0$ não há inativação e portanto as expressões correspondentes são deixadas em branco $\left(h_{i}=1\right)$. As medidas de voltagem estão em $\mathrm{mV}$ e de tempo em ms. 


\subsection{Modelagem estocástica}

Para verificar o efeito de incluir uma dinâmica do tipo estocástico em um modelo de neurônio e comparar os resultados com os obtidos sem a dinâmica estocástica foi necessário implementar um mesmo modelo em suas duas versões: a determinística e a estocástica. O modelo escolhido é o descrito na seção anterior (Seção 4.1). Como a versão determinística já existia, aqui descrevemos como traduzimos esse modelo e obtivemos sua versão estocástica. As equações diferenciais 4.1 e 4.4 são mantidas, no entanto agora $g_{i}(V, t)=n_{i}(V, t) \phi$, sendo $n_{i}$ o número de canais iônicos do tipo $i$ no estado aberto e $\phi=20 p S$ a condutância de um único canal iônico.

É conveniente recuperar a formalização original de Hodgkin-Huxley, utilizando taxas de transição entre estados abertos e fechados, e construir os microestados acessíveis aos canais iônicos (Schneidman et al., 1998). As taxas de abertura e fechamento, $\alpha_{m_{i}}$ e $\beta_{m_{i}}$, respectivamente são dadas por: $\alpha_{m_{i}}=\frac{m_{i_{\infty}}}{\tau_{m_{i}}} e, \beta_{m_{i}}=\frac{1-m_{i_{\infty}}}{\tau_{m_{i}}}$. O mesmo método foi usado para obter $\alpha_{h_{i}} \mathrm{e}$ $\beta_{h_{i}}$, as taxas de abertura e fechamento das portas de inativação.

A interpretação para os expoentes $\gamma_{i}$ e $\delta_{i}$ vem da estrutura microscópica dos canais iônicos. Cada canal iônico do tipo $i$ é uma proteína formada por $\gamma_{i}$ subunidades do tipo $m_{i}$ e $\delta_{i}$ subunidades do tipo $h_{i}$. Todas as subunidades de um canal iônico são independentes, e abrem/fecham de acordo com as probabilidades dadas por suas taxas de transição. Para um canal estar aberto e consequentemente deixar passar íons através dele, é necessário que todas as suas subunidades estejam abertas ao mesmo tempo. 
Portanto o esquema markoviano dos microestados para os canais do tipo $K_{d}$ e $K_{(C a)}$ é:

$$
\left[m_{0}\right] \underset{\beta_{m_{i}}}{\stackrel{4 \alpha_{m_{i}}}{\rightleftharpoons}}\left[m_{1}\right] \underset{2 \beta_{m_{i}}}{\stackrel{3 \alpha_{m_{i}}}{\rightleftharpoons}}\left[m_{2}\right] \underset{3 \beta_{m_{i}}}{\stackrel{2 \alpha_{m_{i}}}{\rightleftharpoons}}\left[m_{3}\right] \underset{4 \beta_{m_{i}}}{\rightleftharpoons}\left[m_{4}\right]
$$

Onde o estado aberto é o $\left[m_{4}\right]$. Este esquema é tradicionalmente usado para simular a condutância do potássio "retificadora" $\left(K_{d}\right)$. Um modelo mais preciso para os canais $K(C a)$, poderia considerar outros microestados, usando taxas de transição diferentes para os receptores de cálcio e para os sensores de voltagem, porém para manter a fidelidade ao modelo determinístico tanto a dependência do cálcio quanto a dependência da voltagem foram incluídas nas mesmas taxas de transição.

O esquema para os canais do tipo $H$ é dado por:

$$
\left[m_{0}\right] \underset{\beta_{m_{H}}}{\rightleftharpoons}\left[m_{1}\right]
$$

Onde o estado aberto é o $\left[m_{1}\right]$.

Os canais $\mathrm{Na}, \mathrm{Ca} 1, \mathrm{Ca} 2$, e $A$ podem ser descritos por um mesmo esquema geral:

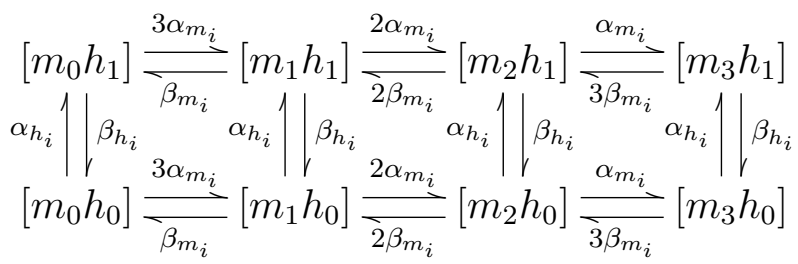

Onde o estado aberto é o $\left[m_{3} h_{1}\right]$.

Dada uma população $N_{j}$ de canais em um estado $j$ e uma taxa de transição do estado $j$ para um estado $k$ dada por $r_{j k}$, em um intervalo de tempo $\Delta t$ 


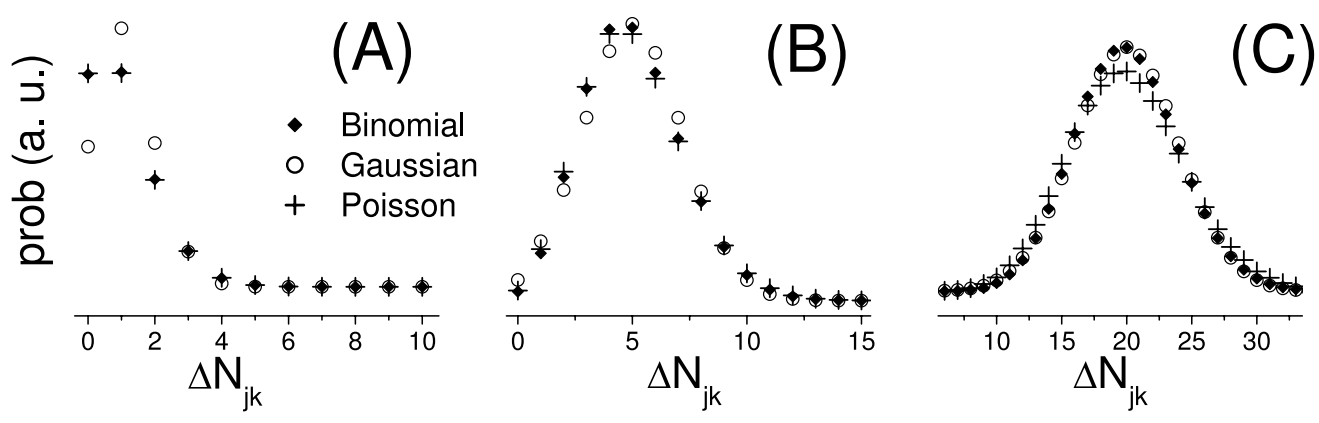

Figura 4.2 - Distribuições comparadas para diferentes valores do número médio de transições. Extraído de (Carelli et al., 2005).

o número médio de canais $\left(n_{j k}\right)$ que sofrem esta transição será $n_{j k}=N_{j} \Delta t r_{j k}$, e a probabilidade de que cada canal sofra esta transição é $p=\Delta t r_{j k}$ (Schneidman et al., 1998). Ao invés de calcular as transições de cada canal, podemos achar o número $\Delta N_{j k}$ de canais que sofrem a transição de $j$ para $k$, escolhendo um número aleatório com a seguinte distribuição binomial:

$$
\operatorname{Prob}\left(\Delta N_{j k}\right)=\left(\begin{array}{c}
N_{j} \\
\Delta N_{j k}
\end{array}\right) p^{\Delta N_{j k}}(1-p)^{\left(N-\Delta N_{j k}\right)}
$$

No entanto, a distribuição binomial é muito cara computacionalmente, exigindo muitas horas para calcular alguns segundos de atividade neural. Nós utilizamos então duas aproximações para a distribuição binomial (Carelli et al., 2005). Quando a média da distribuição binomial está longe de zero, a binomial fica simétrica, e pode ser bem aproximada pela distribuição gaussiana. No caso de a média da binomial ser próxima de zero ela pode ser bem aproximada pela distribuição de poisson (Fig.4.2). 


\subsection{Simulação estocástica em tempo real}

O Dynamic Clamp (Pinto et al., 2001; Sharp et al., 1993) é um protocolo que permite interagir modelos computacionais com neurônios reais. Os modelos podem ser usados tanto para gerar correntes artificiais no neurônio empalado, alterando suas propriedades intrínsecas, como criar sinapses artificiais entre neurônios, e até mesmo interagir um neurônio real com um neurônio modelo, onde as equações diferenciais do modelo são integradas numericamente em tempo real.

A simulação estocástica no entanto é mais lenta que a integração de equações diferenciais, o que torna mais difícil fazer a simulação em tempo real de modo que o Dynamic Clamp possa interagir o neurônio modelo com o neurônio biológico. O gargalo de tempo computacional da simulação estocástica está na geração dos números aleatórios com a distribuição adequada.

O método padrão para se gerar um número aleatório com distribuição Gaussiana utiliza dois números aleatórios com distribuição uniforme e funções do tipo sen, cos, log, etc..., o que acaba tornando lenta a simulação (Para mais detalhes ver apêndice 1, página 104).

Desenvolvemos então, um método para gerar um número aleatório com distribuição gaussiana, a partir de um único número aleatório uniformemente distribuído e uma tabela com valores da integral da Gaussiana.

Dadas duas variáveis aleatórias $x$ e $y$ onde $x$ tem distribuição uniforme e y tem uma distribuição Gaussiana:

$$
\begin{gathered}
\rho(x)= \begin{cases}1 \quad \text { para } 0 \leq x \leq 1, \\
0 \quad \text { para } x<0 \text { ou } x>1 .\end{cases} \\
\rho(y)=\frac{1}{\sqrt{2 \pi}} e^{\frac{-y^{2}}{2}}
\end{gathered}
$$




$$
\begin{gathered}
\rho(x) d x=\rho(y) d y \quad \Longrightarrow \quad \frac{d x}{d y}=\rho(y) \\
x(y)=\int_{-\infty}^{y} \rho\left(y^{\prime}\right) d y^{\prime}=F(y) \\
y(x)=F^{-1}(x)
\end{gathered}
$$

Desta forma pode-se obter uma variável aleatória com distribuição gaussiana a partir de uma variável aleatória com distribuição uniforme entre 0 e 1, utilizando a transformação acima. O problema é que não se tem uma expressão analítica para a integral da função gaussiana. Para contornar este problema, fizemos uma tabela da função 4.13 e invertemos a função através de interpolação linear.

A distribuição Poisson, também exige que se calcule funções computacionalmente caras (como exponenciais, potenciação, e fatoriais) para simulações em tempo real. Para contornar este problema separamos o cálculo da distribuição poisson em dois casos. Quando a média de canais iônicos que vão sofrer a transição é muito menor do que 1, podemos desprezar a probabilidade de que dois canais sofram esta transição, o que torna trivial escolher se um canal vai sofrer a transição:

$$
\begin{gathered}
p_{n}=e^{-\alpha} \frac{\alpha^{n}}{n !} \\
\text { Se } \alpha \ll 1 \Rightarrow p_{n} \approx\left(1-\alpha+O\left(\alpha^{2}\right)\right) \frac{\alpha^{n}}{n !}\left\{\begin{array}{l}
p_{n=0} \approx 1-\alpha+O\left(\alpha^{2}\right), \\
p_{n=1} \approx \alpha+O\left(\alpha^{2}\right), \\
p_{n=2} \approx O\left(\alpha^{2}\right)
\end{array}\right.
\end{gathered}
$$

Nos demais casos, tivemos que criar diversas tabelas da distribuição Poisson com diferentes médias, e usar o item da tabela que mais se aproximasse do valor desejado. 


\subsection{Implementação do modelo estocástico no dynamic clamp}

O painel de controle do dynamic clamp com o modelo implementado é mostrado na Figura 4.3. No menu Computer Neuron podemos ajustar os parâmetros do modelo e chavear o comportamento individual de cada condutância do modelo (g_X) entre determinístico e estocástico. Podemos implementar duas sinapses elétricas (Elec $0=1$ ) entre $\mathrm{CN}$ e o neurônio biológico, que podem ser normais ou retificadoras, duas sinapses químicas de CN para o neurônio biológico (Chem $\mathrm{CN}=<\mathrm{CH}$ ) e duas sinapses químicas do neurônio biológico para o $\mathrm{CN}$ (Chem $\mathrm{CH} 0=<\mathrm{CN}$ ). Também incluímos tres sub-painéis gráficos que utilizamos para monitorar os potenciais de membrana de CN e do neurônio biológico e a corrente a ser injetada em CN, facilitando assim o ajuste dos parâmetros intrínsecos do neurônio artificial e das sinapses. 


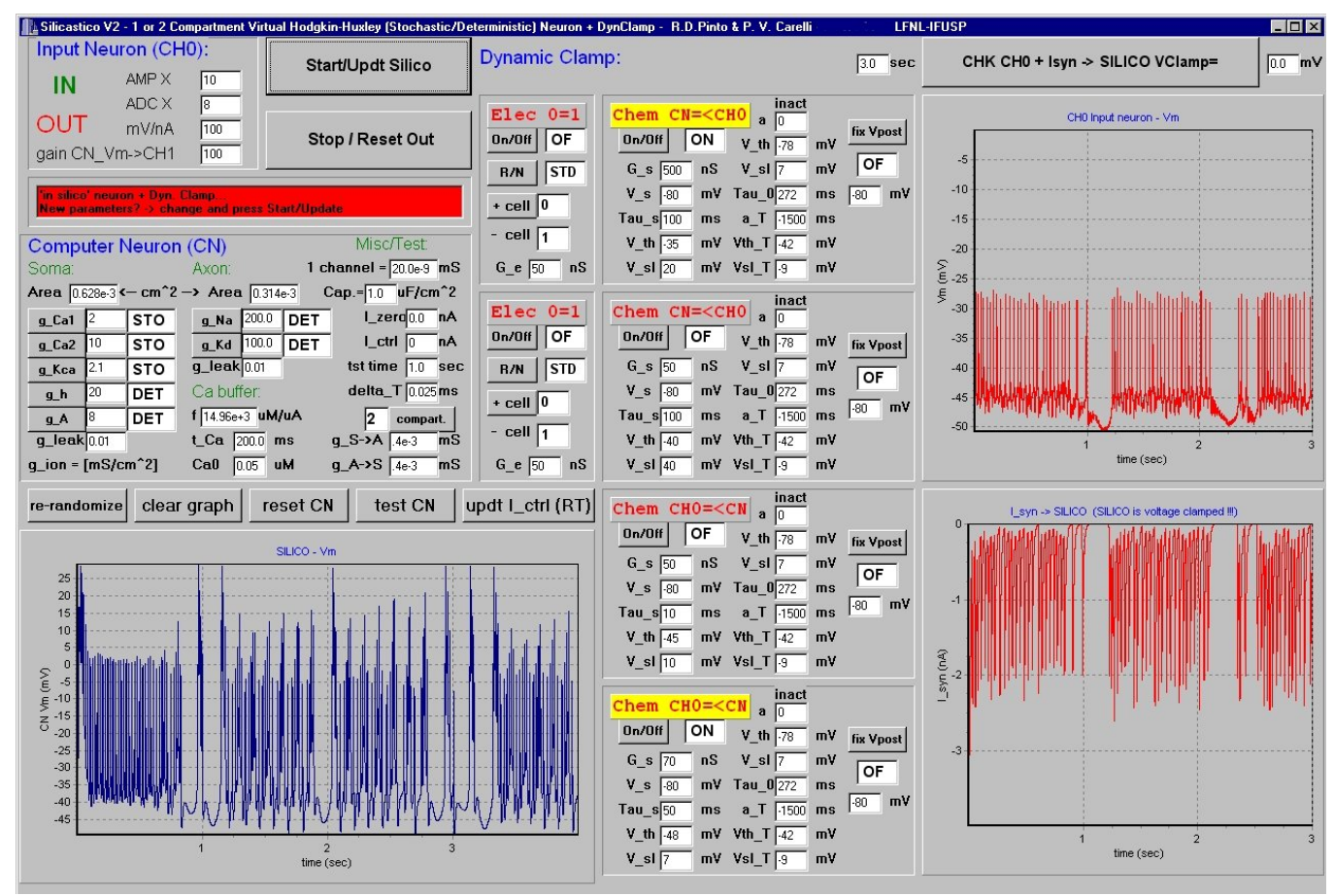

Figura 4.3 - Layout do Dynamic Clamp com modelo estocástico, na versão windows. No painel Computer Neuron pode-se escolher a condutância de cada corrente iônica e se ela será simulada como estocástica ou determinística, além de outros parâmetros do neurônio modelo. No painel Dynamic Clamp pode-se escolher os parâmetros das sinapses conectando o modelo com o neurônio biológico. 


\section{Capítulo 5}

\section{Resultados e discussão}

\subsection{Simulação da atividade de neurônios isola- dos}

Uma primeira comparação entre o comportamento dinâmico dos modelos determinístico e estocástico é mostrada na figura 5.1, onde comparamos as séries temporais de ambos os modelos com os mesmos valores de parâmetros (Tabela 5.1).

Mesmo com um número de canais iônicos muito grande (Tabela 5.2) os efeitos do caráter probabilístico deles ainda estão presentes no comportamento do potencial de membrana.

Ao incluir as propriedades estocásticas no modelo, este continua com um comportamento médio semelhante ao modelo determinístico original, mas seus bursts são irregulares no período, na duração e no número de potenciais de ação (spikes) por bursts.

Verificamos uma tendência do modelo estocástico apresentar bursts mais curtos e menor número médio de spikes por burst do que o modelo deter- 


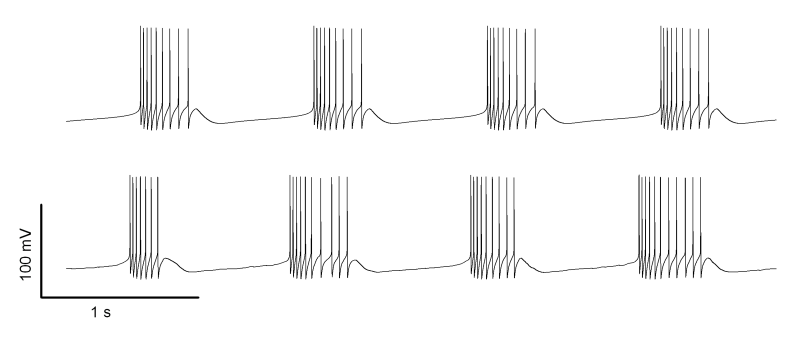

Figura 5.1 - Séries temporais típicas do potencial de membrana do modelo nas versões determinística (acima) e estocástica (abaixo). Os mesmos valores de parâmetros (mostrados na seção de métodos) foram usados em ambos os modelos. Embora o modelo determinístico apresente um padrão periódico de bursts, o modelo estocástico apresenta variabilidade no número de spikes por burst, duração da hiperpolarização, e período.

minístico. Este fato está relacionado com a atividade dos canais de cálcio e potássio dependente de cálcio, como será discutido mais adiante.

Como uma primeira tentativa de verificar quão reprodutível é a atividade do modelo estocástico, seguimos a evolução temporal do potencial de membrana quando ele parte de condições iniciais próximas. Após a hiperpolarização as condutâncias iônicas do modelo convergem para valores similares a cada burst, então detectamos o primeiro spike após uma hiperpolarização e o usamos para alinhar e sobrepor diversos bursts consecutivos. Na figura 5.2 plotamos 50 bursts sobrepostos para cada modelo e também de um neurônio LP biológico. Os bursts do modelo determinístico são exatamente iguais, portanto aparecem como uma única curva. No entanto, no modelo estocástico, apenas o primeiro spike se alinha, os subsequentes vão perdendo precisão e os últimos spikes do burst tem pouca confiabilidade, o que torna o momento em que o burst termina também pouco confiável de modo similar ao observado no neurônio biológico.

Uma outra forma de analisar o comportamento dos modelos, é detectar os 


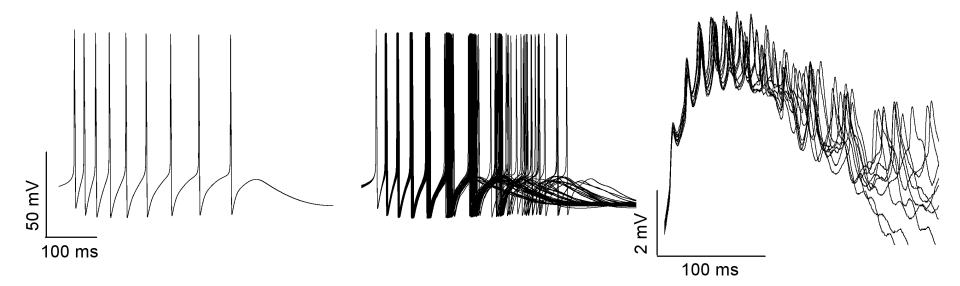

Figura 5.2 - Bursts sobrepostos. Da esquerda para a direita temos o modelo determinístico (50 bursts), o modelo estocástico ( 50 bursts), e um exemplo de neurônio LP isolado do gânglio estomatogástrico (10 bursts). Para visualizar a variabilidade nos bursts tanto dos modelos quanto do neurônio biológico, detectamos a ocorrência de diversos bursts consecutivos e os sobrepomos alinhados pelo primeiro spike. O modelo determinístico tem um comportamento periódico, sendo cada burst exatamente igual ao anterior. Já o neurônio biológico tem um comportamento bem diferente, sendo que seus primeiros spikes ficam razoavelmente bem alinhados, mas gradativamente vão perdendo a precisão e confiabilidade. Além disso a duração do burst também varia bastante. O modelo estocástico capta melhor estas propriedades da dinâmica do neurônio biológico, tendo seus primeirosa spikes bem alinhados, sendo o final do burst menos confiável do que o começo. 


\begin{tabular}{|c|c|c|c|}
\hline & Modelo determinístico & Modelo estocástico & Neurônio LP \\
\hline Período (ms) & 1102 & $1049 \pm 65(6 \%)$ & $(82 \pm 14) \times 10(17 \%)$ \\
\hline Duração do burst (ms) & 305 & $237 \pm 60(25 \%)$ & $230 \pm 80(35 \%)$ \\
\hline Spikes/Burst & 9 & $7.9 \pm 1.1(14 \%)$ & $11.3 \pm 1.6(14 \%)$ \\
\hline
\end{tabular}

Tabela 5.1 - Principais propriedades estatísticas (e seus respectivos desvios), da atividade dos modelos determinístico e estocástico, assim como um de um neurônio LP isolado. O modelo estocástico apresenta uma tendência a produzir oscilações com período um pouco menor do que o determinístico. Os modelos não foram ajustados para reproduzir a atividade do neurônio LP, mas é claro que o neurônio real apresenta uma maior variabilidade em sua atividade do que o modelo estocástico. No entanto o modelo determinístico não apresenta variabilidade alguma.

intervalos entre spikes (ISIs) e plotar seus mapas de retorno (ISI $\mathrm{IS}_{n+1}$ vs. ISI $\left._{n}\right)$, como mostrado na figura 5.3. Como esses mapas associam o valor de um ISI com o ISI anterior, eles são uma ótima maneira de detectar correlações nos padrões de ISIs (ou numa série temporal).

Para o modelo estocástico, apenas os primeiros ISIs se repetem com precisão, como pode ser visto pelas pequenas nuvens de pontos formadas. Este comportamento mais preciso dos primeiros ISIs do modelo estocástico é similar ao apresentado pelo modelo determinístico, e é uma assinatura de determinismo que ainda está presente no modelo estocástico, embora ele seja constituído de elementos discretos e probabilísticos. Novamente, apenas o modelo estocástico reproduz o comportamente encontrado nos mapas de retorno da atividade de neurônios do STG. Uma análise mais detalhada de mapas de retorno do STG, pode ser encontrada em (Szucs et al., 2003).

Comparamos também o comportamento dos modelos com um experimento (Fig. 5.4), onde se injeta uma corrente DC em um neurônio vivo. O que se observa tanto nos modelos quanto no neurônio, é uma mudança qua- 


\begin{tabular}{|c|r|}
\hline Corrente Iônica & Número de Canais \\
\hline $\mathrm{Na}$ & 6.280 .000 \\
\hline $\mathrm{Kd}$ & 3.140 .000 \\
\hline $\mathrm{A}$ & 1.570 .000 \\
\hline $\mathrm{CaT}$ & 78.500 \\
\hline $\mathrm{CaS}$ & 125.000 \\
\hline $\mathrm{KCa}$ & 157.000 \\
\hline $\mathrm{H}$ & 314 \\
\hline
\end{tabular}

Tabela 5.2 - Tabela com o número absoluto de canais iônicos presentes no modelo com valores plausíveis de condutâncias máximas

litativa de comportamento de bursts (quando a corrente é mais inibitória) para disparo tônico (quando a corrente injetada é mais excitatória). Além disso vemos tanto no modelo estocástico quanto no neurônio que, quando se encontram menos excitados, disparam bursts de forma menos irregular, e quando estão mais perto de apresentar uma atividade tônica, ficam mais irregulares. Um detalhe interessante é que para os mesmos parâmetros em que o modelo determinístico apresenta comportamento tônico, o modelo estocástico continua apresentando hiperpolarizações.

Uma maneira mais sistemática de caracterizar a transição de bursts para disparo tônico que ocorre em ambos os modelos, é através de diagramas de bifurcação (Figs. 5.5 e 5.6) onde diversos ISIs são plotados para cada valor de corrente injetada. As únicas irregularidades encontradas no modelo determinístico são devidas a intermitências entre bursts com N spikes e bursts com $\mathrm{N}+1$ spikes, o que caracteriza uma bifurcação de adição de período. Para o valor do parâmetro $I_{e x t}=0.16 n A$, há uma transição repentina do comportamento de burst para o de disparo tônico. No modelo estocástico, ao invés de uma transição brusca, o intervalo entre bursts fica gradativamente menor, até se confundir com os intervalos entre spikes dentro do bursts. 

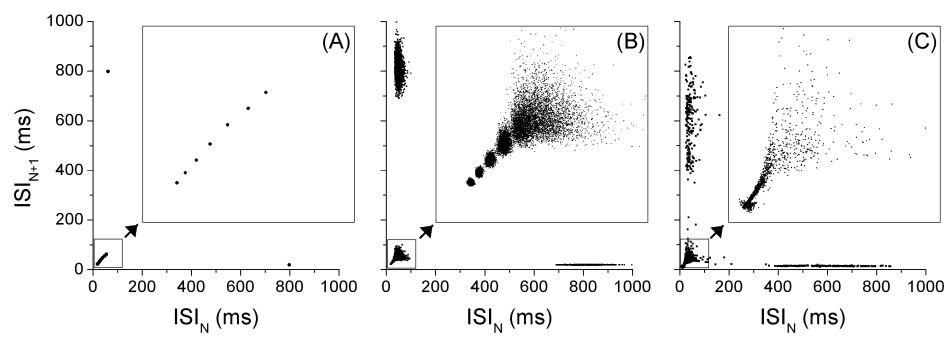

Figura 5.3 - Mapas de retorno de 3000s da atividade de cada modelo e 200 s da atividade do neurônio LP. Em cada gráfico mostramos uma região ampliada correspondendo aos ISIs dentro de um burst. O modelo determinístico (A) apresenta um padrão repetitivo de ISIs, por isso vemos no seu mapa de retorno apenas alguns pontos que se repetem a cada ciclo. No neurônio LP $(C)$, observa-se que a precisão dos ISIs de maior ordem decai de maneira semelhante ao que acontece na versão estocástica do modelo (B).

Uma maneira alternativa de construir diagramas de bifurcação também encontrada na literatura é usar os tempos dos spikes no burst (STB). Para medir os STBs usa-se como referência o primeiro spike do burst, e o STB é dado pelo tempo entre o primeiro spike do burst e o spike atual. Quando a atividade do modelo é tônica, o STB é simplesmente igual ao ISI. No modelo determinístico (Fig. 5.6) temos bifurcações do tipo adição de período para os valores do parâmetro de controle entre 0.10 e $0.16 \mathrm{nA}$. Isso significa que a cada bifurcação, o burst ganha um spike a mais. Finalmente, podemos ver claramente que na transição de disparo em bursts para tônico $\left(I_{e x t}=0.16 n A\right)$, há uma acumulação cada vez mais rápida de períodos, e tanto o número de spikes por burst quanto a duração dos bursts tende a infinito. No caso do modelo estocástico a transição da atividade de bursts para tônica não é tão clara. Para um intervalo de valores do parâmetro de controle onde o modelo determinístico já dispara com atividade tônica $\left(0.17<I_{\text {ext }}<0.28 \mathrm{nA}\right)$, o modelo estocástico parece alternar de maneira irregular entre disparo tônico e de bursts. 


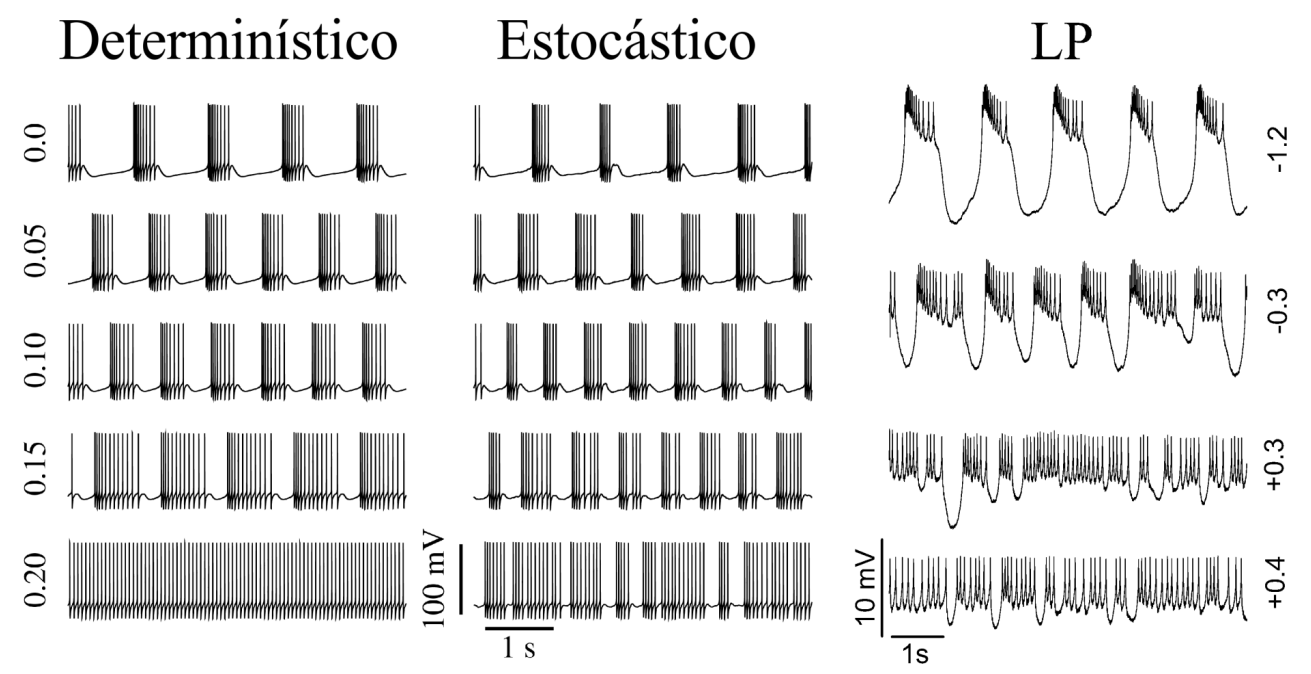

Figura 5.4 - Exemplos de comportamento de ambos os modelos e de um neurônio LP, quando diferentes valores de corrente DC são aplicados (corrente em nA). A corrente aumenta de cima para baixo. No caso do modelo determinístico o número de spikes por burst aumenta com a corrente, e com isso aumenta também a duração dos bursts, até chegar a um regime de disparo tônico. No modelo estocástico o número médio de spikes por burst também aumenta com a corrente, no entanto temos bursts curtos alternados com longos, como acontece com o neurônio LP. Além disso, o modelo estocástico tem uma atividade de bursts mais persistente que o modelo determinístico, pois continua apresentando bursts para valores de parâmetros que o modelo determinístico já apresenta atividade de disparo tônico. 

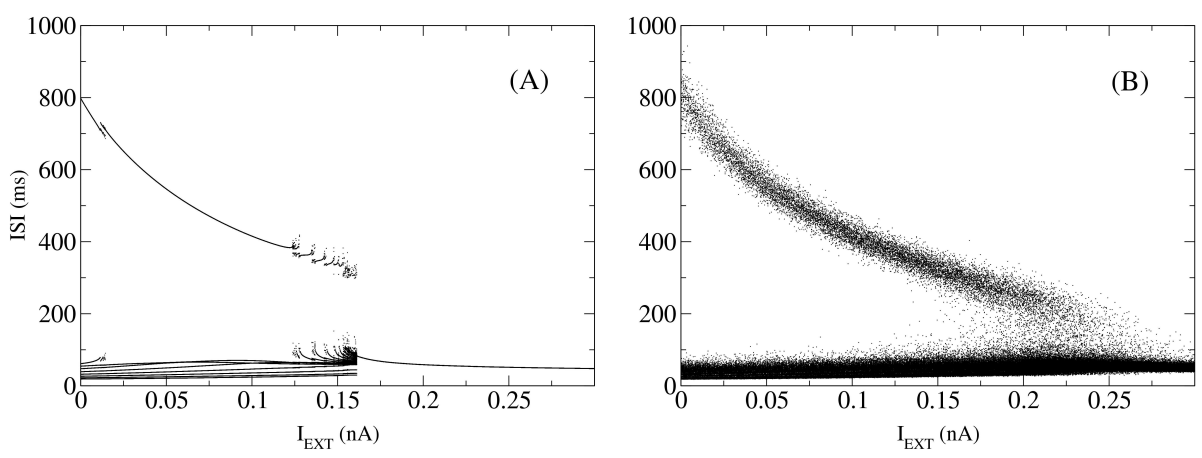

Figura 5.5 - Diagrama de bifurcações dos intervalos entre potenciais de ação (ISI), em função da corrente DC injetada. (A) Modelo determinístico, (B) Modelo Estocástico. No modelo determinístico, ocorre uma cascata de bifurcações do tipo adição de período até que em torno do valor 0.16 do parâmetro de controle o comportamento do neurônio torna-se tônico. Esta transição no modelo estocástico ocorre de uma forma mais suave, e para uma grande faixa de valores em que o modelo determinístico já é tônico o modelo estocástico continua apresentando bursts.
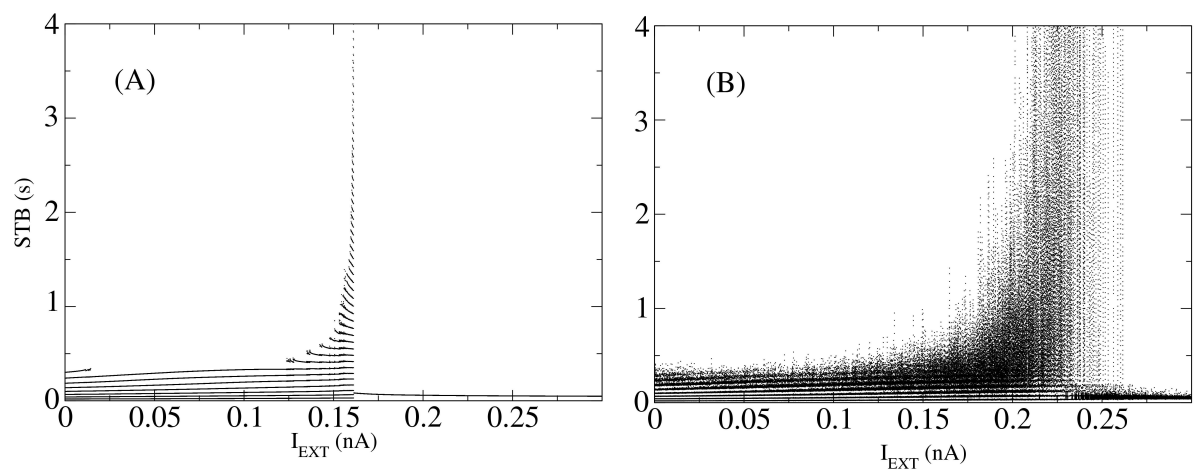

Figura 5.6 - Diagrama de bifurcações dos Tempos dos Spikes no Burst (STB) em função da corrente DC injetada. Quando a atividade do neurônio é em bursts, definimos o STB como uma série de intervalos de tempo formada pela distância entre cada spike detectado e o primeiro spike do burst ao qual ele pertence. Quando a atividade do neurônio é de disparo tônico plotamos simplesmente os intervalos entre spikes (ISI). Desta forma podese visualizar imediatamente no diagrama de bifurcações a duração do burst e seu número de spikes. (A) Modelo determinístico, (B) Modelo Estocástico. 
Alguns estudos (Falcke et al., 2000; Selverston et al., 2000) mostram que o neurônio LP apresenta propriedades dinâmicas compatíveis com caos determinístico. Esta análise usa somente as séries temporais obtidas experimentalmente e não é necessário saber as equações que regem a dinâmica a ser caracterizada. Aplicamos as mesmas técnicas de análise nas séries temporais do nosso modelo estocástico, como se elas tivessem sido obtidas experimentalmente, e mostramos que os resultados são compatíveis com aqueles de neurônios reais.

O espaço de fases das séries temporais foram reconstruídos usando uma única variável dinâmica atrasada temporalmente (o potencial de membrana), e a dimensão de imersão (número mínimo de variáveis dinâmicas necessárias para reconstruir o atrator) foi estimada em 3, pelo método dos falsos vizinhos. Isso está em acordo com resultados experimentais (Falcke et al., 2000; Selverston et al., 2000).

O espectro de expoentes de Lyapunov da série do modelo estocástico, calculado usando o programa TISEAN (Hegger et al., 1999), tem um expoente positivo $\left(\lambda_{1}=0.050 \mathrm{~ms}^{-1}\right)$, um expoente próximo de zero $\left(\lambda_{2}=-0.007 \mathrm{~ms}^{-1}\right)$ e um expoente negativo $\left(\lambda_{3}=-0.070 \mathrm{~ms}^{-1}\right)$. A soma de todos os expoentes é negativa, como esperado para um sistema dissipativo onde as trajetórias ficam confinadas em uma região finita do espaço de fases. Dos expoentes de Lyapunov estimamos a dimensão fractal de Kaplan-Yorke como sendo 2.6.

Para identificar quais as condutâncias iônicas que têm papel mais importante para a atividade irregular que observamos no modelo estocástico, implementamos modelos mistos, onde podemos escolher individualmente se cada corrente iônica será simulada como estocástica ou determinística. Os resultados de diversos modelos mixtos são resumidos na Figura 5.7, onde plotamos algumas propriedades estatísticas da atividade dos modelos quando 

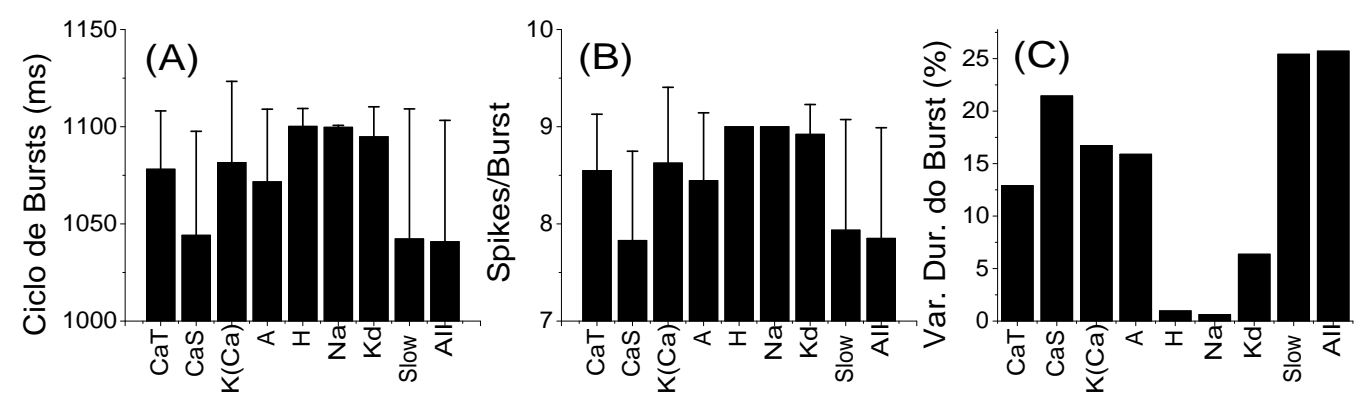

Figura 5.7 - Modelos mixtos: O efeito de cada corrente iônica ser modelada como estocástica enquanto as outras são determinísticas. (A) O ciclo de bursts significa o tempo entre o primeiro spike de um burst e o primeiro spike do próximo burst e é análogo ao período em séries temporais com comportamento periódico. (B) Número de spikes/burst. (C) Variação percentual da duração do burst. A barra denominada "slow" representa o modelo com todas as correntes iônicas, com exceção de $\mathrm{Na}$ e $\mathrm{Kd}$, sendo simuladas como estocásticas. Cem segundos de comportamento do modelo foram usados para fazer as estatísticas de cada barra.

cada uma das correntes era individualmente escolhida como estocástica e as outras eram determinísticas. Também comparamos os resultados com os obtidos quando todas as correntes iônicas eram estocásticas ou quando todas, com excessão de $\mathrm{Na}+$ e Kd, eram estocásticas.

As principais correntes responsáveis pela variabilidade apresentada pelo modelo estocástico são: $I_{C a T}, I_{C a S}, I_{K(C a)}$, conhecidas como as correntes "Slow wave" ou "platô", e a corrente $I_{A}$, conhecida como corrente de adaptação. Isso ocorre pois as duas correntes de cálcio, que tendem a despolarizar a membrana, e competem com a corrente de potássio dependente de cálcio $\left(K_{(\mathrm{Ca})}\right)$, que tende a repolarizar a membrana, têm um número de canais iônicos bem menor que as correntes iônicas responsáveis pelo potencial de ação. Além disso, as correntes de cálcio também alteram a concentração intracelular de cálcio, que por sua vez regula a abertura dos canais de potássio 
dependente de cálcio $\left(K_{(C a)}\right)$. O motivo pelo qual a corrente $H$ (corrente com menor número de canais) não tem grande importância na atividade irregular do potencial de membrana, é que ela praticamente não se ativa no modelo isolado, somente quando este é hiperpolarizado. Nosso ponto é que as correntes iônicas responsáveis pela geração dos potenciais de ação não tem grande efeito na atividade irregular do modelo, mas os disparos do neurônio são modulados pelas correntes iônicas lentas, como pode ser visto na figura 5.7, onde o comportamento do modelo com todas as correntes estocásticas é praticamente igual ao seu comportamento quando apenas as correntes lentas são estocásticas.

O final do burst é determinado pela competição entre a entrada de cálcio na célula e a saída de potássio através dos canais $K_{(C a)}$. No começo do burst, as condutâncias de cálcio tem valores muito elevados, então suas flutuação estocásticas não afetam muito o comportamento do modelo. No entanto, da metade para o final do burst, como mostrado na figura 5.8, o número de canais iônicos conduzindo em ambas as populações é pequeno (da ordem de $10^{3}$ canais abertos), fazendo com que as flutuações estocásticas sejam mais importantes, o que causa um aumento na incerteza de quando será o próximo spike e quando o burst vai terminar. 


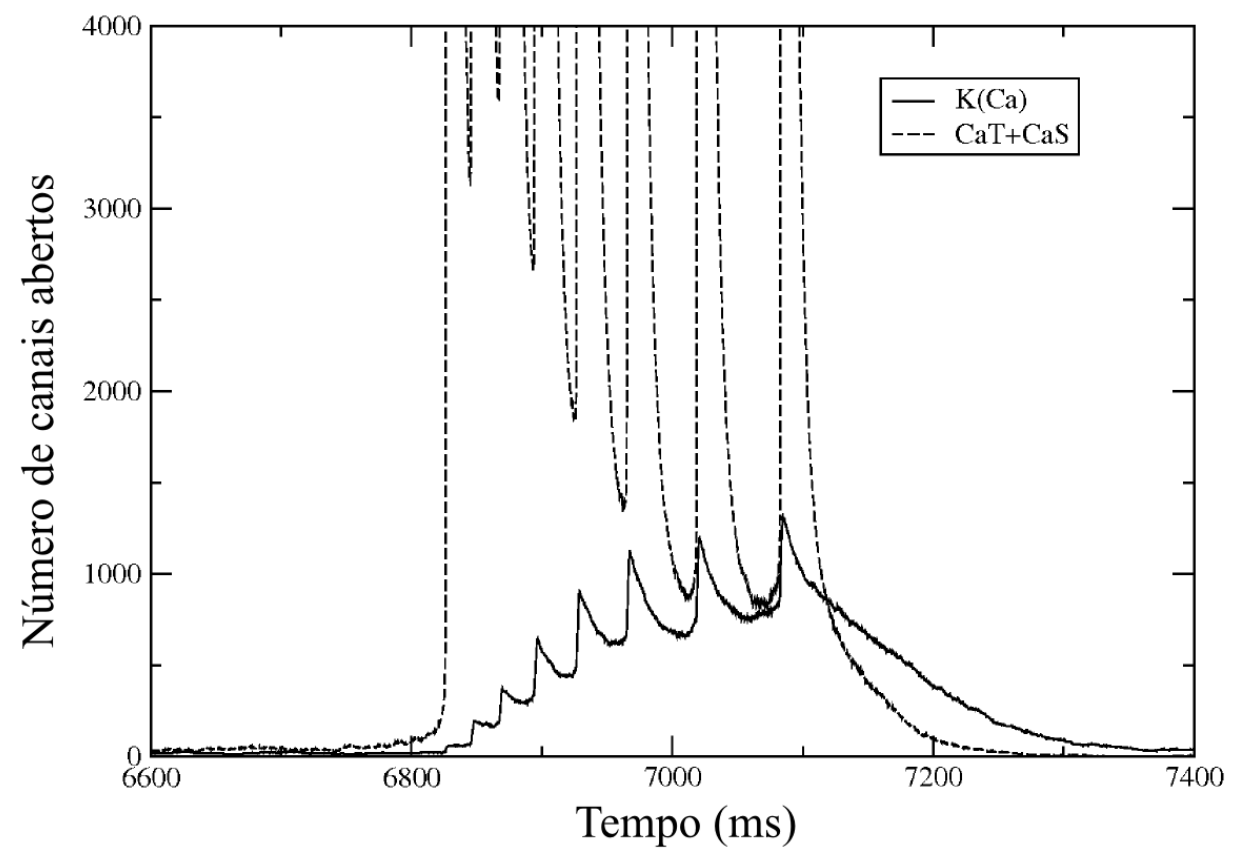

Figura 5.8 - Número total de canais iônicos abertos durante um burst típico do modelo estocástico. Mesmo o número total de canais iônicos sendo da ordem de $10^{5}$, o número de canais que estão efetivamente conduzindo é 100 vezes menor, o que explica que ainda vejamos efeitos da estocasticidade dos canais iônicos no comportamente macroscópico do potencial de membrana. O final do burst é especialmente sensível a essas flutuações, uma vez que elas podem fazer com que as correntes de cálcio e potássio dependente de cálcio se cancelem e produzam um final antecipado do burst e consequentemente uma hiperpolarização da membrana. 


\subsection{Perturbando as variáveis dinâmicas}

O efeito das flutuações estatísticas do modelo estocástico pode ser, a grosso modo, comparado à adição de ruído nas equações diferenciais do modelo determinístico.

Aqui investigamos esta analogia introduzindo perturbações em algumas variáveis dinâmicas em diversos pontos da evolução temporal do modelo determinístico. Para isto, integramos as equações do modelo diversas vezes, sempre partindo das mesmas condições iniciais. Em cada uma das integrações, efetuamos uma perturbação em um instante diferente e observamos a evolução temporal após a perturbação. A perturbação consistia em modificar o valor de uma das variáveis dinâmicas no instante da perturbação.

A figura 5.9 mostra estas simulações para o modelo determinístico em que as perturbações foram feitas na variável dinâmica de ativação da corrente de potássio dependente de cálcio $m_{K(C a)}$, entre os instantes 1300 e 1350 ms. A variável perturbada tem o seu valor acrescido de 0.01 no instante da perturbação. Dependendo do instante em que a perturbação é aplicada, o número de potenciais de ação do burst é diferente, mostrando que a pequena alteração do valor da variável dinâmica é capaz de modificar o padrão de comportamento do neurônio. Preferimos perturbar uma variável de ativação pois isto poderia ser causado por uma flutuação do número de canais ativos naquele instante.

Podemos interpretar estas observações da seguinte maneira. O fato das órbitas do sistema passarem freqüentemente próximas de separatrizes (como as que separam o comportamento tudo-ou-nada dos potenciais de ação, por exemplo) pode fazer com que ruídos muito pequenos tenham conseqüências grandes no comportamento final do sistema. Como o sistema tem uma alta dimensionalidade (12 dimensões), é bem provável que as órbitas passem perto 

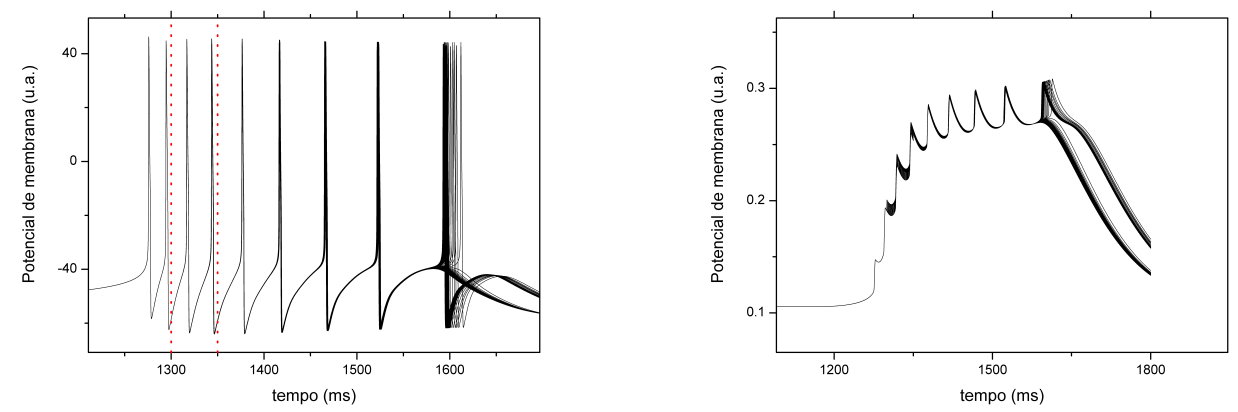

Figura 5.9 - Resultados de diversas integrações do modelo determinístico partindo das mesmas condições iniciais e perturbando a variável dinâmica $m_{K(\mathrm{Ca})}$ em instantes diferentes, entre 1300 e $1350 \mathrm{~ms}$. $O$ instante $t=0 \mathrm{~ms}$ equivale aproximadamente ao início do burst anterior. À esquerda mostramos o potencial de membrana do neurônio e a faixa de instantes em que foram feitas as perturbações. Dependendo do instante da perturbação, a célula pode disparar um potencial de ação a mais no burst. À direita temos a variável $m_{K(\mathrm{Ca})}$ na qual foi feita a perturbação, que é aparentemente atenuada, mas posteriormente tem um efeito bastante significativo, determinando o número de disparos do burst. 
de diversas outras separatrizes cuja identificação não é óbvia. Além disto as perturbações estocásticas causadas pelas flutuações dos canais iônicos têm direções muito variadas, podendo fazer com que o sistema ultrapasse linhas proibidas pelo sistema determinístico, o que proporcionaria um comportamento mais rico ao sistema.

Desta forma, vemos que um espaço de fases complexo e de alta dimensionalidade pode amplificar de forma inesperada as flutuações introduzidas pela modelagem estocástica, criando um comportamento macroscópico compatível com um sistema caótico a partir de flutuações estocásticas microscópicas nas variáveis dinâmicas. 


\subsection{Transmissão de informação entre modelos "in silico" e o CPG pilórico}

Nos experimentos realizados os neurônios modelo foram ajustados para disparar aproximadamente na mesma fase do neurônio LP, e com aproximadamente o mesmo número de spikes por burst, como mostrado na Figura 5.10. A idéia é comparar os resultados da análise da teoria da informação para três casos diferentes: Conectividade normal, LP substituído por um neurônio modelo estocástico, e LP substituído por um neurônio modelo determinístico.

As seguintes grandezas são utilizadas na análise: informação mútua média $(A M I)$, informação mútua média surrogate $\left(A M I_{S U R}\right.$ - onde embaralhamos a ordem dos bursts para comprovar a significância estatística da AMI), entropia do estímulo $\left(H_{E}\right)$, AMI normalizada pela entropia do estímulo $\left(A M I / H_{E}\right)$, entropia da resposta $\left(H_{P D}\right)$ e AMI normalizada pela entropia da resposta $\left(A M I / H_{P D}\right)$.

A entropia do estímulo, é uma medida do máximo de informação contida no estímulo (Figura 5.11). A entropia da resposta, corresponde à máxima informação que o neurônio resposta pode codificar/transmitir. A informação mútua média mede o quanto do estímulo está sendo codificado pela resposta. A $A M I / H_{E}$ mede a fração da variabilidade do estímulo que está sendo codificada pela resposta. A $A M I / H_{P D}$ nos dá a fração da variabilidade da resposta que está sendo utilizada para codificar o estímulo.

De forma geral, tanto a posição quanto os valores dos picos de AMI do modelo estocástico estão bem próximos dos do neurônio LP (valor dos picos é de $\sim 1.2$ bits - Figura 5.13). Além disso, a entropia do estímulo nos dois casos também chega a mais de 5 bits, e a AMI normalizada pela entropia 


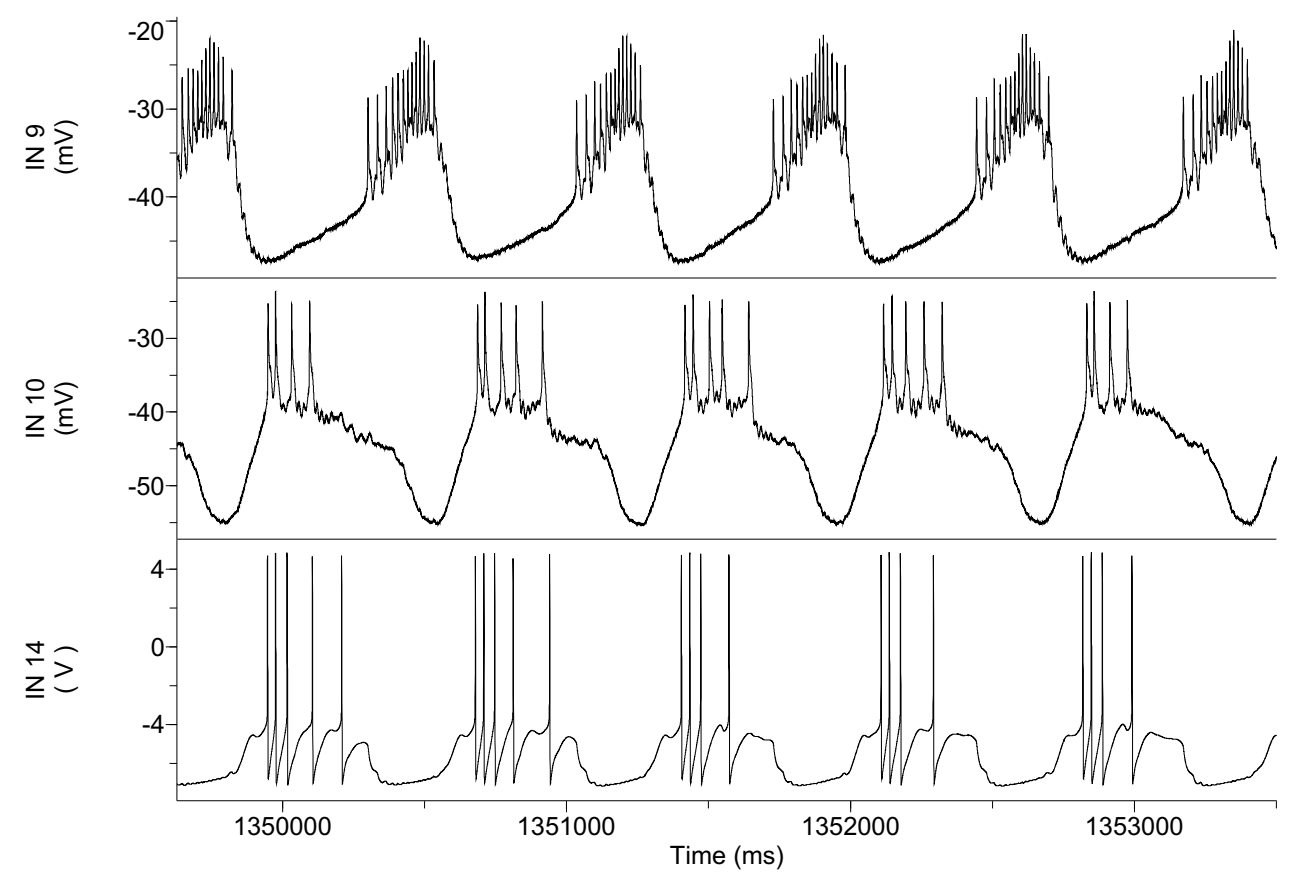

Figura 5.10 - Exemplo do ajuste do neurônio modelo para ter aproximadamente a mesma fase e número de spikes por burst que o neurônio LP. IN 9 - Medida intracelular do potencial de membrana do neurônio PD; IN 10 - Medida intracelular do potencial de membrana do neurônio LP; IN 14 - Potencial de membrana do neurônio modelo (unidades arbitrárias).

do estímulo tem seu valor máximo em torno de 20 a $22 \%$, o que significa que $20 \%$ da variabilidade do estímulo está sendo codificada pela resposta nos dois casos (Figura 5.14). No caso do modelo determinístico ocorre algo bem diferente.

Se compararmos o gráfico de $H_{P D}$ do experimento com o neurônio modelo determinístico com $H_{P D}$ nos outros experimentos (Figura 5.12) observamos que a capacidade de codificação de informação do $P D$ não se altera, entretanto observa-se que a complexidade do estímulo determinístico é menor que nos outros dois casos (Figura 5.11). Intuitivamente poderíamos esperar 

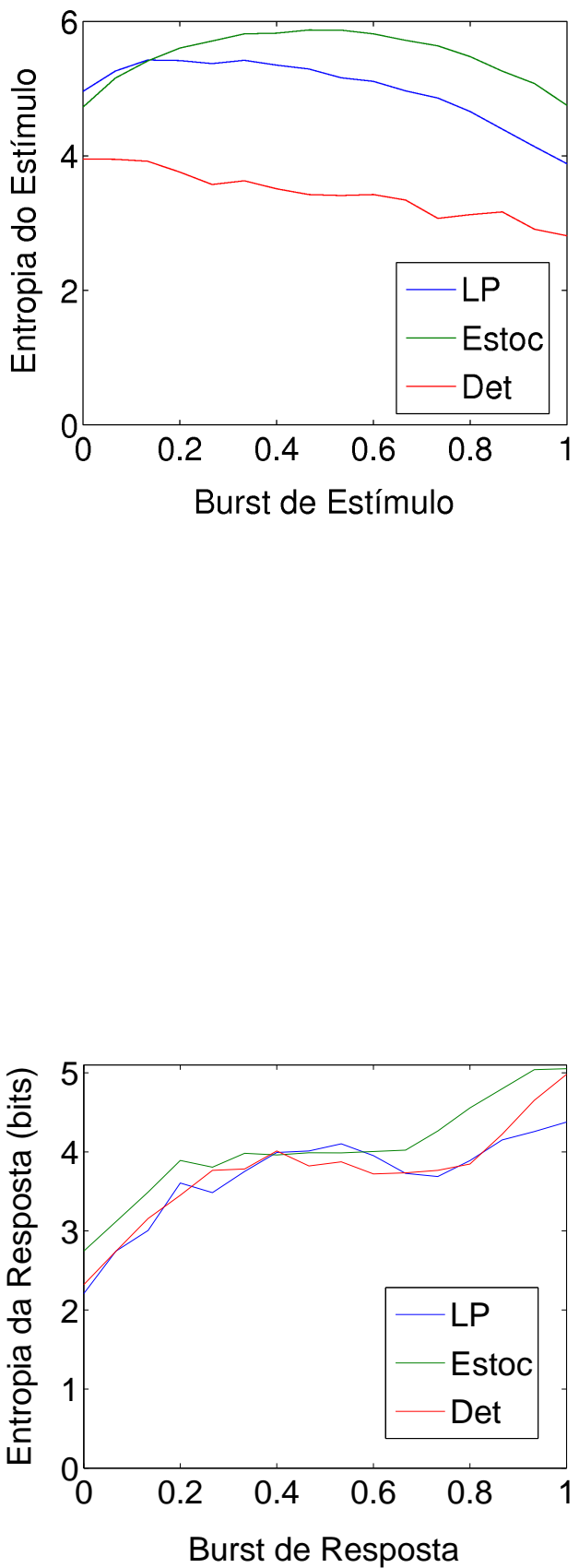

Figura 5.11 - Entropia do estímulo nos três experimentos. As entropias do neurônio LP e do modelo estocástico variam em torno de patamares de 5 e 5.5 bits. Já a entropia do modelo determinístico fica entre 3 e 4 bits. No eixo horizontal temos a posição do burst da qual a entropia é calculada, sendo 0 o começo do burst e 1 seu final.

Figura 5.12 - Entropia da resposta nos três experimentos. As entropias do neurônio PD, quando é estimulado em três casos diferentes, pelo neurônio LP, pelo modelo estocástico e pelo modelo determinístico. Em todos os casos os bursts do neurônio PD têm uma entropia muito parecida, o que quer dizer que sua capacidade de codificar os bursts de estímulo não varia significativamente nos três experimentos. No eixo horizontal temos o trecho do burst do qual a entropia é calculada, sendo 0 o começo do burst e 1 seu final. 
Estoc

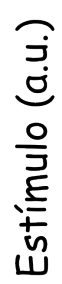

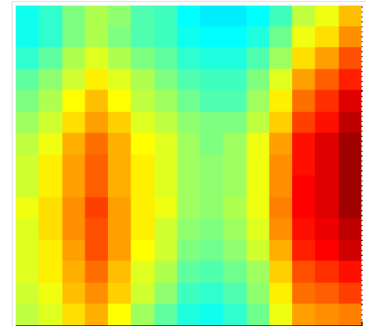

Resposta (a.u.)
LP

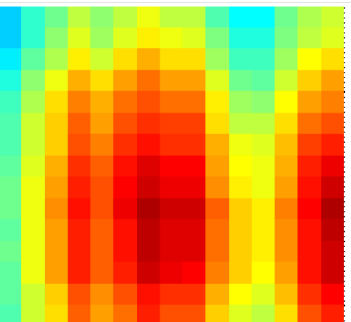

Resposta (a.u.)
Det

AMI

(Bits)
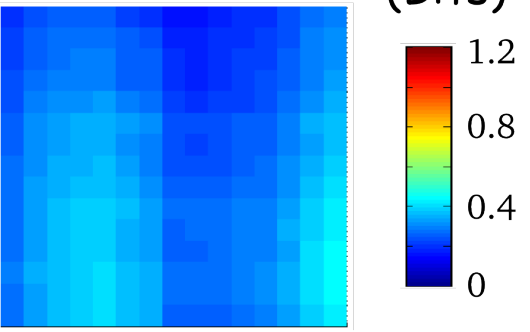

Figura 5.13 - Informação mútua média entre os bursts de estímulo e de resposta para os três experimentos. Os picos das AMIs do neurônio LP com o PD e do modelo estocástico com o PD ficam próximos a 1.2 bits. Já o pico da AMI do modelo determinístico com o PD é bem mais baixo, não chegando a 0.5 bits. Nos eixos vertical e horizontal temos respectivamente a posição do burst de estímulo e resposta a partir da qual a AMI é calculada.

Estoc

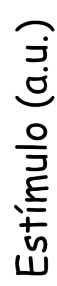

LP

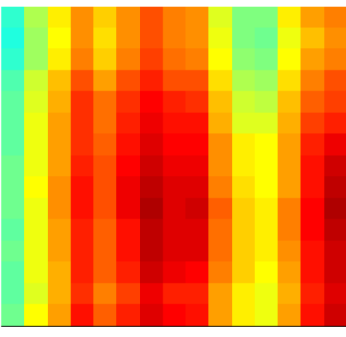

Det

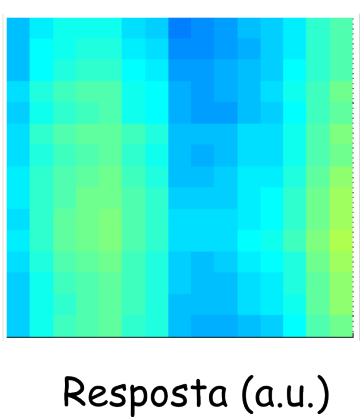

AMI\%

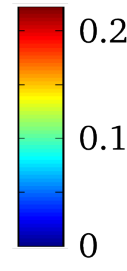

\section{Resposta (a.u.) Resposta (a.u.) Resposta (a.u.)}

Figura 5.14 - Informação mútua média entre os bursts de estímulo e de resposta normalizada pela entropia do estímulo, para os três experimentos. Nos eixos vertical e horizontal temos respectivamente a posição do burst de estímulo e resposta a partir da qual a AMI é calculada. 
Estoc

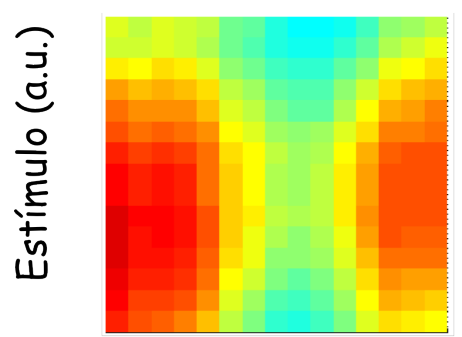

Resposta (a.u.)
LP

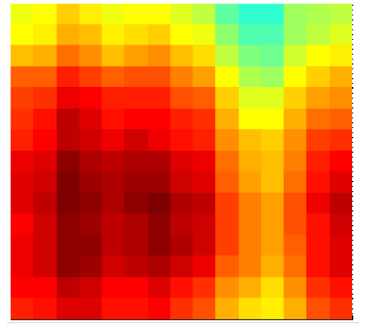

Resposta (a.u.)
Det

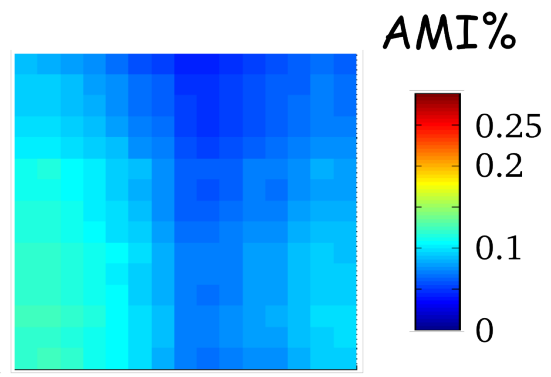

Resposta (a.u.)

Figura 5.15 - Informação mútua média entre os bursts de estímulo e de resposta normalizada pela entropia da resposta, para os três experimentos. Nos eixos vertical e horizontal temos respectivamente a posição do burst de estímulo e resposta a partir da qual a AMI é calculada.

que no caso determinístico uma maior proporção da informação do estímulo poderia ser codificada pelo neurônio biológico, entretanto o oposto ocorre: enquanto no caso biológico e no estocástico observamos picos com mais de $20 \%$ nos gráficos de $A M I / H_{E}$ (Figura 5.14) no mesmo gráfico para o caso determinístico o pico é de $\sim 12 \%$.

Este resultado sugere que o neurônio biológico de algum modo é seletivo à complexidade do estímulo: estímulos mais complexos são codificados com mais detalhe que estímulos mais simples.

Há um paralelo entre esta maior atenção dedicada pelo neurônio biológico a sinais mais complexos e um dos princípios da teoria da informação: a informação contida em um evento menos provável é maior que a informação contida em eventos repetitivos. Entretanto não está claro como este princípio pode ser encontrado em uma unidade de processamento de informação tão pequena quanto um neurônio isolado. 


\subsection{CPGs artificiais}

\subsubsection{CPGs de modelos estocásticos e neurônios eletrô- nicos}

No experimento descrito a seguir utilizamos uma versão mais nova do dynamic clamp, desenvolvida no nosso grupo, que roda em ambiente Linux (Mazur, 2006)(Fig. 5.16).

\begin{tabular}{|c|c|c|c|c|c|c|c|}
\hline$v$ & \multicolumn{6}{|c|}{ RTLDC - synapse_2comp 0} & $x$ \\
\hline Area & & 0.000628 & S_prev & & 0 & S_prev n_ext & 0 \\
\hline Area_Ax & & 0.000314 & S_inf_prev & & 0 & S_inf_prev n_exi & 0 \\
\hline GVV & & 0.0004 & Pre & & 0 & G_syn n_ext (nS & d \\
\hline G_CaT & & 2 & Pos & & 0 & V_syn n_ext (m) & -100 \\
\hline STOC_CaT & & 0 & ao_i & & 1 & Tau_syn n_ext (I & 10 \\
\hline G_CaS & & 10 & G_syn (nS) & & 30000 & V_thres n_ext (m & -1.8 \\
\hline STOC_CaS & & 0 & V_syn (mV) & & -3.5 & V_slope n_ext (r & 1 \\
\hline G_KCa & & 2 & Tau_syn (ms) & & 10 & & \\
\hline STOC_KCa & & 1 & V_thres (mV) & & -45 & & \\
\hline G_A & & 5 & V_slope (mV) & & 50 & & \\
\hline STOC_A & & 0 & & & & & \\
\hline G_H & & 15 & & & & & \\
\hline STOC_H & & 0 & & & & & \\
\hline G_Na & & 200 & & & & & \\
\hline STOC_Na & & 0 & & & & & \\
\hline G_K & & 100 & & & & & \\
\hline STOC_K & & 0 & & & & & \\
\hline Apply & Okay & Cancel & Unload & Pause & & & \\
\hline
\end{tabular}

Figura 5.16 - Layout do modelo estocástico no Dynamic Clamp Linux, com os valores de parâmetros utilizados no experimento. 
Utilizamos o Dynamic Clamp para conectar o modelo estocástico com um neurônio eletrônico em condições de uso iguais as de experimentos com neurônios biológicos. O programa Dynamic Clamp simulou o modelo Estocástico mais dois modelos de sinapses com uma taxa de atualização de $5 k \mathrm{~Hz}$.

A idéia é estudar os possíveis efeitos na sincronização de CPGs, devido ao fato do modelo ser estocástico. Como já vimos, o modelo estocástico recupera a atividade irregular típica de neurônios isolados, no entanto, a questão que se coloca é como isso afeta os circuitos neurais compostos por estes neurônios. A figura 5.17 mostra uma situação em que ambos os neurônios (modelo e eletrônico) são altamente irregulares quando isolados, mas quando acoplados com mútua inibição se sincronizam formando um padrão regular de disparo alternado, como ocorre nos CPGs biológicos (Selverston et al., 2000).

Uma vez mostrado que um CPG formado por modelos estocásticos pode ter um comportamento coletivo regular compatível com o comportamento de CPGs biológicos, tentamos estudá-lo de forma mais sistemática (Seção $5.4 .2)$. 


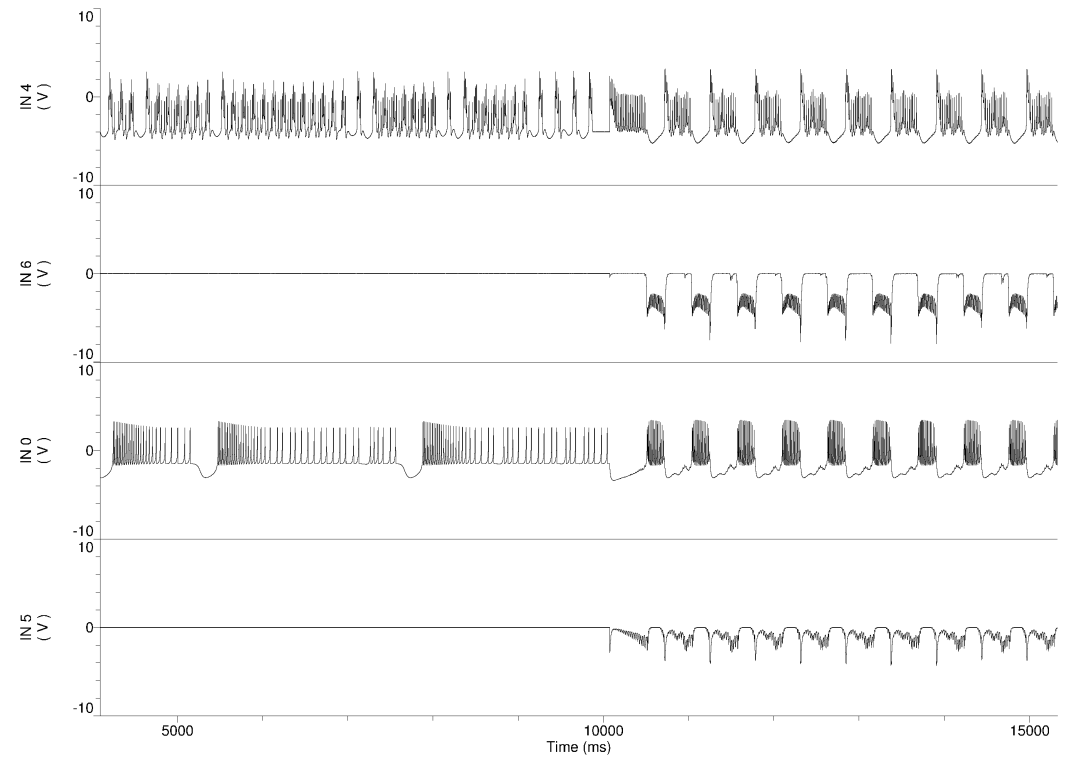

Figura 5.17 - Modelo estocástico sincronizado com neurônio eletrônico. A esquerda temos os dois neurônios funcionando isoladamente, mostrando que ambos são altamente irregulares. $\mathrm{Em} t=10 \mathrm{~s}$ é ligada a conexão sináptica de inibição recíproca entre eles, e o ritmo regular se estabelece. Os parâmetros usados para o modelo estocástico e para as conexões sinápticas estão na figura 5.16. 


\subsubsection{CPGs de modelos estocásticos}

Baseado em trabalhos recentes desenvolvidos em nosso grupo de pesquisa, procuramos estudar o comportamento destes neurônios modelo conectados com mútua inibição, um dos CPGs mais simples que existem. O trabalho de Reyes (Reyes, 2005) mostrou como se pode caracterizar o comportamento de um CPG modelo em função de parâmetros intrínsecos dos neurônios que o compõe e da intensidade da conexão sináptica entre eles.

Exploramos dois parâmetros intrínsecos diferentes: a condutância máxima de cálcio (CaS) e uma corrente DC injetada. A seguir mostramos algumas figuras que explicitam as diferenças entre o modelo determinístico e o modelo estocástico nestas situações.

O CPG simulado com o modelo determinístico, não gera ritmo alternado para algumas regiões do espaço de parâmetros (Fig. 5.18, $G_{C a S}>5.5$ ). Isto não acontece com os neurônios biológicos. Já com o modelo estocástico isto não acontece, recuperando o comportamento compatível com neurônios biológicos (Fig 5.19). O mesmo acontece quando injetamos uma corrente DC no CPG artificial composto por modelos determinísticos (Fig. 5.20) ou estocásticos (Fig. 5.21).

Os CPGs formados por neurônios estocásticos, que se comportam de modo bastante irregular quando isolados, apresentam um pequeno desvio padrão na frequência média de oscilação quando conectados (Figs. 5.19 e 5.21 do lado direito) e este pequeno valor é compatível com as flutuações observadas em circuitos biológicos (Selverston et al., 2000). 

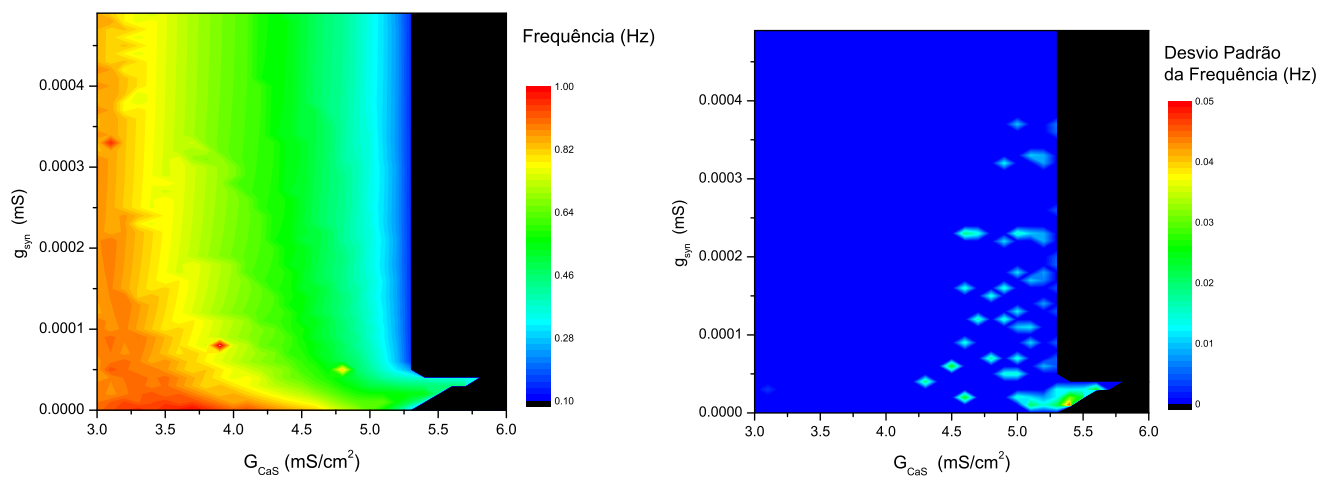

Figura 5.18 - Espaço de parâmetros do modelo determinista usando como parâmetro intrínseco a condutância de calcio $\left(G_{C a S}\right)$. A esquerda temos a frequência em escala de cores como função da intensidade sináptica $g_{\text {syn }}$ e do parâmetro intrínseco. A direita temos o desvio padrão da frequência em escala de cores em função dos mesmos parâmetros.
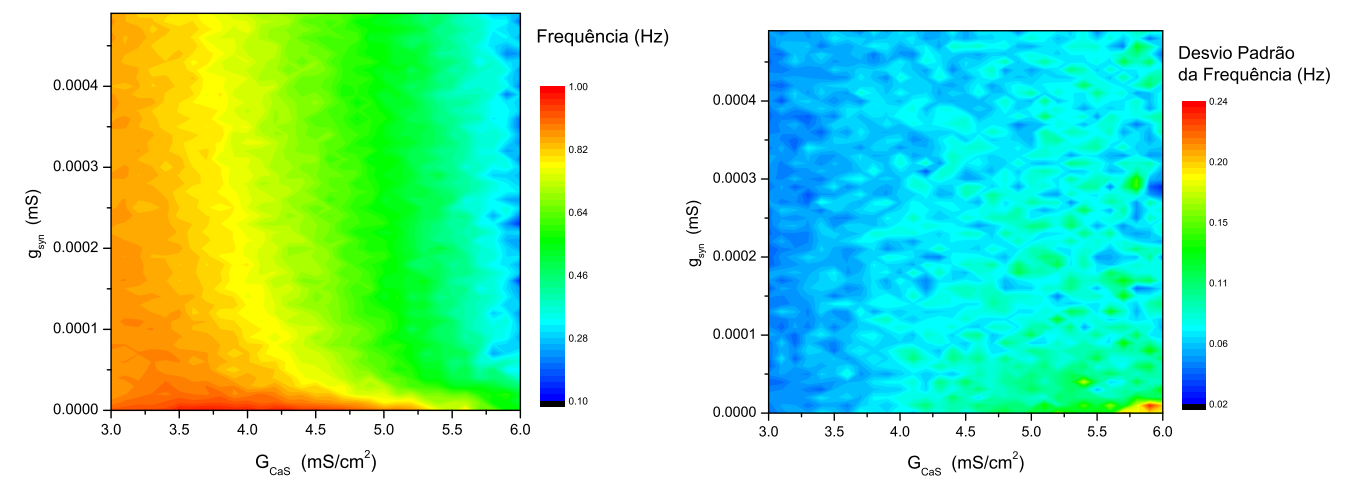

Figura 5.19 - Espaço de parâmetros do modelo estocástico usando como parâmetro intrínseco a condutância de calcio $\left(G_{C a S}\right)$. A esquerda temos a frequência em escala de cores como função da intensidade sináptica $g_{s y n}$ e do parâmetro intrínseco. A direita temos o desvio padrão da frequência em escala de cores em função dos mesmos parâmetros. 

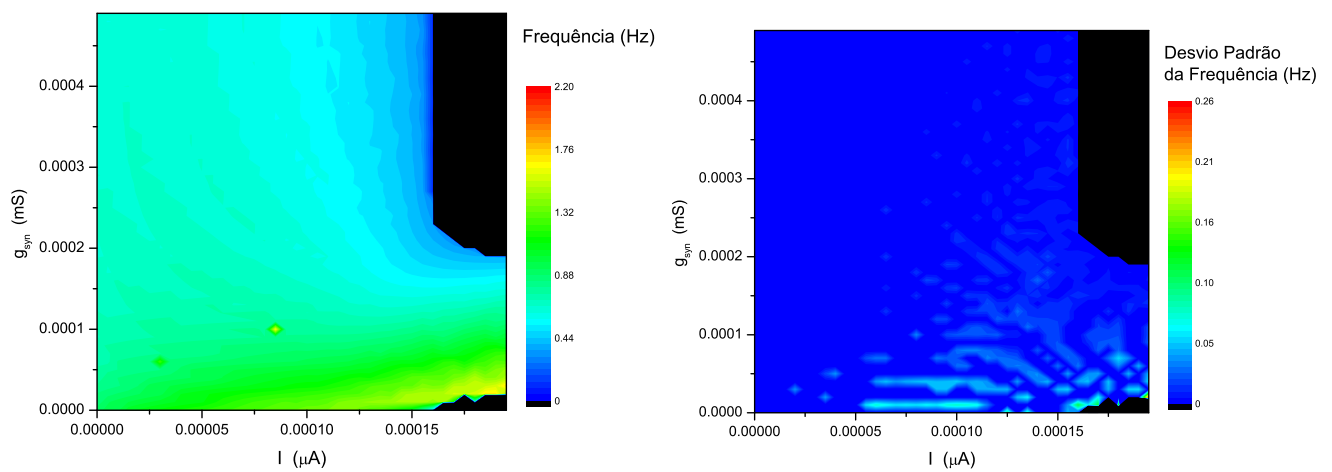

Figura 5.20 - Espaço de parâmetros do modelo determinista usando como parâmetro intrínseco uma corrente DC injetada. A esquerda temos a frequência em escala de cores como função da intensidade sináptica $g_{s y n}$ e do parâmetro intrínseco $I$. A direita temos o desvio padrão da frequência em escala de cores em função dos mesmos parâmetros.
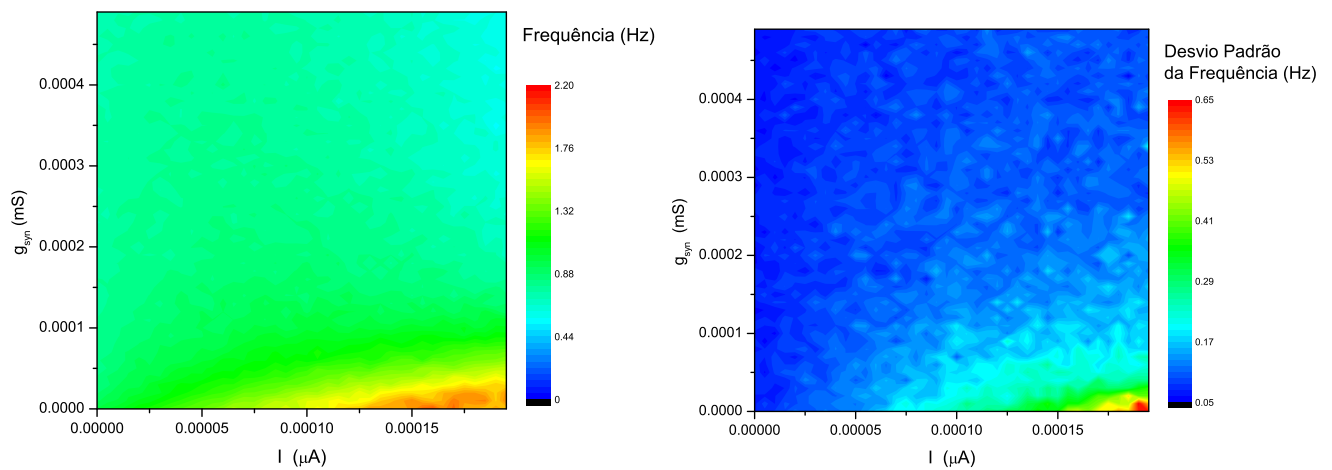

Figura 5.21 - Espaço de parâmetros do modelo estocástico usando como parâmetro intrínseco uma corrente DC injetada. A esquerda temos a frequência em escala de cores como função da intensidade sináptica $g_{\text {syn }}$ e do parâmetro intrínseco $I$. A direita temos o desvio padrão da frequência em escala de cores em função dos mesmos parâmetros. 


\subsection{Modelos de dois compartimentos}

Fizemos um estudo de modelos de 2 compartimentos tentando separar as correntes responsáveis pela dinâmica lenta $\left(\mathrm{CaS}, \mathrm{CaT}, K_{(\mathrm{Ca})}, A, H\right)$ das correntes responsáveis pela geração dos potenciais de ação $(N a, K d)$. Em modelos de dois compartimentos, também encontramos comportamento irregular devido às flutuações estocásticas dos canais iônicos.

Uma das idéias de se fazer um modelo de dois compartimentos era reproduzir de forma mais fiel as medidas experimentais que são feitas no soma do neurônio e por isso apresentam hiperpolarizações bastante pronunciadas. Além disso existem evidências de que apenas uma pequena região da membrana do neurônio é responsável pela iniciação do potencial de ação (axon hillock (Kandel et al., 1991), ver figura 5.23), o que aumentaria ainda mais os efeitos da estocasticidade dos canais iônicos. Ainda não se tem certeza, no entanto, de quantos compartimentos são necessários para modelar a atividade intrínseca do neurônio biológico e também não há muita certeza da forma com que as correntes iônicas deveriam ser separadas. Tentamos então, na forma de modelos trazer algum entendimento sobre este assunto.

Como um primeiro estudo, separamos as correntes lentas em um compartimento e as correntes rápidas em outro, que representariam respectivamente soma + neuropil e axônio, e fizemos um estudo de como deveriam ser os tamanhos dos compartimentos e a intensidade da conexão entre eles, mantendo as densidades de canais constantes.

Quando simulamos dois compartimentos desconectados, o axônio permanece silencioso e o soma adquire uma oscilação lenta com frequência em torno de 1,5 Hz (Fig. 5.22). Mesmo alterando as condutâncias iônicas a atividade do compartimento com as correntes lentas permanece oscilando com uma frequência próxima da mostrada. Ao acoplarmos os dois compartimentos 

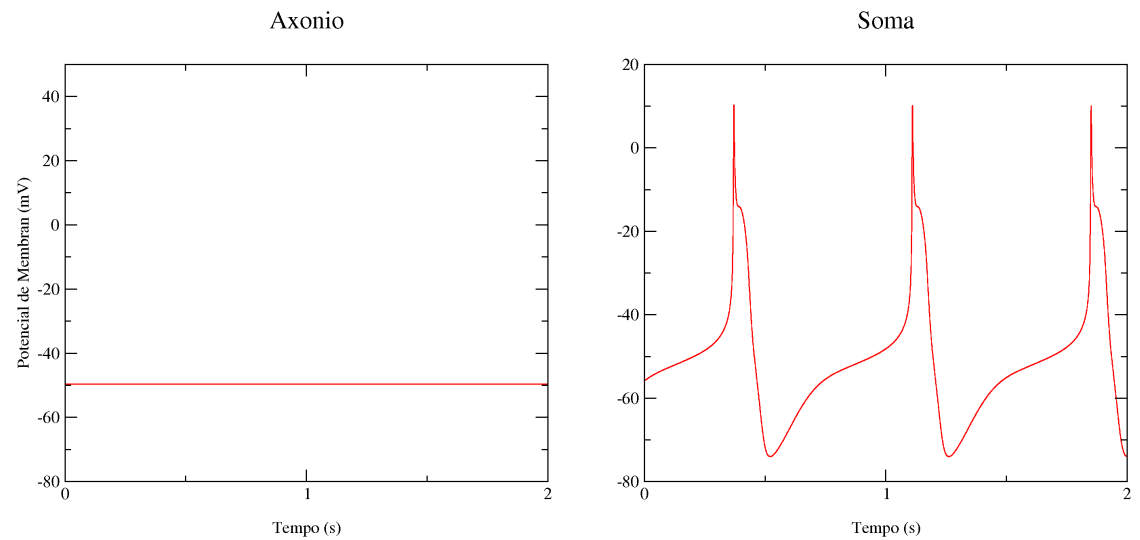

Figura 5.22 - Séries temporais de dois compartimentos isolados, sendo o axônio só com as correntes de sódio e potássio, e o soma só com as correntes lentas.

verificamos uma riqueza maior de comportamentos. Mantendo os mesmos valores de condutâncias máximas, avaliamos dois aspectos: o primeiro é a intensidade do acoplamento e o segundo é o tamanho dos compartimentos. Quando a conectividade era muito fraca, os compartimentos simplesmente se ignoravam, e quando ela era muito forte, o modelo se comportou de forma muito semelhante ao modelo de 1 compartimento. Verificamos que quando o compartimento axonal é maior que o somático, a corrente do compartimento somático não é suficiente para excitar o compartimento axonal, e o sistema todo permanece silencioso. Por outro lado, quando o compartimento somático foi considerado muito maior que o compartimento axonal, praticamente só as oscilações lentas aparecem.

Na figura 5.23 mostramos uma comparação entre os modelos de 2 compartimentos determinístico e estocástico, sobrepondo bursts consecutivos dos modelos. Mostramos também uma segunda versão do modelo estocástico, considerando a zona de geração de spikes com uma área efetiva muito menor que a área do soma. Particularmente na figura mostrada consideramos 

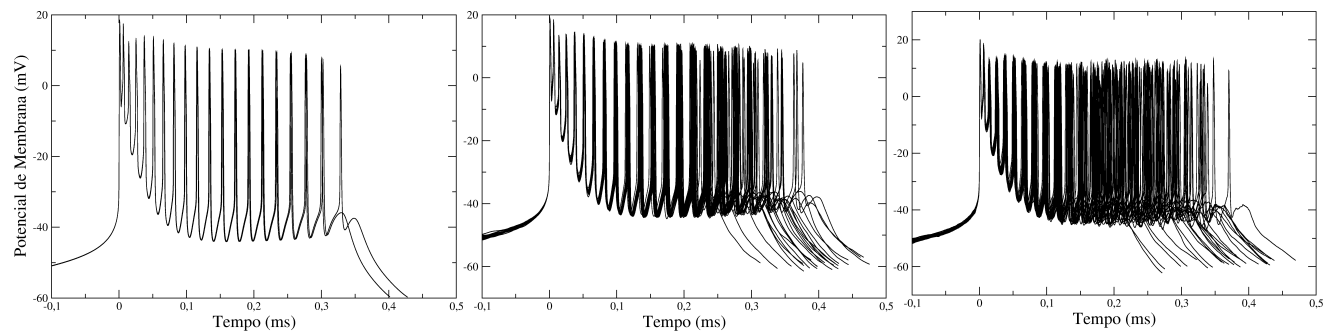

Figura 5.23 - Bursts sobrepostos em modelos de 2 compartimentos. À esquerda temos 25 bursts consecutivos do modelo determinístico. Para estes parâmetros o modelo determinístico intercala bursts com 19 e 20 disparos. Ao centro temos 25 bursts consecutivos do modelo estocástico. Novamente quando incluímos a dinâmica estocástica dos canais iônicos temos séries temporais irregulares. À direita temos novamente o modelo estocástico porém considerando a zona de geração de spikes com uma área muito menor que a do soma.

uma área de $200 \mu \mathrm{m}^{2}$, de acordo com indicações de outros fenômenos explicados com modelos estocásticos (Mainen e Sejnowski, 1995; Schneidman et al., 1998). Como esperávamos, quando consideramos este fator o efeito da dinâmica estocástica dos canais iônicos é aumentado. 


\subsection{Modelo determinístico multicompartimen- tos}

Para que o modelo apresente um potencial de membrana ainda mais semelhante ao que medimos no soma do neurônio, é necessário aumentar ainda mais a complecidade da distribuição espacial do potencial de membrana e das condutâncias iônicas, obtendo o que chamamos de modelo de multicompartimentos.

O primeiro desafio para se construir um modelos desses é escolher as propriedades passivas do neurônio, como a quantidade de compartimentos e sua geometria. Em seguida é preciso escolher como distribuir as correntes iônicas entre os compartimentos, o que pode ser uma tarefa extremamente complicada, pois o número de parâmetros do modelo a serem ajustados é proporcional ao número de compartimentos multiplicado pelo número de correntes iônicas presentes no modelo. Portanto precisamos escolher algum critério para restringir o número parâmetros do modelo.

Em um trabalho com células em cultura do STG (Levi et al., 2003) mostrou-se que a atividade de cálcio desses neurônios ocorre não no soma mas na ramificação principal do neuropil.

Decidimos modelar apenas o soma a a ramificação principal do neuropil, utilizando 10 compartimentos cilíndricos para o neuropil e um compartimento esférico para o soma (Figura 5.25). Como a principal atividade de cálcio está concentrada no neuropil, consideramos que as correntes iônicas de cálcio e potássio dependente de cálcio estão apenas lá. Além disso, as correntes de sódio e potássio estão nas partes mais distantes do neuropil, portanto só os dois compartimentos mais distantes do soma tem essas correntes.

Devido à quantidade de parâmetros envolvendo este modelo utilizamos 
A
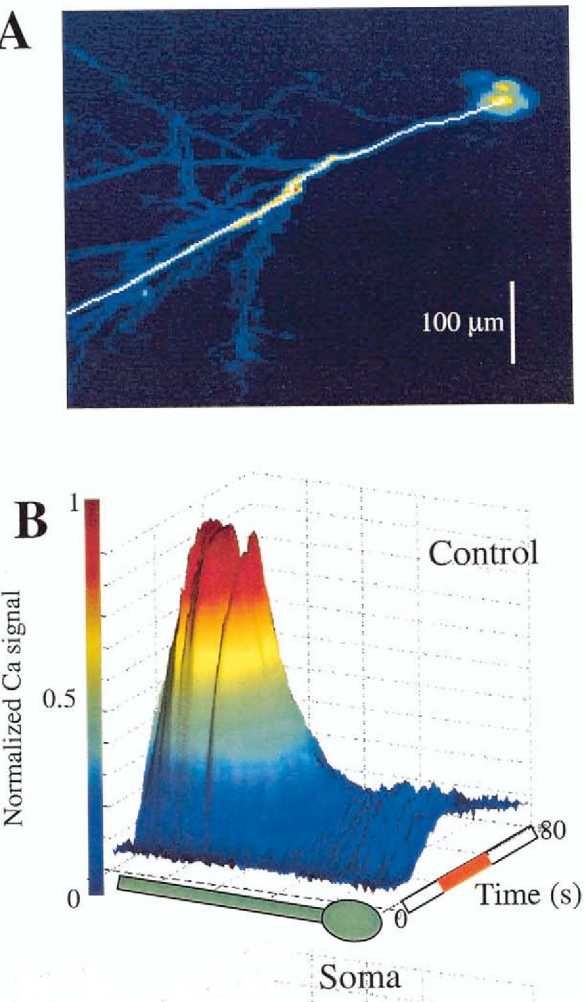

Figura 5.24 - Calcium imaging de uma célula em cultura do STG. Extraído de (Levi et al., 2003)

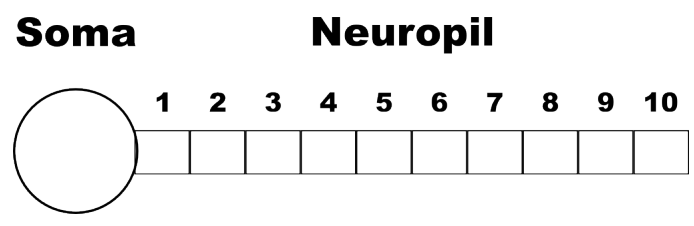

Figura 5.25 - Geometria dos compartimentos do modelo. O soma é um compartimento esférico de $100 \mu \mathrm{m}$ de diâmetro e o neuropil é composto por 10 compartimentos de $50 \mu \mathrm{m}$ de diâmetro por $40 \mu \mathrm{m}$ de comprimento. Nos compartimentos 7 e 8 temos apenas as correntes lentas e responsáveis pela formação do platô, $I_{C a S}, I_{C a T}, I_{K(C A)}, I_{A}$ e $I_{H}$. Os dois último compartimentos (9 e 10) são responsáveis pela geração dos potenciais de ação e por isso também incluem as correntes rápidas $I_{N a}$ e $I_{K}$. 


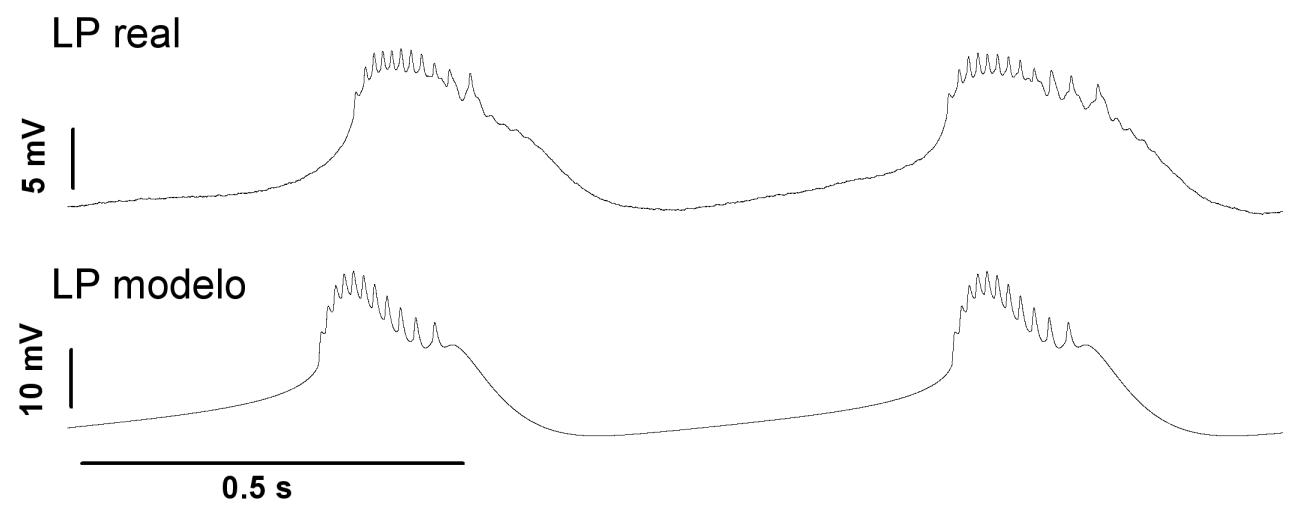

Figura 5.26 - Comparação das atividades elétricas do neurônio LP medida por eletrodo colocado no soma com o potencial de mebrana do compartimento somático do modelo.

o simulador GENESIS (Bower e Beeman, 1998), que tem uma biblioteca automatizada de busca de parâmetros (Vanier e Bower, 1999), para ajustar a duração do burst e tempo entre bursts do neurônio modelo ao biológico. Na busca de parâmetros só eram alteradas as condutâncias máximas das correntes $I_{C a S}, I_{C a T}$ e $I_{K(C a)}$.

O resultado final é um modelo que tem o potencial de membrana bem mais parecido com o neurônio biológico (Figura 5.26). Embora não tenhamos explorado mais neste trabalho, modelos desse tipo são especialmente úteis quando se quer comparar de forma quantitativa efeitos na atividade elétrica do neurônio devido por exemplo à injeção de corrente (uma vez que seu eletrodo está no soma) ou sinapses (que em geral ocorrem em na ponta de finas ramificações do neuropil). Ao contrário do que poderia se imaginar, o aumento no número de compartimentos e consequentemente na complexidade do modelo não torna sua atividade irregular. 


\section{Capítulo 6}

\section{Conclusões}

O comportamento elétrico de neurônios têm sido estudado por mais de seis décadas e existe uma grande quantidade de dados experimentais de voltageclamp, além de modelos detalhados construídos a partir desses dados. Apesar do fato de modelos de pequenas áreas da membrana celular, onde a dinâmica estocástica dos canais iônicos é considerada, apresentarem comportamento irregular compatível com o encontrado em neurônios biológicos, até recentemente acreditava-se que o comportamento desses modelos tenderia a um comportamento médio determinístico quando se considerasse o grande número de canais iônicos presentes em um neurônio inteiro. Assim em detrimento dos modelos estocásticos, os modelos determinísticos sempre foram considerados como paradigmas para o comportamento de neurônios biológicos. Entretanto, é inquietante o fato de nenhum desses modelos apresentar o mesmo tipo de atividade irregular facilmente encontrada em neurônios isolados até mesmo de sistemas simples, que produzem padrões periódicos, como o STG de crustáceos.

Para lidar com esta questão, inicialmente implementamos um modelo determinístico de neurônio do STG, já existente na literatura, e comparamos 
seus resultados com dados experimentais. Alteramos este modelo inicial para incluir o comportamento estocástico microscópico dos canais iônicos e estudar seus efeitos nas características macroscópicas da dinâmica do potencial de membrana. Descobrimos que a idéia de que o comportamento do modelo estocástico tenderia ao comportamento determinístico quando considerássemos uma membrana com a área de um neurônio biológico estava errada. Isso só acontece para áreas muitas ordens de grandeza acima, tendendo ao infinito. Nosso modelo estocástico apresentou uma atividade irregular mais compatível com a dos neurônios biológicos do que a atividade do modelo determinístico original. Além disso, através da implementação de modelos mistos (com algumas condutâncias estocásticas e outras determinísticas), mostramos que algumas condutâncias iônicas estocásticas contribuem mais que outras para a irregularidade do comportamento do modelo.

Estudando o comportamento de pequenos circuitos formados por dois modelos estocásticos acoplados com mútua inibição formando um CPG, observamos que eles sincronizam dando origem a uma atividade rítmica alternada e bastante regular, como é observado em circuitos formados por neurônios vivos. Além disso, mostramos situações em que, para os mesmos parâmetros em que os CPGs formados por modelos determinísticos não geram oscilações (um modelo dispara mantendo o outro silencioso), os CPGs formados por modelos estocásticos continuam gerando ritmo alternado compatível com o que se observa em CPGs biológicos. Ou seja, ao contrário do que se possa imaginar, a presença de dinâmica estocástica nos neurônios modelo torna o comportamento regular dos CPGs mais estável no espaço de parâmetros.

Para verificar se o comportamento dinâmico dos modelos é biologicamente adequado foi necesário desenvolver uma maneira de interfacear estes modelos em tempo real com neurônios biológicos e estudar o comportamento 
desses circuitos híbridos. Para isso, aprendemos as técnicas de dissecação de preparação dos neurônios do STG e desenvolvemos um algoritmo de simulação estocástica otimizado para permitir as simulações e a implementação em tempo real do modelo estocástico, e adaptamos um protocolo dynamic clamp para interagir o modelo estocástico em tempo real com os neurônios vivos através de sinapses artificiais.

Utilizamos os modelos desenvolvidos para substituir um neurônio do gânglio estomatogástrico, formando sistemas híbridos, e estudar como os neurônios artificiais transmitem informação para um neurônio vivo nestes casos. Verificamos que o neurônio biológico codifica informação de maneira mais eficiente e mais próxima do que ocorre no circuito biológico original quando a dinâmica do neurônio artificial é estocástica do que quando é determinística. Além disso observamos que os neurônios biológicos codificam relativamente mais informação sobre estímulos mais complexos do que de estímulos mais simples.

Assim, mostamos nesta tese como trabalhar com modelos realistas de neurônios desde sua simulação computacional até sua interação com neurônios vivos em tempo real: desenvolvemos um modelo estocástico para um neurônio do STG, as técnicas de dissecação e preparação dos neurônios biológicos para interagir com os modelos e as técnicas necessárias para interfacear os modelos com o tecido vivo.

Por fim, discutimos alguns possíveis futuros desdobramentos desta tese que poderiam melhorar ainda mais os modelos, incluindo além da característica estocástica dos canais iônicos a sua distribuição em multicompartimentos. 


\section{Referências}

Abraham, R. H. e Shaw, C. D. (1992). Dynamics: the geometry of behavior. Addison-Wesley, Redwood City, CA.

Ayers, J. (2004). Underwater walking. Arthropod structure $\&$ development, $33: 347-360$.

Bower, J. M. e Beeman, D. (1998). The Book of GENESIS: Exploring Realistic Neural Models with the GEneral NEural SImulation System. SpringerVerlag, New York.

Carelli, P. V., Reyes, M. B., Sartorelli, J. C., e Pinto, R. D. (2005). Whole Cell Stochastic Model Reproduces the Irregularities Found in the Membrane Potential of Bursting Neurons. J Neurophysiol, 94(2):1169-1179.

Carmena, J. M., Lebedev, M. A., Crist, R. E., O’Doherty, J. E., Santucci, D. M., Dimitrov, D. F., Patil, P. G., Henriquez, C. S., e Nicolelis, M. A. L. (2003). Learning to Control a Brain-Machine Interface for Reaching and Grasping by Primates. PLoS Biol, 1(2):193-208.

Chow, C. C. e White, J. A. (1996). Spontaneous action potentials due to channel fluctuations. Biophys. J., 71(6):3013-3021.

Dayan, P. e Abbott, L. F. (2001). Theoretical Neuroscience: computational and mathematical modeling of neural systems. 
Desthexhe, A., Mainen, Z. F., e Sejnowski, T. J. (1994). Syntesis of models for excitable membranes, synaptic transmission and neuromodulation using a common kinetic formalism. J. Comput. Neurosci., 1:195-231.

Elson, R. C., Huerta, R., Abarbanel, H. D. I., Rabinovich, M. I., e Selverston, A. I. (1999). Dynamic Control of Irregular Bursting in an Identified Neuron of an Oscillatory Circuit. J Neurophysiol, 82(1):115-122.

Faisal, A. A. e Laughlin, S. B. (2007). Stochastic Simulations on the reliability of action potential propagation in thin axons. PLoS Comp. Biol., $3(5): 783-795$.

Falcke, M., Huerta, R., Rabinovich, M. I., Abarbanel, H. D. I., Elson, R., e Selverston, A. I. (2000). Modeling observed chaotic oscillations in bursting neurons: the role of calcium dynamics and IP3. Biol. Cybern., $82: 517-527$.

Gillespie, D. T. (1977). Exact stochastic simulation of coupled chemical reactions. J. Phys. Chem., 81:2340-2361.

Guckenheimer, J. e Oliva, R. (2002). Chaos in the Hodkin-Huxley model. SIAM J. Applied Dyn. Systems, 1:105-114.

Hegger, R., Kantz, H., e Schreiber, T. (1999). Practical implementation of nonlinear time series methods: the TISEAN package. Chaos, 9:413-435.

Hille, B. (1992). Ionic channels of excitable membranes. Sinauer Associates, Sunderland, Mass.

Hodgkin, A. L. e Huxley, A. F. (1952). A quantitative description of membrane current and its application to conduction and excitation in nerve. J. Physiol., 117(4):500-544. 
Holden, A. (1997). Nonlinear Science - The impact of biology. Int J Bif Chaos, 7:2075-2104.

Ikeda, M. (2004). Calcium Dynamics and Circadian Rhythms in Suprachiasmatic Nucleus Neurons. Neuroscientist, 10(4):315-324.

Izhikevich, E. M. (2000). Neural excitability, spiking and bursting. Int. J. Bif. and Chaos, 10:1171-1266.

Kandel, E., Schwartz, J., e Jessel, T. (1991). Principles of Neuroscience. Appleton and Lange, Norwalk, VT.

Koch, C. (1999). Biophysics of computation : information processing in single neurons. Oxford University Press, New York, New York.

Komendantov, A. O. e Kononenko, N. I. (1996). Deterministic chaos in mathematical model of pacemaker activity in bursting neurons of snail Helix pomatia. J. theor. Biol., 183:219-230.

Levi, R., Samoilova, M., e Selverston, A. I. (2003). Calcium signaling components of oscillating invertebrate neurons in vitro. Neuroscience, 118:283296.

Levitan, I. e Kaczmarek, L. (1997). The Neuron: cell ans molecular biology. Oxford University Press, New York, New York.

Liu, Z., Lai, Y.-C., Billings, L., e Schwartz, I. B. (2002). Transition to chaos in continuous-time random dynamical systems. Phys. Rev. Lett., 88(12):124101.

Mainen, Z. e Sejnowski, T. (1995). Reliability of spike timing in neocortical neurons. Science, 268(5216):1503-1506. 
Marder, E. (1998). From biophysics to models of network function. Annu. Rev. Neurosci., 21:25-45.

Mazur, R. (2006). Implementação de um protocolo Dynamic Clamp em sistema Linux em tempo real para a produção de condutâncias artificiais em neurônios biológicos e eletrônicos. PhD thesis, Universidade de São Paulo.

Mino, H., Rubinstein, J. T., e White, J. A. (2002). Comparison of algorithms for the simulation of action potentials with stochastic sodium channels. Annals Biomed. Engineering, 30:578-587.

Mulloney, B. e Selverston, A. I. (1974). Organization of the stomatogastric ganglion of the spiny lobster. J. Comp. Physiol., 91:1-32.

Oliveira, M. J. d. e Tomé, T. (2001). Dinâmica Estocásticas e Irreversibilidade. Edusp, São Paulo, SP.

Parri, H. R. e Crunelli, V. (2001). Pacemaker calcium oscillations in thalamic astrocytes in situ. Neuroreport, 12:3897-3900.

Pinto, R., Elson, R., Szucs, A., Rabinovich, M., Selverton, A., e Abarbanel, H. (2001). Extended dynamic clamp: controling up to four neurons using a single desktop computer and interface. J. Neurosci. Methods, 108:39-48.

Pinto, R. D., Varona, P., Volkovskii, A. R., Szücs, A., Abarbanel, I., H. D., e Rabinovich, M. I. (2000). Synchronous behavior of two coupled electronic neurons. Phys. Rev. E, 62(2):2644-2656.

Prinz, A. (2004). Neural networks: models and neurons show hybrid vigor in real time. Curr. Biol., 14:R661-R662. 
Prinz, A., Ramirez, J., Buzsaki, G., e K.J., S. (2004). How dynamic interactions of intrinsic bursting and synaptic properties shape network functions. Soc Neurosci Abstr, 813.

Prinz, A. A., Billimoria, C. P., e Marder, E. (2003a). Alternative to HandTuning Conductance-Based Models: Construction and Analysis of Databases of Model Neurons. J Neurophysiol, 90(6):3998-4015.

Prinz, A. A., Thirumalai, V., e Marder, E. (2003b). The Functional Consequences of Changes in the Strength and Duration of Synaptic Inputs to Oscillatory Neurons. J. Neurosci., 23(3):943-954.

Rabinovich, M. I., Abarbanel, H. D. I., Huerta, R., Elson, R., e Selverston, A. I. (1997). Self-regulation of chaos in neural systems: experimental and theoretical results. IEEE Trans. Circ. Syst. I, 44:997-1005.

Reyes, M. (2005). Comportamento complexo em centros geradores de padrões. $\mathrm{PhD}$ thesis, Universidade de São Paulo.

Rinzel, J. e Ermentrout, G. B. (1998). Analysis of neural excitability and oscillations. MIT Press, Cambridge, MA.

Rubinstein, J. T. (1995). Threshold fluctuations in an N sodium channel model of the node of Ranvier. Biophysical Journal, 68:779-785.

Saarinen, A., Linne, M.-L., e Yli-Harja, O. (2008). Stochastic differential equation model for cerebellar granule cell excitability. PLoS Comput Biol, 4(2):e1000004.

Schneidman, E., Freedman, B., e Segev, I. (1998). Channel Stochasticity May Be Critical in Determining the Reliability and Precision of Spike Timing. Neural Comput., 10(7):1679-1703. 
Selverston, A. I. e Moulins, M. (1986). The crustacean stomatogastric system. Springer-Verlag, Berlim.

Selverston, A. I., Rabinovich, M. I., Abarbanel, H. D. I., Elson, R., Szucs, A., Pinto, R. D., Huerta, R., e Varona, P. (2000). Reliable circuits from irregular neurons: A dynamical approach to understanding central pattern generators. J. Physiol. (Paris), 94:357-374.

Sharp, A. A., O’Neil, M. B., Abbott, L. F., e Marder, E. (1993). Dynamic clamp: computer-generated conductances in real neurons. J Neurophysiol, 69(3):992-995.

Skaugen, E. e Walloe, L. (1979). Firing behavior in a stochastic nerve membrane model based upon the Hodgkin-Huxley equations. Acta Physiol Scand, 107:343-363.

Szucs, A., Pinto, R. D., Rabinovich, M. I., Abarbanel, H. D. I., e Selverston, A. I. (2003). Synaptic Modulation of the Interspike Interval Signatures of Bursting Pyloric Neurons. J Neurophysiol, 89(3):1363-1377.

Szücs, A., Varona, P., Volkovskii, A. R., Abarbanel, H. D. I., Rabinovich, M. I., e Selverston, A. I. (2000). Interacting biological and electronic neurons generate realistic oscillatory rhythms. Neuroreport, 11:563-569.

Turrigiano, G., LeMasson, G., e Marder, E. (1995). Selective regulation of current densities underlies spontaneous changes in the activity of cultured neurons. J. Neurosci., 15(5):3640-3652.

Vanier, M. C. e Bower, J. M. (1999). A comparative survey of automated parameter-search methods for compartmental neural models. J Comput Neurosci, 7(2):149-171. 
White, J. A., Klink, R., Alonso, A., e Kay, A. R. (1998). Noise From VoltageGated Ion Channels May Influence Neuronal Dynamics in the Entorhinal Cortex. J Neurophysiol, 80(1):262-269.

White, J. A., Rubinstein, J. T., e Kay, A. R. (2000). Channel noise in neurons. TINS, 23:131-137.

Zhang, M., Goforth, P., Bertram, R., Sherman, A., e Satin, L. (2003). The Ca2+ Dynamics of Isolated Mouse beta-Cells and Islets: Implications for Mathematical Models. Biophys. J., 84(5):2852-2870. 
Apêndices 


\section{Apêndice A}

\section{Gerando uma variável aleatória com distribuição} gaussiana.

Sejam $\varepsilon$ e $\zeta$ duas variáveis aleatórias independentes e uniformemente distribuídas no intervalo $[0,1]$. As variáveis aleatórias $r$ e $\theta$ dadas por ${ }^{1}$ :

$$
r=\sqrt{\frac{2}{\alpha}|\ln (1-\varepsilon)|} \quad e \quad \theta=2 \pi \zeta
$$

sendo $\alpha>0$, terão as seguintes densidades de probabilidades:

$$
\rho_{1}(r)=\alpha r e^{-\frac{\alpha}{2} r}
$$

e

$$
\begin{gathered}
\rho_{2}(\theta)=\frac{1}{2 \pi}, \quad 0 \leq \theta \leq 2 \pi \\
x=r \operatorname{sen} \theta \quad e \quad y=r \cos \theta \\
\rho_{c}(x, y) d x d y=\rho_{1}(r) \rho_{2}(\theta) d r d \theta \\
\rho_{c}(x, y)=\frac{\alpha}{2 \pi} e^{-\frac{\alpha}{2}\left(x^{2}+y^{2}\right)} \\
\rho(x)=\left(\frac{\alpha}{2 \pi}\right)^{1 / 2} e^{\left(-\frac{\alpha}{2} x^{2}\right)}
\end{gathered}
$$

\footnotetext{
${ }^{1}$ Ver referência (Oliveira e Tomé, 2001)
} 
Apêndice B

Artigo publicado 


\title{
Whole Cell Stochastic Model Reproduces the Irregularities Found in the Membrane Potential of Bursting Neurons
}

\author{
Pedro V. Carelli, Marcelo B. Reyes, José C. Sartorelli, and Reynaldo D. Pinto \\ Laboratório de Fenômenos Não-Lineares, Instituto de Física da Universidade de São Paulo, Sao Paulo, Brazil
}

Submitted 20 January 2005; accepted in final form 23 March 2005

Carelli, Pedro V., Marcelo B. Reyes, José C. Sartorelli, and Reynaldo D Pinto. Whole cell stochastic model reproduces the irregularities found in the membrane potential of bursting neurons. $J$ Neurophysiol 94: 1169-1179, 2005. First published March 30, 2005; doi:10.1152/jn.00070.2005. Irregular intrinsic behavior of neurons seems ubiquitous in the nervous system. Even in circuits specialized to provide periodic and reliable patterns to control the repetitive activity of muscles, such as the pyloric central pattern generator (CPG) of the crustacean stomatogastric ganglion (STG), many bursting motor neurons present irregular activity when deprived from synaptic inputs. Moreover, many authors attribute to these irregularities the role of providing flexibility and adaptation capabilities to oscillatory neural networks such as CPGs. These irregular behaviors, related to nonlinear and chaotic properties of the cells, pose serious challenges to developing deterministic Hodgkin-Huxley-type (HHtype) conductance models. Only a few deterministic HH-type models based on experimental conductance values were able to show such nonlinear properties, but most of these models are based on slow oscillatory dynamics of the cytosolic calcium concentration that were never found experimentally in STG neurons. Based on an up-to-date single-compartment deterministic HH-type model of a STG neuron, we developed a stochastic HH-type model based on the microscopic Markovian states that an ion channel can achieve. We used tools from nonlinear analysis to show that the stochastic model is able to express the same kind of irregularities, sensitivity to initial conditions, and low dimensional dynamics found in the neurons isolated from the STG. Without including any nonrealistic dynamics in our whole cell stochastic model, we show that the nontrivial dynamics of the membrane potential naturally emerge from the interplay between the microscopic probabilistic character of the ion channels and the nonlinear interactions among these elements. Moreover, the experimental irregular behavior is reproduced by the stochastic model for the same parameters for which the membrane potential of the original deterministic model exhibits periodic oscillations.

\section{IN T R O D U C TION}

The study of realistic models for the electrical behavior of neurons, where one can freely manipulate the dynamics of individual conductances and test several different hypothesis about the behavior of single cells, is an invaluable tool to address several questions that neurophysiologists have to deal with, such as: how individual conductances shape the cell behavior or what is the role of these individual cellular properties in determining the behavior of a complex network (Marder 1998). Even in the smallest networks these questions are far from being answered because the neurons are themselves highly nonlinear complex systems (Holden 1997; Izhikevich 2000; Rinzel and Ermentrout 1998).

Address for reprint requests and other correspondence: P. V. Carelli, Laboratório de Fenômenos Não-Lineares, Instituto de Física da Universidade de São Paulo, Cx. Postal.66318, Sao Paulo, SP, 05315-970 Brazil (E-mail: pcarelli@if.usp.br).
Model neurons, built on electrophysiological data from real neurons, not only constitute an adequate test-bed for hypotheses about the processes that generate a particular observed experimental behavior but can also be used to make predictions and orientate the experimenter to reveal new dynamics (Dayan and Abbott 2001; Marder 1998).

This closed loop of information exchange between experiments and models can reach really exciting new perspectives when we consider the possibilities of interfacing, in real-time, computer, or analog neuron models and living neural tissue in hybrid networks (Pinto et al. 2000; Prinz 2004; Szücs et al. 2000 ) to better understand on how the living network operates (Selverston et al. 2000), to restore the properties of damaged neural circuits (Szücs et al. 2000), to build circuits with new properties (Ayers 2004), or even to feed a living network with sensory data coming from artificial devices or to control such devices in brain machine interfaces (Nicolelis 2003).

Since the pioneer work introducing the voltage-clamp technique and mathematical modeling of electrical activity of the squid giant axon (Hodgkin and Huxley 1952), deterministic models of the behavior of ionic conductances have been adopted by neurophysiologists as the main paradigm of the macroscopic electrical behavior of nerve membranes.

The main reason for the success of such models is that they were able to put most of the electrical behavior of nerve cells, including the generation of action potentials, in a mathematically rigorous framework. Because most of the parameters of the model could be inferred almost directly from voltage-clamp experiments, where the contributions of many ionic populations to the current passing through the membrane can be separated and studied in detail, deterministic models became very popular among experimentalists (Dayan and Abbott 2001; Kandel et al. 1991).

These models are called deterministic in the sense that once specific initial conditions are chosen, the time integration of a set of differential equations (that model the specific membrane currents and other intracellular processes such as calcium buffering) determines a unique solution that represent the evolution of the membrane potential.

However, it is well known that the intrinsic electrical behavior of many living neurons is very far from deterministic. Experiments where cortical neurons were isolated and repeatedly presented with the same artificially generated current time series (Mainen and Sejnowski 1995) have shown that the spike timing reliability of the neurons depends on statistical proper-

The costs of publication of this article were defrayed in part by the payment of page charges. The article must therefore be hereby marked "advertisement" in accordance with 18 U.S.C. Section 1734 solely to indicate this fact. 
ties of the input signal in disagreement with deterministic predictions.

Even in circuits specialized to provide periodic and reliable patterns to control repetitive activity of muscles, such as the well studied pyloric central pattern generator $(\mathrm{CPG})$ of the crustacean stomatogastric ganglion (STG) (Mulloney and Selverston 1974; Selverston and Moulins 1986), most of the motor neurons of the circuit present variable and irregular bursting behavior when synaptically isolated (Elson et al. 1999; Rabinovich et al. 1997; Selverston et al. 2000).

Every time one of these neurons is isolated from the pyloric $\mathrm{CPG}$, it reveals a similar repertoire of irregular behaviors, but it is known that there are, at least, small changes in specific conductances from neuron to neuron and from animal to animal. In a mathematical sense, this means that if it is possible to write down equations to model the experimental behavior, these equations can never be specified exactly, yet similar behavior is expected from these equations when the parameters are allowed to vary. This is exactly the idea of structural stability from dynamical systems theory (Abraham and Shaw 1992).

So the irregular behavior, found to be related to nonlinear and chaotic properties of the cells (Falcke et al. 2000; Rabinovich et al. 1997), is structurally stable in a high-dimensional experimental parameter space, where the neurons are subject to small fluctuations not only in intrinsic properties but also in several other external parameters, such as temperature, ionic concentrations of the saline, etc.

The structural stability of the irregular behavior is a serious obstacle to developing deterministic Hodgkin-Huxley-type (HH-type) conductance models. In simple HH deterministic models of the axonal dynamics, the chaotic behavior was found to be structurally unstable because it was confined to a tiny volume of the parameter space (Guckenheimer and Oliva 2002). In more realistic models, where a dozen nonlinear equations are coupled, it could be intuitively expected that the higher complexity would enlarge the regions in the parameter space that correspond to irregular behaviors, providing structural stability to them. Surprisingly, this is not the case.

Recently, a very popular deterministic HH-type model for cultured stomatogastric neurons (Turrigiano et al. 1995), which is able to well reproduce tonic spiking and several regimes of bursting activity, was extensively studied (Prinz et al. 2003a) and a database of $\sim 1.7$ million different neurons (each 1 corresponding to a particular set of conductance values in a 8-dimensional conductance parameter space) was built to characterize the possible types of dynamical behavior. In the entire database, only $0.1 \%$ of the neurons corresponded to truly irregular behaviors (not related to spike adding transitions in periodic bursting behavior). Moreover, this small percentage of irregular neurons are not condensed in a specific region of the parameter space, instead, they are spread over the parameter space (Prinz et al. 2004), suggesting the irregular behavior is not structurally stable in this model.

Structurally stable complex or chaotic behaviors were only reported in a few deterministic models (Falcke et al. 2000; Komendantov and Kononenko 1996) that included a nonlinear model of the dynamics of calcium exchange between endoplasmic reticulum stores and the cytosol. The main appeal of such models is that the modulation of $\left[\mathrm{Ca}^{+2}\right]$ is a major way to regulate many cellular processes (Ikeda 2004). These models predict that the cell must present slow macroscopic oscillations of the cytosolic levels of calcium. Such $\left[\mathrm{Ca}^{+2}\right]$ oscillations were observed experimentally in some vertebrates neurons (Parri and Crunelli 2001; Zhang et al. 2003) but not in STG cells (Levi et al. 2003)

The reasons why realistic deterministic models fail to reproduce the variability of the living behavior are the simplifications introduced by the voltage-clamp method and by the modeling. When a neuron is voltage-clamped, the experimenter has no access to the real spatial distribution of its membrane potential but only to a single point measurement that is taken as a good approximation for the membrane potential all over the neuron. Also, the discrete probabilistic character of the opening/closing of the membrane ion channels (Hille 2001; Levitan and Kaczmarek 1997) is replaced by average conductance activations/ inactivations. These two simplifications make it possible to write much simpler differential equations, more amenable to analysis or simulations than complex multicompartment models with probabilistic channels. Moreover, because most of the experimental efforts made to characterize the currents present in STG neurons were made in cultured cells submitted to whole cell voltage clamp, there is not enough data to decide, without any speculative assumptions, neither how many compartments are needed, nor how to segregate or how to split the many different conductances among compartments.

However, some of the lost properties can be recovered even in a still limited single-compartment model by using a stochastic model based on Markovian states of ion channels (Desthexhe et al. 1994) where the probabilistic nature of channel operation is an intrinsic property (Hille 2001; Skaugen and Walloe 1979; White et al. 1998, 2000) and no additive noise needs to be included. If we consider a simple Markovian model of a population of channels of a specific type with only two possible and independent states (closed or open), the average number of channels $(N)$ that are expected to suffer a transition from closed to open state in a given time interval can be easily obtained from the $\mathrm{HH}$ opening rate. The fluctuation (SD) of the number of channels that eventually undergo the transition is of the order of $\sqrt{N}$. Considering $N$ to be $\sim 10^{6}$ (for axonal sodium channels) the fluctuation represents only $0.1 \%$ of $N$, and the behavior of the stochastic sodium current is practically the same as the one presented by the deterministic model. However, if one considers that action potentials are generated in the spike initiation zone, a much smaller region than the whole axon, with just $\sim 10^{3}$ to $10^{4}$ sodium channels and that the spikes are then propagated to other regions of the cell membrane, the fluctuation of the number of channels suffering the transition from closed to open can be $2 \%$ of $N$, enough to produce macroscopic effects.

Based on this mechanism of enhancement of the effects of the fluctuations of smaller numbers of ion channels, a stochastic model of an axon membrane patch (Schneidman et al. 1998) was compared with its deterministic version, and it was shown that the stochastic model is able to reproduce the same spike time reliability properties found in living neurons (Mainen and Sejnowski 1995) where the deterministic model fails.

Inspired by the success of the stochastic axon patch and by the fact that in stomatogastric neurons the slow ionic conductances, responsible for the starting and stopping of a burst of action potentials, are several orders of magnitude smaller than 
the conductances for axonal sodium and potassium (Prinz et al. 2003b), we present a single compartment stochastic HH-type model for a whole stomatogastric neuron.

The stochastic model presented here was obtained by translating to stochastic an up-to-date deterministic model for a stomatogastric neuron (Prinz et al. 2003b; Turrigiano et al. 1995). Our stochastic algorithm was adapted from a method developed for simulation of chemical reactions (Gillespie 1977) and later implemented for nonlinear membrane conductances (Skaugen and Walløe 1979), and although computationally intensive, it is considered an exact algorithm (Mino et al. 2002).

The translation of the deterministic model was carefully done in order not to change or include any new dynamics or ad hoc noise sources that were not present in the original model, so rather than comparing our results to the behavior of real living stomatogastric neurons, we can directly compare them to the results of the deterministic model when using the same parameters (maximum conductances of the different ion channel types), and the nonperiodic dynamics can be fully attributed to the role of the stochastic nature of the channels' behavior in generating macroscopic fluctuations of the membrane potential.

The present paper deals with data analysis using several tools from nonlinear dynamics to characterize and compare the results between the models and the ones reported in experiments. Bifurcation diagrams, return maps of interspike intervals (ISIs), reconstruction of dynamic attractors in phasespace, and Lyapunov exponents are used for identification and analysis of several types of neuronal activity (Abarbanel 1996; Hegger et al. 1999).

The beauty of the model presented here is that it allows the recovery of the irregularities found in real neurons by building up chaotic like global events from local stochastic dynamics that were directly translated from a realistic single-compartment deterministic model that does not itself exhibit any structurally stable chaotic behavior. Preliminary reports on the progress of our findings have been previously published in abstract form (Carelli and Pinto 2004; Carelli et al. 2004).

METHODS

\section{Deterministic model}

The deterministic HH-type model used in this paper is a singlecompartment version based on voltage-clamp experiments of cultured STG neurons (Prinz et al. 2003b; Turrigiano et al. 1995). With appropriate tuning of the ion conductances this model is able to mimic very well both periodic bursting and tonic firing patterns. The behavior of different cells of the pyloric CPG as well as general properties of other bursting neurons can be, in principle, mimicked by fine tuning the maximal conductances of the model.

We used a sixth-order Runge-Kutta algorithm, with a fixed time step of $10 \mu$ s, implemented in a program written in $\mathrm{C}++$ language on an Athlon XP-2400 PC-compatible computer to integrate the set of nonlinear differential equations of the model.

The membrane potential dynamics is given by

$$
\frac{\mathrm{d} V}{\mathrm{~d} t}=\frac{1}{C_{\mathrm{m}}}\left[I_{\mathrm{ext}}-\sum_{i} g_{i}\left(V-V_{i}\right)\right]
$$

where $V$ is the membrane potential, $C_{\mathrm{m}}$ is the membrane capacitance, $I_{\text {ext }}$ is an external current that can be either used to tune the model to a desired behavior or to simulate synaptic input, $V_{i}$ is the reversal potential of the ion of the conductance of type $i$ calculated from the Nernst equation. $g_{i}$ is the instantaneous value of the conductance of type $i$, expressed by

$$
g_{i}(V, t)=\bar{g}_{i} m_{i}^{\gamma_{i}} h_{i}^{\delta_{i}}
$$

where $\bar{g}_{i}$ is the maximum conductance of type $i, m_{i}$ and $h_{i}$ are the $\mathrm{HH}$ activation and inactivation variables that assume values in the interval $[0,1], \gamma_{i}$ and $\delta_{i}$ are integers chosen to fit the experimental data.

The model includes two types of spike generating conductances: sodium $(i=\mathrm{Na})$ and rectifier potassium $\left(i=K_{\mathrm{d}}\right)$, as well as five types of slower conductances: $C a_{\mathrm{T}}$ (transient calcium), $C a_{\mathrm{S}}$ (slow calcium), $K_{\text {[Ca] }}$ (calcium-dependent potassium), $A$ (adaptation current), and $H$ (hyperpolarization-activated current).

The dynamics of $m_{i}$ and $h_{i}$ (for all conductances but $K_{[\mathrm{Ca}]}$ ) is determined by

$$
\begin{aligned}
\frac{\mathrm{d} m_{i}}{\mathrm{~d} t} & =\frac{m_{i, \infty}(V)-m_{i}(t)}{\tau_{m_{i}}(V)} \\
\frac{\mathrm{d} h_{i}}{\mathrm{~d} t} & =\frac{h_{i \infty}(V)-h_{i}(t)}{\tau_{h_{i}}(V)}
\end{aligned}
$$

where $m_{i \infty}, \tau_{m}, h_{i \infty \infty}, \tau_{h,}$ are the sigmoidal functions (shown in Table 1) inferred from voltage-clamp experimental data. The activation variable of the calcium-dependent potassium conductance, different from the others that depend only on the membrane potential, also depends on the calcium concentration.

There is a simple calcium buffer based on the competition between the mechanism of $\mathrm{Ca}^{2+}$ extrusion and the $\mathrm{Ca}^{2+}$ influx through $\mathrm{Ca}_{\mathrm{T}}$ and $\mathrm{Ca}_{\mathrm{S}}$ channels, expressed by

$$
\frac{\mathrm{d}\left[\mathrm{Ca}^{2+}\right]}{\mathrm{d} t}=-\frac{1}{\tau_{\mathrm{Ca}}}\left(f *\left(I_{\mathrm{CaT}}+I_{\mathrm{CaS}}\right)+\left[\mathrm{Ca}^{2+}\right]-\left[\mathrm{Ca}^{2+}\right]_{0}\right)
$$

where $f,\left[\mathrm{Ca}^{2+}\right]_{0}$, and $\tau_{\mathrm{Ca}}$ are constants. More details of the deterministic model can be found in Prinz et al. (2003b) and Turrigiano et al. (1995).

The parameters used in our simulations were 1) $C_{\mathrm{m}}=1.0 \mu \mathrm{F} / \mathrm{cm}^{2}$; 2) maximal conductances $\left(\bar{g}_{i}\right)$ in $\mathrm{mS} / \mathrm{cm}^{2}: 200$ for $\mathrm{Na}^{+}, 100$ for $K_{\mathrm{d}}, 2.5$ for $C a_{\mathrm{T}}, 4.0$ for $C a_{\mathrm{S}}, 5.0$ for $K_{[\mathrm{Ca}}, 50$ for $A, 0.01$ for $H, 0.01$ for the leak current; 3) reversal potentials in $\mathrm{mV}:+50$ for $\mathrm{Na}^{+},-80$ for $K_{\mathrm{d}}$, $K_{[\mathrm{Ca}]}$, and $A,-50$ for the leak current, and -20 for $H$. Since the intracellular concentration of calcium is not constant, $V_{\mathrm{Ca}}$ is computed as a function of $\left[\mathrm{Ca}^{2+}\right]$ considering an external calcium concentration of $3,000 \mu \mathrm{M}$, according to the Nernst equation

$$
V_{\mathrm{Ca}}=12.5 \ln \left(\frac{3000}{\left[\mathrm{Ca}^{2+}\right]}\right)
$$

And 5) calcium buffer: $\tau_{\mathrm{Ca}}=200 \mathrm{~ms}, f=14.96 \mu \mathrm{M} / \mathrm{nA},[\mathrm{Ca}]_{O}=0.5$ $\mu \mathrm{M}$.

The initial conditions used in the simulations were: $V_{\mathrm{m}}=-55.0$ $\mathrm{mV},\left[\mathrm{Ca}^{2+}\right]=0.5 \mu \mathrm{M}, m_{\mathrm{Na}}=0.9$. All other activation and inactivation variables were initialized to 0.1 , and an initial transient of $10 \mathrm{~s}$ was disregarded in all simulations to ensure stability of the time series.

\section{Stochastic version}

The stochastic version of the model was also implemented in a $\mathrm{C}++$ written program and ran on the same computer used for the simulations of the deterministic model. An Euler algorithm with a time step of $10 \mu$ s was used to integrate the differential equations for $V$ and $\left[\mathrm{Ca}^{2+}\right]$. Although these equations were kept unchanged from the deterministic model, $g_{i}$ now is expressed as

$$
g_{i}(V, t)=n_{i}\left(A_{m}, V, t\right) \phi
$$

where $n_{i}\left(A_{m}, V, t\right)$ is the total number of channels of type $\mathrm{i}$ in the open and activated state at a given time for a neuronal membrane with 
TABLE 1. Steady-state activation and inactivation functions and exponents underlying the dynamics of the deterministic model

\begin{tabular}{|c|c|c|c|c|c|c|}
\hline$I_{\mathrm{Na}}$ & 3 & 1 & $\frac{1}{1+e^{\left(\frac{V+25.5}{-5.29}\right)}}$ & $\frac{1}{1+e^{\left(\frac{V+48.9}{5.18}\right)}}$ & $2.64-\frac{2.52}{1+e^{\left(\frac{V+120}{-25}\right)}}$ & $\frac{1.34}{1+e^{\left(\frac{V+62.9}{-10}\right)}} *\left(1.5+\frac{1}{1+e^{\left(\frac{V+34.9}{3.6}\right)}}\right)$ \\
\hline$I_{\mathrm{CaT}}$ & 3 & 1 & $\frac{1}{1+e^{\left(\frac{V+27.1}{-7.2}\right)}}$ & $\frac{1}{1+e^{\left(\frac{V+32.1}{5.5}\right)}}$ & $43.4-\frac{42.6}{1+e^{\left(\frac{V+68.1}{-20.5}\right)}}$ & $210-\frac{179.6}{1+e^{\left(\frac{V+55}{-16.9}\right)}}$ \\
\hline$I_{\mathrm{CaS}}$ & 3 & 1 & $\frac{1}{1+e^{\left(\frac{V+33}{-8.1}\right)}}$ & $\frac{1}{1+e^{\left(\frac{V+60}{6.2}\right)}}$ & $2.8+\frac{14}{\mathrm{e}^{\left(\frac{V+27}{10}\right)}+e^{\left(\frac{V+70}{-13}\right)}}$ & $120+\frac{300}{e^{\left(\frac{V+55}{9}\right)}+e^{\left(\frac{V+65}{-16}\right)}}$ \\
\hline$I_{\mathrm{A}}$ & 3 & 1 & $\frac{1}{1+e^{\left(\frac{V+27.2}{-8.7}\right)}}$ & $\frac{1}{1+e^{\left(\frac{V+56.9}{4.9}\right)}}$ & $23.2-\frac{20.8}{1+e^{\left(\frac{V+32.9}{-15.2}\right)}}$ & $77.2-\frac{58.4}{1+e^{\left(\frac{V+38.9}{-26.5}\right)}}$ \\
\hline$I_{\mathrm{K}(\mathrm{Ca})}$ & 4 & 0 & $\frac{[\mathrm{Ca}]}{[\mathrm{Ca}]+3} * \frac{1}{1+e^{\left(\frac{V+28.3}{-12.6}\right)}}$ & & $180.6-\frac{150.2}{1+e^{\left(\frac{V+46}{-22.7}\right)}}$ & \\
\hline$I_{\mathrm{Kd}}$ & 4 & 0 & $\frac{1}{1+e^{\left(\frac{V+12.3}{-11.8}\right)}}$ & & $14.4-\frac{12.8}{1+e^{\left(\frac{V+28.3}{-19.2}\right)}}$ & \\
\hline
\end{tabular}

Observe that in the cases were $\delta=0$, there is no inactivation and thus the corresponding expressions are left blank $\left(h_{i}=1\right)$. Voltages are in $m V$, time constants are in $m s$.

surface area $A_{m}$, and $\phi$ is the conductance of a single ion channel, here for simplicity considered to be $20 \mathrm{pS}$ for all channel types. The total number of channels of type $i, N_{i}$ is thus obtained from the maximal conductances of the deterministic model as the closest integer to

$$
\frac{\bar{g}_{i} \cdot A_{\mathrm{m}}}{\phi}
$$

The average opening and closing rates, $\alpha_{m_{1}}$ and $\beta_{m_{1}}$ are obtained directly from the sigmoidal expressions given in Table 1 , according to

$$
\alpha_{m_{i}}=\frac{m_{i, \infty}}{\tau_{m_{i}}}, \beta_{m_{i}}=\frac{1-m_{i, \infty}}{\tau_{m_{i}}}
$$

The same method is used to obtain $\alpha_{h_{i}}$ and $\beta_{h_{i}}$, the rates of activation and inactivation.

A microscopic Markovian kinetic description is considered for representing the states that each ion channel can assume. Based on the current interpretation given to the exponents $\gamma_{i}$ and $\delta_{i}$, empirically inferred by $\mathrm{HH}$, each channel of type $i$ is modeled as a microscopic protein formed by $\gamma_{i}$ gating subunits and $\delta_{i}$ inactivating subunits. All subunits in a channel act independently, according to the probabilities of transition given by their $\alpha$ 's and $\beta$ 's. To allow the flow of current, an ion channel must have all its $\gamma_{i}$ gating subunits in the open state and all its $\delta_{i}$ inactivating subunits in the activated state. $K_{[\mathrm{Ca}]}$ channels have more complex microscopic structures and more than one open state because of the $\left[\mathrm{Ca}^{2+}\right]$ dependence of the channels, but here we are not considering the effects of the stochastic binding of ions $\mathrm{Ca}^{2+}$ to the $K_{[\mathrm{Ca}]}$ channel binding sites. To keep the fidelity to the deterministic version the $\left[\mathrm{Ca}^{2+}\right]$ dependence is only included in the evaluation of $\mathrm{m}_{\infty \mathrm{K}_{\left[\mathrm{C}_{\mathrm{a}}\right]}}$.

According to this formalism, the Markovian kinetic scheme of states for $H$ channels is the simplest one

$$
\left[\mathrm{m}_{0}\right] \underset{\beta_{\mathrm{m}_{\mathrm{H}}}}{\stackrel{\alpha_{\mathrm{m}_{\mathrm{H}}}}{\rightleftharpoons}}\left[\mathrm{m}_{1}\right]
$$

[ $\left.m_{i}\right]$ represents the number of $H$ channels in the state $m_{i}$ and the open state is $m_{1}$. The total conductance provided by all open $H$ channels is given by $g_{H}(V, t)=\left[m_{i}\right](V, t) \phi$.
The kinetic scheme for $K_{\mathrm{d}}$ and $K_{\text {[Ca] }}$ channels is

$$
\left[m_{0}\right] \underset{\beta_{m_{i}}}{\stackrel{4 \alpha_{m_{i}}}{\rightleftharpoons}}\left[m_{1}\right] \underset{2 \beta_{m_{i}}}{\stackrel{3 \alpha_{m_{i}}}{\rightleftharpoons}}\left[m_{2}\right] \underset{3 \beta_{m_{i}}}{\rightleftharpoons}\left[m_{3}\right] \underset{4 \beta_{m_{i}}}{\stackrel{\alpha m_{i}}{\rightleftharpoons}}\left[m_{4}\right]
$$

The open state is $m_{4}$ and $g_{i}(V, t)=\left[m_{4}\right](V, t) \phi$.

Because the $\mathrm{Na}, C a_{\mathrm{T}}, C a_{\mathrm{S}}$, and $A$ channels also have inactivation dynamics, a more complex scheme was used

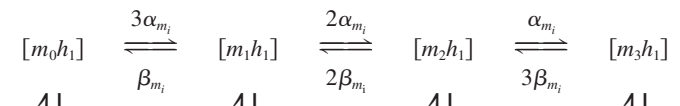

$$
\begin{aligned}
& \alpha_{h_{i}} 1_{\beta_{h_{i}}}{ }^{\beta_{m_{i}}} \alpha_{h_{i}}\left\|_{\beta_{h_{i}}}^{2 \beta_{m_{\mathrm{i}}}} \alpha_{h_{i}} 1_{\beta_{h_{i}}}^{3 \beta_{m_{i}}} \alpha_{h_{i}}\right\|_{\beta_{h_{h}}} \\
& {\left[m_{0} h_{0}\right] \stackrel{3 \alpha_{m_{i}}}{\rightleftharpoons} \underset{\beta_{m_{i}}}{\rightleftharpoons}\left[m_{1} h_{0}\right] \underset{2 \beta_{m_{i}}}{\stackrel{2 \alpha_{m_{i}}}{\rightleftharpoons}}\left[m_{2} h_{0}\right] \underset{3 \beta_{m_{i}}}{\stackrel{\alpha_{m_{i}}}{\rightleftharpoons}}\left[m_{3} h_{0}\right]}
\end{aligned}
$$

Here the open state is $m_{3} h_{1}$ and $g_{i}(V, t)=\left[m_{3} h_{1}\right](V, t) \phi$.

The key feature of the translation of the model consists in recovering the stochastic character of ion channel operation by giving a probabilistic interpretation to the original $\mathrm{HH}$ rates of transition between open and closed states (Schneidman et al. 1998) that is reflected in the number of open and activated channels $n_{i}(V, t)$. If we know the population $N_{j}$ of channels in state $j$ and the transition rate $r_{j k}$ from state $j$ to state $k$, then in the time interval $\Delta t$, the mean number of channels expected to suffer this transition is $\overline{\Delta N}_{j k}=N_{j} \Delta t r_{j k}$. Because the probability of transition for one channel is $P=\Delta t r_{j k}$, we can find the number $\Delta N_{j k}$ of channels that jump from the state $j$ to the state $k$ by choosing a random number from the binomial distribution of probabilities

$$
\operatorname{prob}\left(\Delta N_{j k}\right)=\left(\begin{array}{c}
N_{j} \\
\Delta N_{j k}
\end{array}\right) p^{\Delta N_{j k}(1-p)^{N_{j}-\Delta N_{j k}}}
$$

The main drawback of the stochastic model is that the binomial distribution requires intensive computation and the simulation of long time series can become infeasible. To surmount this constraint, we used an approximation for the exact binomial distribution. When the mean of the binomial distribution is bigger than five, the distribution has a symmetric shape, and a Gaussian approximation is possible. However when $0 \leq$ mean $\leq 5$, the binomial is asymmetric, and the 

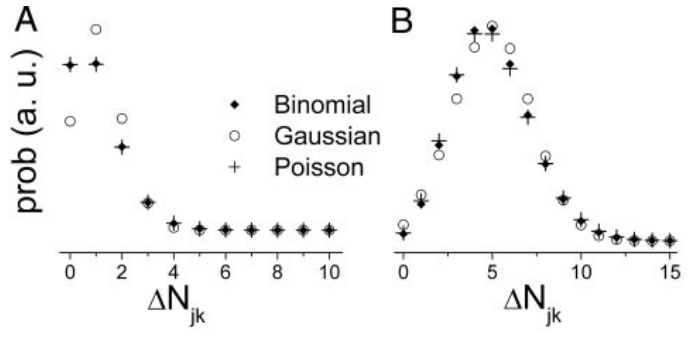

Poisson distribution becomes a good approximation, as can be seen in Fig. 1. Our simulation program automatically detects and uses the best approximation for the current mean value of the distribution.

All values of parameters used in the simulations of the stochastic version are either the same as in the deterministic model or obtained from them.

The initial conditions used in the simulations were: $V_{m}=-55.0$ $\mathrm{mV},\left[\mathrm{Ca}^{2+}\right]=0.5 \mu \mathrm{M}$. The total number of channels of each channel type was obtained using the conductances of the deterministic model and considering a membrane area of $6.28 \times 10^{-4} \mathrm{~cm}^{2}$, a typical value for a stomatogastric neuron. The total number of channels of each type $\left(N_{i}\right)$ and the initial number of channels in each population were chosen as follows: $\mathrm{Na}^{+}: N_{\mathrm{Na}}{ }^{+}=6.28 \times 10^{6}$, initial number of channels in each one of the eight possible states $=N_{\mathrm{Na}}{ }^{+} / 8 ; K_{\mathrm{d}}: N_{\mathrm{Kd}}=3.14 \times$ $10^{6}$, initial number of channels in each one of the five possible states $=N_{\mathrm{Kd}} / 5 ; C a_{\mathrm{T}}: N_{\mathrm{CaT}}=7.85 \times 10^{4}$, initial $\left[m_{0} h_{0}\right]=$ initial $\left[m_{0} h_{1}\right]=N_{\mathrm{CaT}} / 2$, all other initial $\left[m_{i} h_{j}\right]=0 ; C a_{\mathrm{S}}: N_{\mathrm{CaS}}=1.25 \times 10^{5}$, initial $\left[m_{0} h_{0}\right]=$ initial $\left[m_{0} h_{1}\right]=N_{\mathrm{CaS}} / 2$, all other initial $\left[m_{i} h_{j}\right]=0$; $K_{[\mathrm{Ca}]}: N_{\mathrm{K}[\mathrm{Ca}]}=$ initial $\left[m_{0}\right]=1.57 \times 10^{5}$, all other initial $\left[m_{i}\right]=0$; $A: N_{A}=1.57 \times 10^{6}$, initial $\left[m_{0} h_{0}\right]=$ initial $\left[\mathrm{m}_{0} \mathrm{~h}_{1}\right]=N_{A} / 2$, all other initial $\left[m_{i} h_{j}\right]=0 ; H: N_{H}=\left[m_{0}\right]=314$, all other initial $\left[m_{i}\right]=0$.

Using these initial conditions, the simulation of the stochastic model neuron starts with a spike that is followed by a fast convergence of the ionic populations to dynamical "steady-state" values.

When not specified in the text, an initial transient of $10 \mathrm{~s}$ was disregarded.

\section{Mixed (stochastic/deterministic) model}

A third program in which it is possible to choose each individual current to be stochastic or deterministic was also written. We used this program to test the role of each ion channel type in producing irregular behavior. When a current is chosen to be stochastic, the simulation method described in Stochastic version is used for that current, and when the current is deterministic the method described in Deterministic model is used, however, in this case, the program integrates the activation/inactivation variables using an Euler method instead of the Runge-Kutta. The use of different integration methods, in this case, do not impact the results shown. We performed several tests using both Euler and Runge-Kutta methods for the deterministic model, and it behaved in a perfectly periodic fashion in both cases.

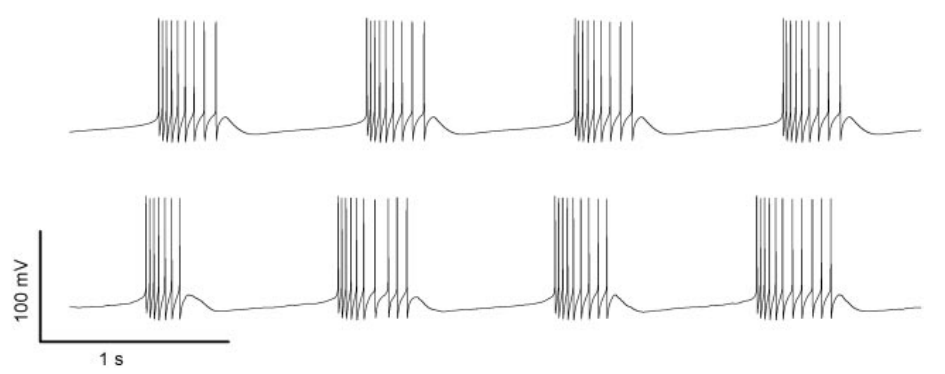
rent injection.

\section{Data analysis}

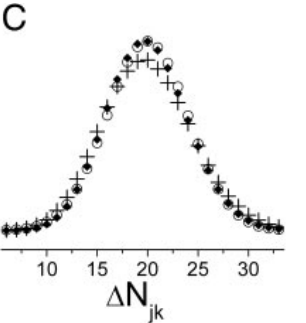

FIG. 1. Comparative graphics of the exact disribution (binomial) and the 2 approximations used in our simulations. The Poisson distribution is a good approximation when the binomial is asymmetric, for values of the mean $<5$ as shown in $A$ and $B$. However, a Gaussian distribution is the best approximation of the binomial in the cases it is symmetric, which happens for values of the mean $>5$ as shown in $C$

\section{Stomatogastric isolated neuron}

To allow a direct comparison between the results of the simulations and the behavior of a real neuron, the membrane potential of an isolated lateral pyloric (LP) neuron from the stomatogastric ganglion of the spiny lobster Panulirus interruptus was recorded. The nervous system was dissected from the animal, the ganglion was prepared for intracellular recordings, and the cells were identified as described in Mulloney and Selverston 1974. The synaptic isolation of the LP neuron was done by using standard pharmacological and cell-killing techniques (Bal et al. 1988; Miller and Selverston 1979). In short, glutamatergic synapses were blocked by using lobster saline with 10 $\mu \mathrm{M}$ picrotoxin, and the two pyloric dilators (PD) and the ventral dilator (VD) neurons were photoinactivated. The LP was impaled with two electrodes for separated membrane potential recording and cur-

Data analysis was performed in the original simulated time series as well as in the interspike intervals (ISIs) sequences obtained from them. ISIs were detected in the time series using a simple threshold method implemented in a home-made $\mathrm{C}++$ program: every time the membrane potential crossed a $0.0-\mathrm{mV}$ threshold level with positive derivative a spike was attributed to the model neuron. Nonlinear analysis methods were applied to the original time series and in the ISI series: we used the method of false nearest neighbors (Abarbanel 1996; Kennel et al. 1992) to calculate the embedding dimension of the dynamical attractor reconstructed from the simulated data and calculated the positive Lyapunov exponent (Sano and Sawada 1985), which is a measure of the presence of sensitivity to initial conditions and chaos in a system. We used algorithms from the package TISEAN (Hegger et al. 1999) in our nonlinear analysis.

RESULTS AND ANALYSIS

A first comparison of the dynamical behavior of the deterministic and the stochastic model is shown in Fig. 2 where the time series obtained from both models for the same values of parameters are plotted.

FIG. 2. Typical time series of the membrane potential obtained for the deterministic model (top) and for the stochastic version (bottom). The same values of parameters (shown in METHODS) were used in both models. Although the deterministic model presented a periodic pattern of bursts, the duration of the bursts, the number of spikes/burst and the duration of the hyperpolarizations are all irregularly variable in the stochastic version. 
TABLE 2. Main statistical properties of the bursting activity of the deterministic and the stochastic models as well as the same values obtained from a time series of an isolated LP neuron

\begin{tabular}{lrcc}
\hline \hline & Deterministic & & \\
& Model & Stochastic Model & LP Neuron \\
\hline Oscillation period, ms & 1102 & $1049 \pm 65(6 \%)$ & $820 \pm 140(17 \%)$ \\
Burst duration, ms & 305 & $237 \pm 60(25 \%)$ & $230 \pm 80(35 \%)$ \\
Spikes/burst & 9 & $7.9 \pm 1.1(14 \%)$ & $11.3 \pm 1.6(14 \%)$ \\
\hline
\end{tabular}

The stochastic model presents a tendency of producing oscillations with shorter period and burst duration as well as a smaller number of spikes/bursts than the deterministic model. The models were not tuned to reproduce the lateral pyloric (LP) neuron behavior, but it is clear that the real neuron, excepting the number of spikes/burst, presents a higher variability in its oscillations than the stochastic model, however, the deterministic model presents no variability at all.

As can be seen in Fig. 2, irregular activity is obtained in the stochastic model, where the original deterministic model presented only regular oscillations. However, the activity of the stochastic model still resembles the main characteristics of the deterministic model as shown in Table 2.

There is a tendency of the stochastic model to present shorter bursts and smaller number of spikes/burst than the deterministic model. This fact was found to be related to the behavior of the $\mathrm{Ca}^{2+}$ and $K_{[\mathrm{Ca}]}$ stochastic conductances as will be further discussed later.

As a first attempt to identify how much determinism there is in the time series, we followed the time evolution of the membrane potential when the model neurons start from close initial conditions. After a hyperpolarization, the conductances of the neuron are reset to similar values at every burst, so we detected the first spike of the neurons after the hyperpolarizations and used these first spikes to trigger a plot of superimposed bursts. In Fig. 3 we plotted 50 superimposed bursts for each model. The bursts of the deterministic model are all identical, so the superimposed bursts appear just as a single curve that repeats over and over. However, in the stochastic model, only the first spikes overlap, then the precision of the spiking time decreases with the higher order of the spike in the burst and the last spike is very unreliable, consequently the burst end is highly variable. The picture for the stochastic model clearly reproduces the behavior of isolated biological neurons and suggests the small differences present in the afterhyperpolarization are amplified in the stochastic model as is the case in a nonlinear system with sensitivity to the initial conditions. Further experimental data for comparison can be found in Selverston et al. (2000).

Another way used to analyze the behavior of the models during the bursting activity was to detect their ISIs and to plot their ISI return maps (ISI ${ }_{n+1}$ vs. ISI $_{n}$ ) as shown in Fig. 4.
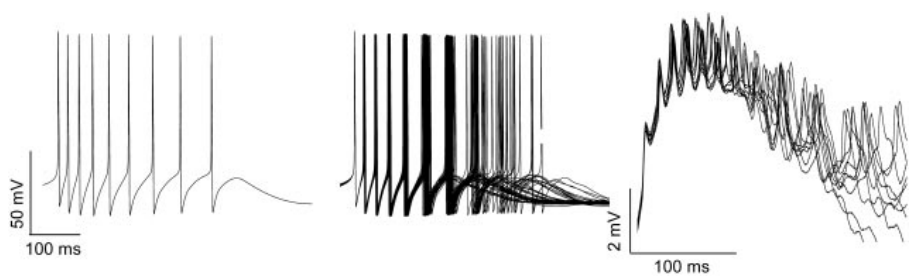
FIG. 3. The 1st spike of each burst was used as a trigger to align and superimpose different bursts $(n=50)$ and simulate similar initial conditions for both models. All the spikes and bursts of the deterministic model (left) are precisely and identically repeated time after time and the pattern obtained is a narrow curve. Superimposition bursts of the lateral pyloric (LP) neuron (right) shows different properties: the precision decreases for each successive spike, and the burst end is very unreliable, as is the case in a nonlinear system with sensitivity to initial conditions. The stochastic model (middle) mimics very well the observed gradual decreasing of the spike timing precision. 

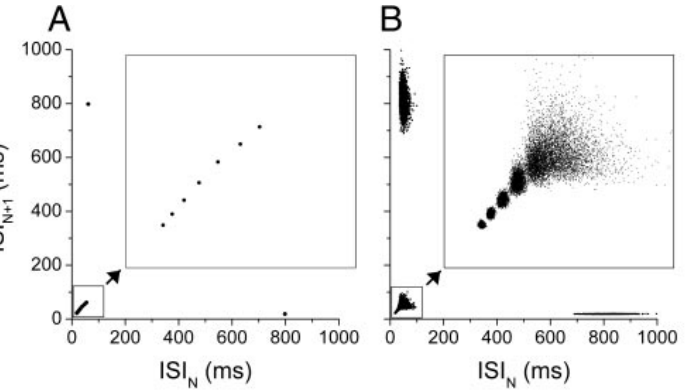

stochastic model (Fig. 7, right), however, the transition from bursting to tonic firing is not so clear. For a range of current values in which the deterministic model is already tonic $\left(0.17<I_{\text {ext }}<0.28 \mathrm{nA}\right)$, the stochastic model switches between irregular tonic firing and bursting behavior.

Some works in the literature (Falcke et al. 2000; Selverston et al. 2000) indicate that the LP neuron presents statistical dynamical properties compatible with deterministic chaos. This analysis assumes that the neurons have deterministic dynamical evolution rules. We applied the same analysis to our stochastic model time series, as if they were experimentally obtained, to show that our results are compatible with those from real neurons.

The phase space of the time series was reconstructed by using delayed coordinates (Abarbanel 1996), and the embedding dimension (the minimum number of dynamical variables needed to fully detangle the dynamical attractor) was estimated to be three by the method of false nearest neighbors. This is in agreement with experimental results (Falcke et al. 2000; Selverston et al. 2000).

The Lyapunov spectrum of the stochastic model time series, calculated by using the package TISEAN, has one positive exponent $\left(\lambda_{1}=0.050 \mathrm{~ms}^{-1}\right)$, one exponent that lies very close to zero $\left(\lambda_{2}=-0.007 \mathrm{~ms}^{-1}\right)$ and a negative exponent $\left(\lambda_{3}=\right.$ $\left.-0.070 \mathrm{~ms}^{-1}\right)$. The sum of all exponents is negative, as expected for a dissipative system where the trajectories are confined in a finite region of the phase space. From the Lyapunov exponents, the Kaplan-Yorke fractal dimension was estimated to be 2.6. Considering that we are using a singlecompartment model, with large stereotyped spikes and without

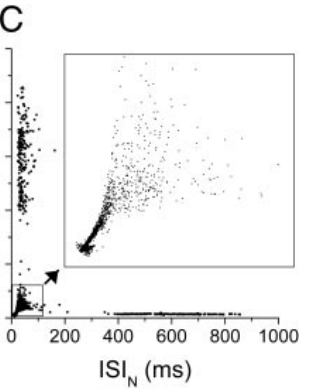

FIG. 4. ISI return maps from $3,000 \mathrm{~s}$ of the activity of both models and $\sim 200$ s of LP activity. In each graph, we show an amplified region corresponding to intraburst ISIs. The deterministic model $(A)$ presents a very precise and repetitive pattern of ISIs. However, in the LP neuron (C), when intra-burst ISIs of higher order are considered the precision decreases in the same fashion as it happens in the stochastic version $(B)$.

$\mathrm{ISI}_{\mathrm{N}}(\mathrm{ms})$

deep hyperpolarizations, these results are compatible to the ones found in Falcke et al. (2000).

Because most of the works where the stochastic nature of the ion channels was considered relied on the effects of the fluctuations produced by a small population of channels (Rowat and Elson 2004; Schneidman et al. 1998; Skaugen and Walloe 1979; White et al. 1998), there is another important question about the irregularities reproduced by our stochastic model: How robust are these irregularities to changes in the number of channels considered in the model (surface of the neuronal membrane). To address this question, we ran the stochastic model for many different sizes of the membrane and plotted the ISI bifurcation diagram as a function of the membrane area, as shown in Fig. 8. As the area is increased, the ISIs of the stochastic model become more reliable and the model behavior tends to be more periodic. In the limit of the area going to infinity, the periodic behavior of the deterministic model is recovered, as one can see by comparing the scattered ISIs of the stochastic model with the deterministic model ISIs (which are area independent) shown in the right of the figure as small horizontal segments. The stochastic nature of ion channels is indeed important for the behavior of an STG neuron, as we can see in the irregular behavior pointed to by the arrow at the left of Fig. 8.

To identify which are the conductances that play more important roles in generating the irregularities showed by the stochastic model we implemented mixed models, as explained in Mixed (stochastic/deterministic) model, where we could choose each individual current either to be stochastic or deterministic. The results of several mixed models are resumed in

\section{Deterministic \\ LP}

우

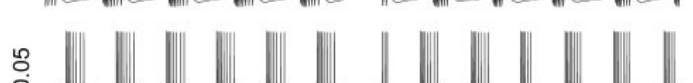

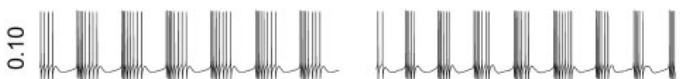

$\stackrel{\circ}{\circ}$

ํㅗㅇ

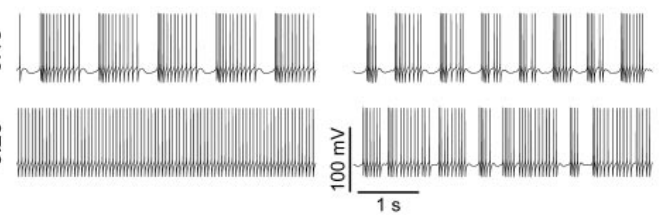

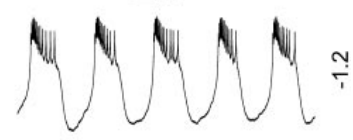
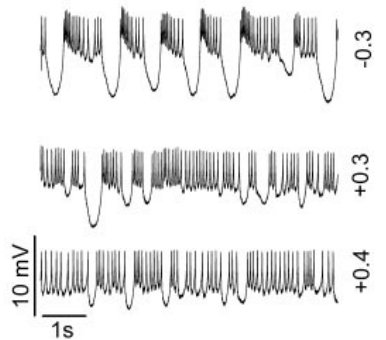

FIG. 5. Examples of the behavior of both model neurons and the LP under injection of a DC current (side labels in $\mathrm{nA}$ ). The current increases top-down. In the deterministic model the number of spikes/burst increases with the current, longer and longer periodic bursts are produced, until a tonic firing regime is reached. In the stochastic model, the average number of spikes/burst also increases, but there are short bursts mixed with long ones as it happens in the LP. Moreover, the stochastic model has a more persistent bursting behavior than the deterministic model, as it keeps bursting for the same value of current that produces tonic firing in the deterministic model. 
A

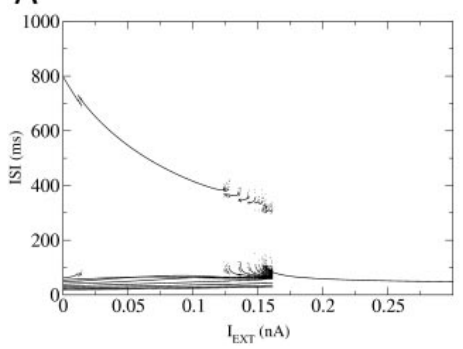

B

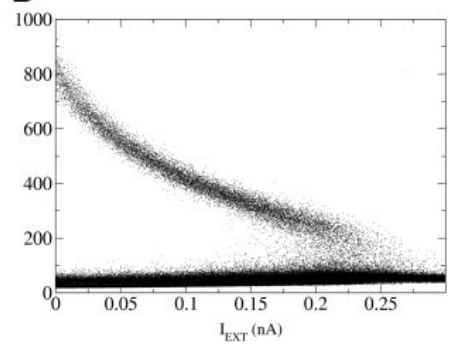

FIG. 6. ISI bifurcation diagram obtained for both models when an external DC current is injected in the neurons. Twenty seconds of the membrane potential was recorded for each value of current. In the deterministic model (left), the only irregularities found are due to intermittent bursts with $N$ spikes and $n+1$ spikes, which is characteristic of a period adding bifurcation. For $I_{\text {ext }} \approx 0.16 \mathrm{nA}$, there is sudden transition between bursting behavior and tonic spiking. In the stochastic model the period adding bifurcation is not clearly present and the sudden transition does not take place, instead, the interburst ISI intervals get smaller and smaller to finally mix with the intraburst ISIs.
Fig. 9 where we plotted statistical properties of models where each one of the currents was made stochastic alone and the other currents were kept deterministic. We also compare the results with those obtained when all currents are stochastic and when all the currents but $\mathrm{Na}^{+}$and $\mathrm{K}_{\mathrm{d}}$ are stochastic.

The main currents responsible for the variability found in the stochastic model are: $I_{\mathrm{CaT}}, I_{\mathrm{CaS}}, I_{\mathrm{K}(\mathrm{Ca})}$, known to be the "slow wave" or "plateau" currents in living neurons and $I_{\mathrm{A}}$, the adaptation current. This is not surprising because the two calcium currents have a special relation with their competing $K_{\text {[Ca] }}$ current: they change the cytosolic $\left[\mathrm{Ca}^{2+}\right]$ which, in turn, regulates the gating of the $K_{[\mathrm{Ca}]}$ channels. The key feature here is that there are much fewer of these channels than the spike generating $\mathrm{Na}^{+}$and $\mathrm{K}_{\mathrm{d}}$ channels, so their relative statistical fluctuations are more important than the fluctuations of spiking channels in determining when a burst is about to start, in increasing the activity of the neuron, or in ending the burst. The reason why the $H$ current (which has the smallest number of channels) doesn't play an important role in the irregularities present in the stochastic model is that this current is practically not activated in this isolated model except when neuron is strongly hyperpolarized. Our finding is that the fluctuations in the number of spiking channels is not important for the macroscopic irregular behavior: the spiking channels tend to be modulated by the slower irregular oscillations produced by the slow wave channels (present in smaller number in the membrane), as can be seen in Fig. 9 in the very similar behavior

\section{A}

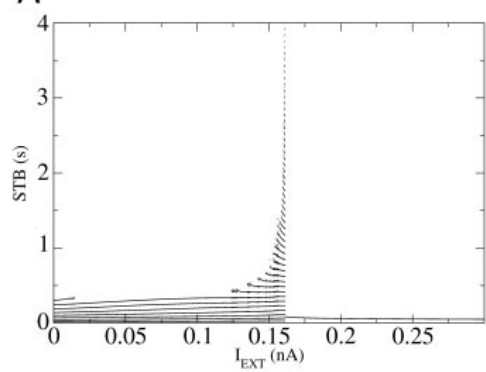

presented by the models built either with all currents stochastic or with only the "slow" currents stochastic.

The end of the burst is determined by the competition between the calcium influx and the outflow of potassium through $K_{[\mathrm{Ca}]}$ channels. In the beginning of a burst, the calcium conductances are very high, so the stochastic fluctuations do not influence the behavior. However, from the middle to the end of a burst, as shown in Fig. 10, the number of conducting channels in both populations is small ( $\sim 10^{3}$ open channels), making the stochastic fluctuations more important, which causes an increase in the probability of ending the burst before the time deterministically predicted.

\section{Conclusion}

We presented a single-compartment whole cell stochastic model for a stomatogastric neuron based on a deterministic $\mathrm{HH}$ model built on realistic measures of conductances from voltage-clamp experiments.

The main question we addressed was: because the behavior of stomatogastric neurons has been studied and known for more than three decades and there is a lot of experimental data from voltage-clamp experiments as well as very good and complex detailed models built on these experimental data, why do the models not present the same kind of irregularities easily found in isolated STG neurons?

Several approaches can be used to build new models: one can include new dynamics in the existing conductances, or a

B

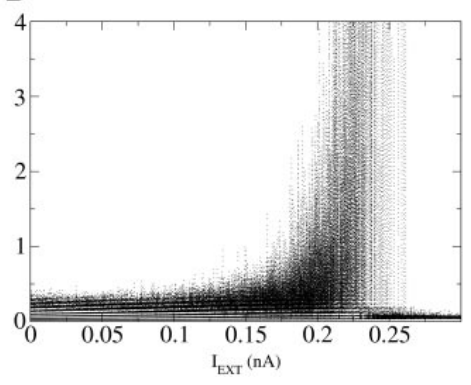

FIG. 7. Bifurcation diagram obtained from the times of occurrence of the spikes in the bursts (STB) as a function of an external DC current injected in the model neurons. After an initial transient, $20 \mathrm{~s}$ of the membrane potential was simulated for each value of current. The times of the spikes are measured using as reference the first spike of the burst. When the model neuron is tonic (no bursts) the dots represent the ISIs. In the deterministic model (left) is observed a period adding bifurcation $\left(0.10<I_{\text {ext }}<0.16 \mathrm{nA}\right)$ that causes increments in the bursts duration by the addition of an extra spike at the end of each burst. Finally, there is a sudden transition when the burst length tends to infinity $\left(I_{\text {ext }} \approx 0.16 \mathrm{nA}\right)$, the model stops bursting and a tonic firing periodic regime takes place. A similar diagram is observed for the stochastic model, however, the transition from bursting to tonic firing behavior is not so clear. For a range of current values in which the deterministic model is already tonic $\left(0.17<I_{\text {ext }}<0.28 \mathrm{nA}\right)$ the stochastic model presents intermittently either irregular tonic firing or bursting behavior. In both models, ISIs $>200 \mathrm{~ms}$ were considered inter burst intervals (IBI). 


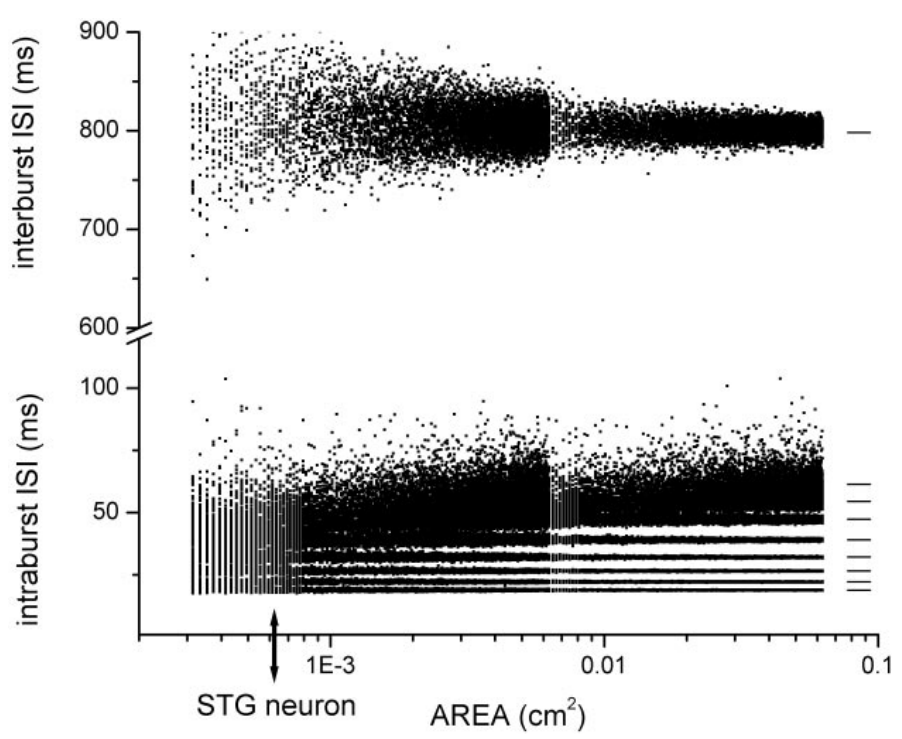

FIG. 8. ISI bifurcation diagram for the stochastic model as a function of the neuronal membrane area Different vertical scales were used to enhance the resolution in the intraburst region. A transient of $10 \mathrm{~s}$ was discarded, and $30 \mathrm{~s}$ of model activity was recorded for each value chosen for the area. As the area (and the number of channels of each type) is increased, the ISIs of the stochastic model become more reliable and the behavior tends to be more periodic. In the limit of the area tending to infinity, the periodic behavior of the deterministic tending to infinity, the periodic behavior of the deterministic
model is recovered (ISIs of the deterministic model are area independent and shown in the right of the figure as small horizontal segments). At the left of the figure the arrow points to the region that correspond to the surface area of a typical STG neuron $\left(6.3 \times 10^{-4} \mathrm{~cm}^{2}\right)$. The smaller density of dots observed in the middle of the log area scale is due to a 10 -fold
area step used for area $>6.3 \times 10^{-3} \mathrm{~cm}^{2}$ for simulation speed reasons.

myriad of new complex ion currents, or mechanisms such as the calcium exchange with internal stores. However, we opted for simply using an existing realistic deterministic model and to include in this model the ingredient we believe is essential to reproduce the experimental irregularities: the stochastic nature of the ion channels operation.

The single-compartment deterministic model used as a basis of our work had the traditional spike-generating conductances $\left(\mathrm{Na}^{+}\right.$and $\left.K_{\mathrm{d}}\right)$, several slower conductances $\left(\mathrm{Ca}_{\mathrm{T}}, \mathrm{Ca}_{\mathrm{S},} \mathrm{K}_{[\mathrm{Ca}]}, \mathrm{H}\right.$, $A$ ), a leak current, and a simple $\mathrm{Ca}^{+2}$ buffer to account for the competition between the $\mathrm{Ca}^{+2}$ influx and the mechanisms of $\mathrm{Ca}^{+2}$ extrusion, most inferred from detailed voltage-clamp experiments.

We made the translation of the deterministic model to stochastic in the simplest possible way: the numbers of channels of each type were determined from the deterministic maximum conductances, the channels were modeled as a chain of Markovian states with transition probabilities given directly by the $\mathrm{HH}$ voltage-dependent transition rates, which constitute one of the most exact stochastic algorithms for describing the microscopic fluctuations the ion channels are subject to. No external noise was added to any gating variable, and all the stochasticity came directly from the channel transition dynamics. The $\mathrm{Ca}^{+2}$ buffer was kept deterministic to ensure that the irregularities obtained from the model are not produced by any other mechanism not present in the original deterministic model.

We found that our stochastic model is able to reproduce the irregular behavior presented by living neurons. Using tools from nonlinear dynamics, we showed that it also presents sensitivity to initial conditions. However, it is well known that the original deterministic model does not present structurally stable deterministic chaos for any set of parameters. So, the chaotic behavior must arise in the stochastic model as the interplay between the stochastic nature of the channels and the nonlinear dynamics already present in the deterministic version. We interpret this emergence of chaotic behavior as the effect of the high dimension of the real state space. The oscillations in the deterministic model lie in a 12-dimensional state space (12 dynamical variables). However, because of the strong attractive periodic orbit, the steady-state behavior can be reduced to a lower dimensional cycle. In the vicinity of this cycle, there are regions where the local dynamics present sensitivity to initial conditions, but these regions are never visited by the periodic orbit. When the stochastic character of ion channels is included, the steady-state solution is perturbed in such a way that the resulting orbit still remains close to the attractive periodic orbit, but now the regions with richer dynamics are accessible, revealing the sensitivity to initial conditions.

Mixed models, where some of the conductances are deterministic and some are stochastic, were used to track which conductances are more important in generating the irregular macroscopic behavior. Using this approach, we found that the
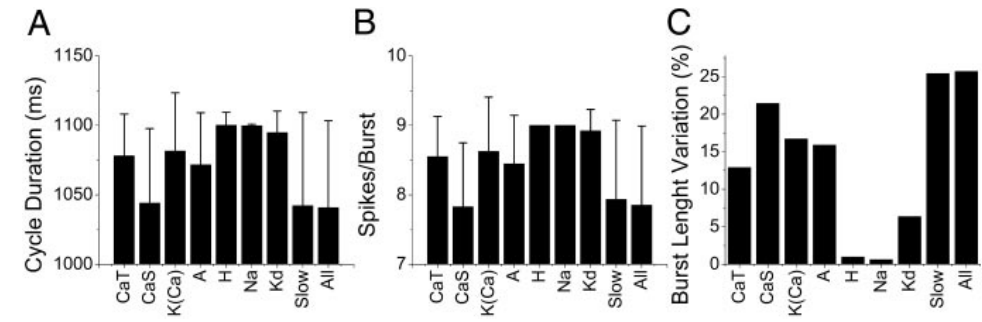

$J$ Neurophysiol $\bullet$ VOL $94 \cdot$ AUGUST $2005 \cdot$ www.jn.or
FIG. 9. Mixed models: the role in the model's behavior of each one of the currents being modeled as stochastic and all other currents modeled as deterministic. $A$ : the cycle duration - analogous to the period in a periodic oscillation; $B$ : the number of spikes/burst is plotted; and $C$ : the percent variation observed in the burst dution. The vertical bar labeled "slow" " all plots represents the behavior of the model when all the currents but $\mathrm{Na}^{+}$and $K_{\mathrm{d}}$ are stochastic and the last bar represents the behavior when all currents are stochastic. One hundred seconds of model activity were used for the statistics in each case. 


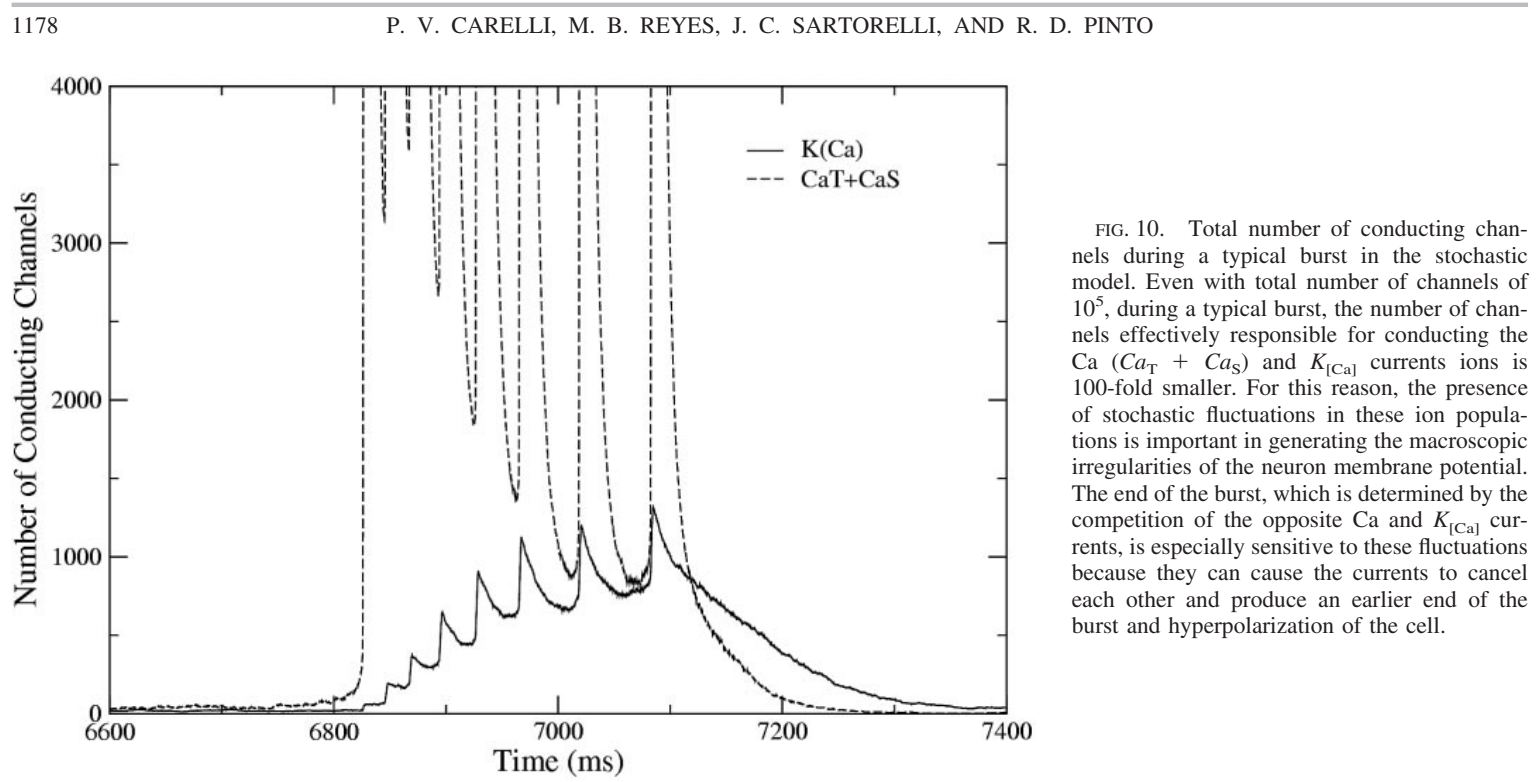

main conductances responsible for generating irregularities are the $\mathrm{Ca}^{+2}$ and the $K_{[\mathrm{Ca}}$ conductances.

Earlier stochastic models used to consider a patch of the membrane where a smaller number of channels could produce relative fluctuations big enough to impact the overall neural behavior. However, here we found that the effective number of conducting channels of a type in a given time is several orders of magnitude smaller than the total number of channels of that type, and the effects of the stochastic nature of channels can be found even in a single-compartment whole cell model, without the need of implementing more compartments or axon patches.

\section{A C K N OWLEDGMENTS}

We thank I. Segev and M.A.L. Nicolelis for encouragement during our poster presentation in the first Neuroscience Symposium of the International Institute for Neurosciences of Natal, Brazil.The authors also acknowledge the hospitality and the help of M. I. Rabinovich and A. I. Selverston, University of California, San Diego, where the experimental data shown in this paper was collected.

\section{G R A N T S}

The authors acknowledge the financial support from the Brazilian agencies Fundação de Amparo à Pesquisa do Estado de São Paulo and Conselho Nacional de Desenvolvimento Científico e Tecnológico.

\section{REFERENCES}

Abarbanel HDI. Analysis of Observed Chaotic Data. New York: SpringerVerlag, 1996.

Abraham RH and Shaw CD. Dynamics: The Geometry of Behavior. Redwood City, CA: Addison-Wesley, 1992

Ayers J. Underwater walking. Arthropod Struct Dev 33: 347-360, 2004.

Bal T, Nagy F, and Moulins M. The pyloric central pattern generator in crustacea: a set of conditional neural oscillators. J Comp Physiol [A] 163: 715-727, 1988.

Carelli PV and Pinto RD. Chaos versus stochasticity in neural activity. First Neuroscience Symposium of the International Institute for Neuroscience of Natal, March 3-7. Natal, RN, Brazil, 2004.

Carelli PV, Reyes MB, Selverston AI, Sartorelli JC, and Pinto RD. A whole cell microscopic stochastic modeling of ion channels reproduces the low dimensional dynamics and sensitivity to initial conditions found in the macroscopic membrane potential of living neurons. Soc Neurosci Abstr 921.4, 2004
Dayan P and Abbott LF. Theoretical Neuroscience: Computational and Mathematical Modeling of Neural Systems, MIT Press 2001.

Desthexhe A, Mainen ZF, and Sejnowski TJ. Syntesis of models for excitable membranes, synaptic transmission and neuromodulation using a common kinetic formalism. J Comput Neurosci 1: 195-231, 1994.

Elson RC, Huerta R, Abarbanel HDI, Rabinovich MI, and Selverston AI. Dynamic control of irregular bursting in an identified neuron of an oscillatory circuit. J Neurophysiol 82: 115-122, 1999.

Falcke M, Huerta R, Rabinovich MI, Abarbanel HDI, Elson RE, and Selverston AI. Modeling observed chaotic oscillations in bursting neurons: the role of calcium dynamics and IP3. Biol Cybern 82, 517-527, 2000.

Gillespie DT. Exact stochastic simulation of coupled chemical reactions. $J$ Phys Chem 81: 2340-2361, 1977.

Guckenheimer $\mathbf{J}$ and Oliva R. Chaos in the Hodkin-Huxley model. SIAM $J$ Appl Dyn Systems 1: 105-114, 2002.

Hegger, R, Kantz, H, and Schreiber, T. Practical implementation of nonlinear time series methods: the TISEAN package (TISEAN is freely downloadable at http://www.mpipks-dresden.mpg.de/ tisean/). Chaos 9: 413435, 1999.

Hille, B. Ionic Channels of Excitable Membranes (3rd ed.). Sunderland, MA: Sinauer, 2001.

Hodgkin AL and Huxley AF. A quantitative description of membrane current and its application to conduction and excitation in nerve. J Physiol 117: $500-544,1952$.

Holden AV. Nonlinear Science - The impact of biology. Int J Bif Chaos 7: 2075-2104, 1997.

Ikeda M. Calcium dynamics and circadian rhythms in suprachiasmatic nucleus neurons. Neuroscientist 10: 315-324, 2004

Izhikevich EM. Neural excitability, spiking and bursting. Int $J$ Bif and Chaos 10: 1171-1266, 2000

Kandel ER, Schwartz JH, and Jessel TM. Principles of Neural Science (3rd ed.). Norwalk, CT: Appleton and Lange, 1991.

Kennel MB, Brown R, and Abarbanel HDI. Determining embedding dimension for phase-space reconstruction using a geometrical construction. Physiol Rev A 45: 3403, 1992

Kepecs A and Wang X-J. Analysis of complex bursting in cortical pyramidal neuron models. Neurocomputing 32: 181-187, 2000.

Komendantov AO and Kononenko NI. Deterministic chaos in mathematical model of pacemaker activity in bursting neurons of snail Helix pomatia. $J$ theor Biol 183: 219-230, 1996.

Levi R, Samoilova M, and Selverston AI. Calcium signaling components of oscillating invertebrate neurons in vitro. Neuroscience 118: 283-296, 2003. Levitan IB and Kaczmarek LK. The Neuron: Cell and Molecular Biology (2nd ed.). Houston, TX: Oxford, 1997. 
Mainen ZF and Sejnowski T. Reliability of spike timing in neocortical neurons. Science 268: 1503-1508, 1995.

Marder E. From biophysics to models of network function. Annu Rev Neurosci 21: 25-45, 1998.

Miller JP and Selverston AI. Rapid killing of single neurons by irradiation of intracellularly injected dye. Science 206: 702-704, 1979.

Mino H, Rubinstein JT, and White JA. Comparison of algorithms for the simulation of action potentials with stochastic sodium channels. Ann Biomed Eng 30: 578-587, 2002.

Mulloney B and Selverston AI. Organization of the stomatogastric ganglion of the spiny lobster. J Comp Physiol 91: 1-32, 1974.

Nicolelis MAL. Brain machine interfaces to restore motor function and probe neural circuits. Nat Rev Neurosci 4: 417-422, 2003

Panchin YV, Arshavsky YI, Selverston AI, and Cleland TA. Lobster stomatogastric neurons in primary culture. I. Basic characteristics. J Neurophysiol 69: 1976-1992, 1993.

Parri HR and Crunelli V. Pacemaker calcium oscillations in thalamic astrocytes in situ. Neuroreport 12: 3897-3900, 2001.

Pinto RD, Varona P, Volkovskii AR, Szücs A, Abarbanel HDI, and Rabinovich MI. Synchronous behaviour of two coupled electronic neurons. Physiol Rev E 62: 2644-2656, 2000.

Prinz A. Neural networks: models and neurons show hybrid vigor in real time. Curr Biol 14: R661-R662, 2004.

Prinz A, Billimoria CP, and Marder E. Alternative to hand-tuning conductance-based models: construction and analysis of databases of model neurons. J Neurophysiol 90: 3998-4015, 2003a.

Prinz AA, Ramirez JM, Buzsaki G, and Stanley KJ. How dynamic interactions of intrinsic bursting and synaptic properties shape network functions. Soc Neurosci Abstr 813, 2004.

Prinz A, Thirumalai V, and Marder E. The functional consequences of changes in the strength and duration of synaptic inputs to oscillatory neurons. J Neurosci 23: 943-954, 2003b.

Rabinovich MI, Abarbanel HDI, Huerta R, Elson R, and Selverston AI. Self-regulation of chaos in neural systems: experimental and theoretical results. IEEE Trans Circ Syst I 44: 997-1005, 1997.
Rinzel J and Ermentrout GB. Analysis of neural excitability and oscillations. In: Methods in Neuronal Modelling, edited by Koch C and Segev I. Cambridge, MA: MIT Press, MA 1998.

Rowat PF and Elson RC. State-dependent effects of Na channel noise on neuronal burst generation. J Comput Neurosci 16: 87-112, 2004.

Sano M and Sawada Y. Measurement of the Lyapunov spectrum from a chaotic time series. Phys Rev Lett 55:1082, 1985.

Schneidman E, Freedman B, and Segev I. Ion channel stochasticity may be critical in determining the reliability of spike timing. Neural Comput 10: 1679-1703, 1998

Selverston AI and Moulins M (Editors). The Crustacean Stomatogastric System. Berlin: Springer-Verlag, 1986.

Selverston AI, Rabinovich MI, Abarbanel HDI, Elson R, Szucs A, Pinto RD, Huerta R, and Varona, P. Reliable circuits from irregular neurons: a dynamical approach to understanding central pattern generators. $J$ Physiol (Paris) 94: 357-374, 2000.

Skaugen $\mathbf{E}$ and Walløe L. Firing behavior in a stochastic nerve membrane model based upon the Hodgkin-Huxley equations. Acta Physiol Scand 107: 343-363, 1979.

Szucs A, Pinto RD, Rabinovich MI, Abarbanel HDI, and Selverston AI. Synaptic modulation of the interspike interval signatures of bursting pyloric neurons. J Neurophysiol 89: 1363-1377, 2003.

Szücs A, Varona P, Volkovskii AR, Abarbanel HDI, Rabinovich MI, and Selverston AI. Interacting biological and electronic neurons generate realistic oscillatory rhythms. Neuroreport 11: 563-569, 2000.

Turrigiano G, LeMasson G, and Marder E. Selective regulation of current densities underlies spontaneous changes in the activity of cultured neurons. J Neurosci 15: 3640-3652, 1995.

White JA, Klink R, Alonso A, and Kay AR. Noise from voltage-gated ion channels may influence neuronal dynamics in the entorhinal cortex. $J$ Neurophysiol 80: 262-269, 1998.

White JA, Rubinstein JT, and Kay AR. Channel noise in neurons. Trends Neurosci 23: 131-137, 2000.

Zhang M, Goforth $\mathbf{P}$, Bertram R, Sherman $\mathbf{A}$, and Satin L. The $\mathrm{Ca}^{+2}$ dynamics of isolated mouse $\beta$-cells and islets: implications for mathematical models. Biophys $J$ 84: 2852-2870, 2003 